02

\title{
Спектральные и амплитудно-временные характеристики излучения Черенкова при возбуждении прозрачных материалов пучком электронов
}

\author{
(C) В.Ф. Тарасенко, Е.Х. Бакшт, М.В. Ерофреев, А.Г. Бураченко \\ Институт сильноточной электроники Сибирского отделения РАН, \\ 634055 Томск, Россия \\ e-mail: VFT@loi.hcei.tsc.ru, BEH@loi.hcei.tsc.ru, MVE@loi.hcei.tsc.ru, BAG@loi.hcei.tsc.ru
}

Поступила в редакцию 21.12.2020 г.

В окончательной редакции 22.01.2021 г.

Принята к публикации 01.02.2021 г.

Интерес к изучению характеристик излучения Вавилова-Черенкова (ИВЧ) возрос в связи с работами по созданию детекторов убегающих электронов (УЭ) для установок типа ТОКАМАК. В обзоре представлены результаты исследований спектральных, амплитудно-временных и пространственных характеристик ИВЧ, полученные в основном за последние годы при возбуждении прозрачных веществ потоком электронов с энергиями десятки-сотни $\mathrm{keV}$. Приведены спектры ИВЧ в алмазе (природном и синтетическом), кварцевом стекле, сапфире, лейкосапфире, сообщается о регистрации ИВЧ в $\mathrm{MgF}_{2}, \mathrm{Ga}_{2} \mathrm{O}_{3}$ и других прозрачных образцах. Проведено сравнение спектров и амплитудно-временных характеристик ИВЧ и импульсной катодолюминесценции (ИКЛ) при различных энергиях электронов. Для ряда образцов выполнены расчеты спектров ИВЧ с учетом дисперсии показателя преломления, а также распределения электронов пучка по энергиям и уменьшения энергии электронов в процессе их торможения в веществе образцов. Исследован спектр излучения полиметилметакрилата (ПММА), который используется в качестве материала для радиаторов в черенковских детекторах и световодов, передающих излучение в сцинтилляционных дозиметрах, а также в качестве пластиковой основы в органических сцинтилляторах.

Ключевые слова: излучение Вавилова-Черенкова, импульсная катодолюминесценция, электронный пучок, фотовозбуждение.

DOI: $10.21883 /$ OS.2021.05.50883.310-20

\section{1. Введение}

В последние годы увеличилось число работ, посвященных исследованиям свечения различных веществ под воздействием пучков электронов. В частности, большое внимание уделяется изучению и анализу характеристик излучения Черенкова [1] при возбуждении образцов из различных материалов пучками электронов с энергиями в десятки-сотни $\mathrm{keV}$, а также его сравнению в одинаковых условиях с характеристиками импульсной катодолюминесценции (ИКЛ). Отметим, что в настоящее время термин „излучение Черенкова“ обычно используется в зарубежной литературе, тогда как в русскоязычных публикациях употребляют термин „излучение ВавиловаЧеренкова (ИВЧ)“. Поэтому в обзоре на русском языке мы будем использовать термин ИВЧ.

Известно, что ИВЧ возникает при движении в веществе заряженных частиц со скоростью, превышающей фазовую скорость света. Излучение Вавилова-Черенкова является универсальным в том смысле, что под действием заряженных частиц с достаточной энергией „светятся“ все прозрачные тела, находящиеся в жидком, газообразном и твердом состоянииях. Это позволяет использовать ИВЧ для регистрации различных частиц. Для появления ИВЧ энергия частицы, имеющей отрица- тельный или положительный заряд, должна превышать пороговую энергию, которая зависит от показателя преломления вещества. Интенсивность ИВЧ увеличивается с ростом энергии заряженной частицы, поэтому ИВЧ широко применяется для регистрации высокоэнергетических частиц $[2-8]$, в частности, при исследованиях частиц с энергиями от сотен $\mathrm{MeV}$ до единиц-десятков $\mathrm{GeV}$, которые постоянно бомбардируют атмосферу Земли [9-12]. При создании детекторов ИВЧ для регистрации высокоэнергетических частиц обычно используется зависимость угловых характеристик ИВЧ в видимой и ультрафиолетовой (УФ) областях спектра от энергии частиц. Согласно теории $[3,13]$, которая подтверждена экспериментальными измерениями, ИВЧ распространяется под углом к направлению движения частицы, причем угол зависит от энергии и сорта частицы, а также от показателя преломления вещества. Это позволяет диагностировать параметры высокоэнергетических пучков электронов. Например, в экспериментах [14] показана (регистрируя ИВЧ, генерируемое в оптических волокнах) возможность измерения профиля поперечного электронного пучка низкой интенсивности с энергией в несколько MeV. Основным преимуществом метода, описанного в [14], является перпендикулярная ориентация волокна относительно оси электронного пучка. 
Это уменьшает погрешности при экспериментальных измерениях по сравнению со случаем, когда оптическое волокно наклонено под углом, соответствующим направлению ИВЧ. В работе [15] с помощью ИВЧ, используя стрик-камеру, была с высоким временным разрешением измерена длительность импульса тока пучка, которая составила $\sim 250 \mathrm{fs}$.

Последнее десятилетие большое внимание стало уделяться созданию черенковских детекторов для регистрации пучков убегающих электронов (УЭ) в установках типа ТОКАМАК и исследованиям условий генерации УЭ в таких установках [16-27]. Предполагалось, что использование ИВЧ для диагностики поможет определить причины разрушения стенок вакуумной камеры УЭ и понять оптимальные условия получения высокотемпературной плазмы. В [28,29] было установлено, что энергия УЭ в установках ТОКАМАК составляет от десятков $\mathrm{keV}$ до десятков MeV. При этом УЭ могут повреждать стенки рабочей камеры [29,30]. Соответственно создаваемые детекторы должны регистрировать электроны с различными энергиями и сохранять свои свойства при высоких дозах облучения. Поэтому в работах [16-19] при создании детекторов ИВЧ в качестве радиатора был использован алмаз. Алмазы имеют высокий показатель преломления, а также высокую теплопроводность и лучевую стойкость [31]. Однако в работах [16-18] спектры излучения алмазных радиаторов не регистрировались. Только в работе [19] калибровка черенковского детектора была проведена при энергии электронов $2.3 \mathrm{MeV}$ и был приведен спектр излучения, однако он не соответствовал спектру ИВЧ. В области 500-700 nm наблюдалась интенсивная полоса с максимумом на длине волны $637 \mathrm{~nm}$.

В работе [32] при облучении электронами слюды, кварцевого стекла и ВаТіО ИВЧ регистрировалось на установке с ускоряющим напряжением до $200 \mathrm{kV}$. Излучение в слюде имело максимум интенсивности при энергии электронов $200 \mathrm{keV}$ на длине волны $400 \mathrm{~nm}$, что соответствует спектру ИВЧ, ослабленному в УФ области поглощением образца. В более поздней работе данных авторов [33] сообщалось об излучении тонких пленок из различных материалов (слюды, кремния и серебра). Параметры излучения определялись с учетом зависимости интенсивности излучения от толщины пленки и ускоряющего напряжения. Излучение, выходящее из слюды в направлении распространения электронного пучка, содержало ИВЧ, которое имело максимум интенсивности при энергии электронов $200 \mathrm{keV}$ на длине волны $300 \mathrm{~nm}$. Однако причина уменьшения интенсивности излучения в коротковолновой области не обсуждалась и спектр пропускания слюды не приводился. В [34-36] было показано, что интенсивность ИВЧ в алмазе при энергиях электронов до $200 \mathrm{keV}$ значительно ниже интенсивности ИКЛ в УФ и видимом спектральных диапазонах и его детектирование затруднено.

Исследование ИКЛ без регистрации ИВЧ описано во многих работах (например, монография [37] и сборники статей [38,39]). В недавних работах $[34,35]$ ИВЧ было зарегистрировано в синтетических и природных алмазах при энергии электронов до $200 \mathrm{keV}$, но только с помощью монохроматора и ФЭУ. Интенсивность ИВЧ, как и следует из теории [3,13], возрастала с уменьшением длины волны в диапазоне 240-360 nm. Однако при энергии электронов до $200 \mathrm{keV}$ выделить ИВЧ на фоне излучения полос катодолюминесценции было сложно. Для регистрации ИВЧ при сравнительно малых энергиях электронов лучше всего использовать образцы, прозрачные в УФ диапазоне и характеризующиеся низкой интенсивностью или отсутствием ИКЛ в этой области.

С увеличением энергии электронов, как и следовало ожидать, интенсивность ИВЧ увеличивалась. Так, в [40-42] были определены условия, при которых ИВЧ регистрировалось при энергиях электронов до 200-400 keV с помощью стандартных спектрометров.

Также представляет интерес исследование свечения под действием электронного пучка полиметилметакрилата (ПММА, оргстекла). Этот материал широко используется в медицинской дозиметрии при определении доз облучения различными видами ионизирующих излучений [43-46]. В нескольких работах, посвященных этой тематике, регистрировались спектры излучения ПММА [44,45,47]. Однако в них отсутствовали данные о спектрах излучения ПММА при прямом воздействии на этот материал электронов с энергией десятки-сотни $\mathrm{keV}$.

Использовать свечение ПММА для оценки энергии в пучке УЭ предлагалось в работах $[48,49]$. При напряжении не более $300 \mathrm{kV}$ на диоде, заполненном воздухом атмосферного давления, были зарегистрированы импульсы излучения, которые, как считали авторы [48,49], принадлежат ИВЧ. При этом длительность импульсов излучения сушественно превышала длительность импульсов тока пучка, а спектры свечения ПММА не регистрировались. С другой стороны, в работах [50-52] было показано, что при энергии электронов пучка до $400 \mathrm{keV}$ в ПММА из-за сильного поглощения излучения в области короче $300-350 \mathrm{~nm}$, а также из-за внутреннего пробоя образцов вследствие накопления в них электронов при больших плотностях тока пучка и/или длительностях импульсов, регистрация ИВЧ затруднена

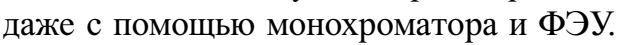

Таким образом, результаты спектральных исследований ИВЧ в алмазе, а также других веществах, полученные в разных научных группах, были неполными и требовали дополнительных исследований, а также тщательного анализа и сравнения с характеристиками ИКЛ.

В данном обзоре приведены результаты исследований при возбуждении пучком электронов с энергией электронов в десятки-сотни keV спектральных, амплитудновременных и пространственных характеристик излучения материалов, прозрачных в видимой и УФ областях спектра, а также показаны условия, в которых интенсивность ИВЧ превышает интенсивность ИКЛ. 
Обзор состоит из 6 разделов, включая введение и заключение. Во втором разделе на качественном уровне объясняется причина возникновения ИВЧ, приводятся основные соотношения для ИВЧ и свойства этого излучения. В третьем разделе описывается экспериментальная аппаратура, которая использовалась в исследованиях, приводятся параметры ускорителей электронов, схемы экспериментальных установок и методики измерений. Четвертый раздел посвящен описанию результатов исследований спектральных и амплитудно-временных характеристик свечения образцов из различных материалов (в основном кристаллических), возбуждаемого электронными пучками с различными параметрами. В пятом разделе описаны результаты исследования взаимодействия образцов ПММА с электронными пучками: амплитудно-временные и спектральные характеристики свечения, а также пороги разрушения. В заключительном разделе приводятся итоги исследований, которые рассмотрены в обзоре.

\section{2. Свойства излучения Вавилова-Черенкова}

\section{1. История открытия}

В 1934 г. физик-экспериментатор П.А. Черенков, в то время - аспирант академика С.И. Вавилова, проводя исследование люминесценции жидкостей под действием гамма-излучения радия, обнаружил новый вид свечения. Сообщение об этом открытии было опубликовано П.А. Черенковым и С.И. Вавиловым в работах $[53,54]$. В экспериментальных исследованиях нового вида свечения П.А. Черенкову удалось определить, что свечение возникало благодаря электронам, образующимся в результате комптон-эффекта гамма-излучения радия на атомных электронах вещества. Свечение в различных жидкостях возникало только при облучении их жестким гамма-излучением и отсутствовало при облучении более мягким рентгеновским излучением (т.е. свечение имело пороговый характер). При этом в отличие от люминесценции не наблюдалось ни температурного, ни примесного тушения свечения. Кроме того, наблюдаемое свечение имело синий цвет (наибольшая интенсивность излучения была сосредоточена в сине-фиолетовой области спектра), резко выраженную направленность (вдоль направления движения комптон-электронов) и было сильно поляризовано (отличалось от поляризации люминесценции). В 1937 г. через три года после обнаружения этого свечения советские физики-теоретики И.Е. Тамм и И.М. Франк создали теорию, полностью объясняющую физический механизм ИВЧ [55].

\section{2. Основные свойства излучения ИВЧ}

Возникновение ИВЧ и его направленность на качественном уровне можно объяснить с помощью принципа Гюйгенса-Френеля. Рассмотрим движение электрона в
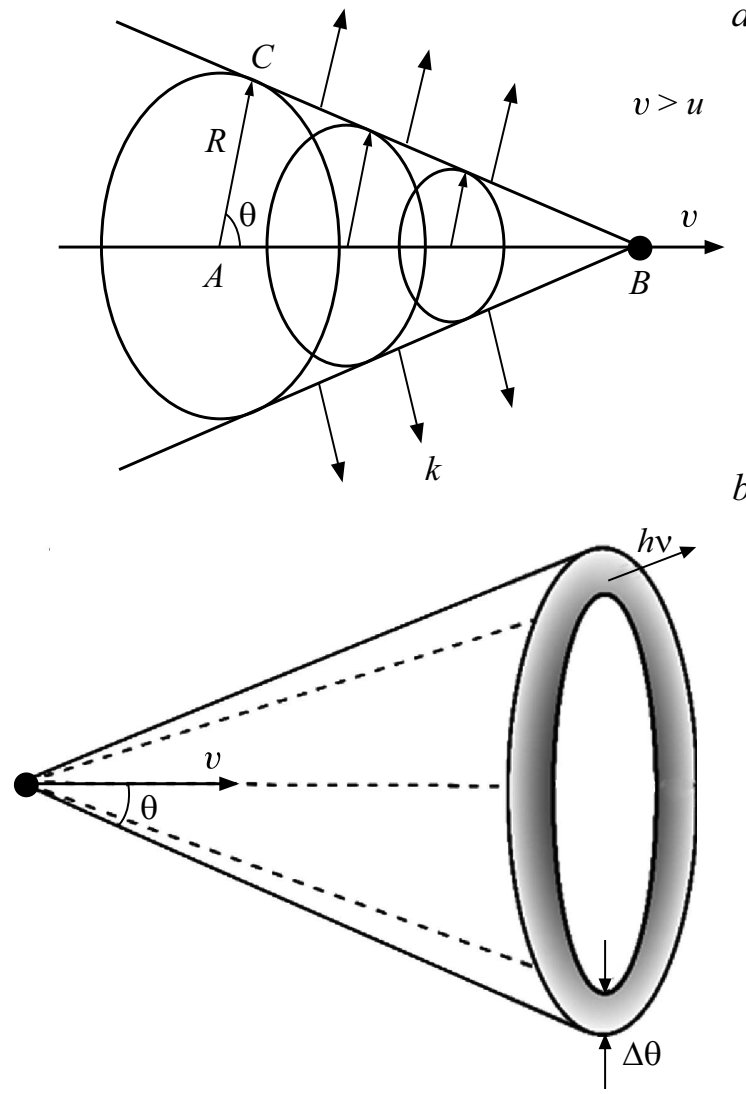

Рис. 1. (a) Образование волнового фронта излучения Вавилова-Черенкова, $(b)$ черенковский конус.

прозрачной среде, подразумевая, что все приведенные ниже рассуждения относятся к любой заряженной частице. При движении электрона со скоростью $v$ в прозрачной среде с показателем преломления $n>1$ возникает кратковременная поляризация вещества вблизи траектории движущегося электрона. После удаления электрона от рассматриваемой области поляризованные молекулы или атомы возвращаются в свое исходное невозмущенное состояние. При этом в среде происходит излучение электромагнитных волн. Если электрон движется в оптически изотропной среде, то вдоль его траектории будут излучаться сферические электромагнитные волны. Фазовая скорость распространения таких электромагнитных волн в среде с показателем преломления $n$ будет определяться как

$$
u=\frac{c}{n},
$$

где $c$ - скорость света в вакууме.

В случае, когда $v<u$, испускаемые вдоль всей траектории волны в любой удаленной от траектории точке будут интерферировать, давая в результате нулевую амплитуду электромагнитного поля. Если скорость движения электрона $v$ будет выше, чем скорость распространения электромагнитных волн $u$ в этой среде (рис. $1, a$ ), то огибающая возникающих сферических 
волн образует волновой фронт с ненулевой амплитудой электромагнитного поля.

Волновой фронт представляет собой коническую поверхность с вершиной в точке, совпадающей с мгновенным положением электрона. На этой конической поверхности выполняется условие когерентности для элементарных сферических волн. Нормали к волновому фронту (волновые векторы $\mathbf{k}$, изображенные на рис. 1, a) показывают направление распространения ИВЧ. Угол $\theta$, образующийся между направлением движения электрона и волновым вектором, можно вычислить, исходя из следующих соображений. Электрон, проходя точку $A$ (рис. $1, a)$ порождает сферическую электромагнитную волну, которая за время $T$ распространяется на расстояние $R=A C=u t$. За это же время электрон, движущийся со скоростью $v>u$, проходит расстояние $A B=v t$.

Таким образом, угол $\theta$, под которым распространяется ИВЧ, определяется из выражения

$$
\cos \theta=\frac{A C}{A B}=\frac{u}{v}=\frac{c}{n v}=\frac{1}{\beta n},
$$

где $\beta=v / c$.

Излучение, возникающее в каждой точке траектории электрона, будет распространятся вдоль поверхности конуса (рис. $1, b)$, вершина которого расположена в этой точке, ось совпадает с траекторией электрона, а плоский угол при вершине равен $2 \theta$. Этот конус часто называют черенковским конусом или конусом ИВЧ.

Измерив угол $\theta$ и зная показатель преломления среды, можно вычислить скорость, следовательно, и энергию электрона. Чем выше скорость электрона и/или показатель преломления $n$ среды, тем больше угол $\theta$, под которым распространяется ИВЧ. Максимально возможный угол, под которым может распространяться ИВЧ в среде с показателем преломления $n$, можно определить из формулы (2) при $\beta=1$. Так, например, для воды $(n=1.33)$ этот угол равен $\theta_{\max } \approx 41^{\circ}$, а для алмаза $(n=2.42) \theta_{\max } \approx 66^{\circ}$. Если длина траектории частицы $l$ в среде сравнима с длиной волны ИВЧ $\lambda$, то существенными становятся дифракционные эффекты и ИВЧ распространяется в интервале углов $\theta$ и $\theta+d \theta$, где $d \theta \approx \frac{\lambda}{t} \sin \theta[56]$.

Показатель преломления реальной среды $n$ зависит от длины волны излучения $\lambda$, поэтому в выражении (2) угол $\theta$ будет меняться в зависимости от $\lambda$. В случае нормальной дисперсии показатель преломления света в фиолетовой области спектра $n_{\phi}$ больше, чем в красной $n_{\text {кр}}$, поэтому углы $\theta$ для красного и фиолетового света будут различными. Угол, под которым распространяется ИВЧ, будет „размыт“ на величину $\Delta \theta=\theta_{\phi}-\theta_{\text {кр }}$ (рис. $\left.1, b\right)$. Поэтому ИВЧ, возникающее на каждом малом отрезке траектории электрона, будет распространяться между двух конических поверхностей (область, выделенная серым цветом на рис. $1, b$ ), где внешний конус соответствует распространению ИВЧ в
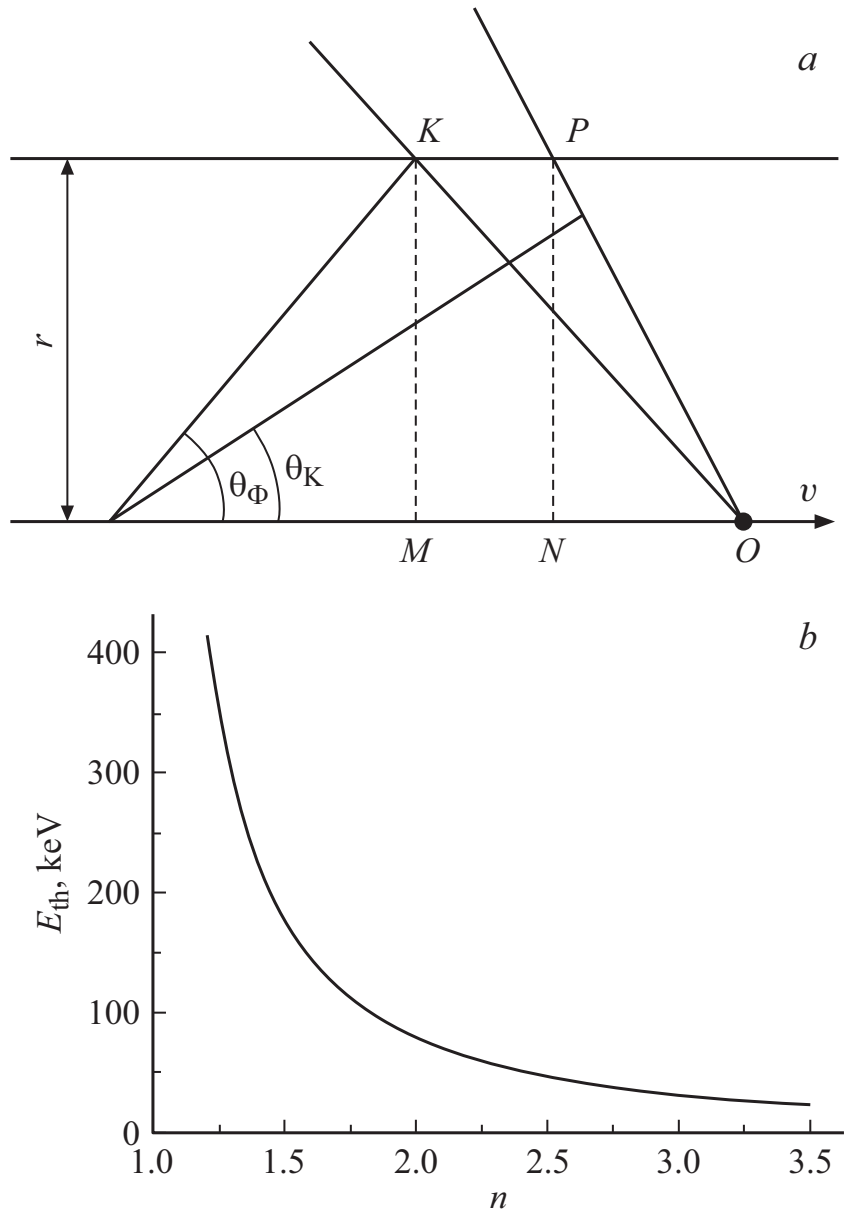

Рис. 2. (a) Формирование конечной длительности ИВЧ. (b) Зависимость пороговой энергии электронов для возникновения ИВЧ от показателя преломления среды.

фиолетовой области спектра, а внутренний - в красной области спектра.

На угловую ширину черенковского конуса оказывает влияние и многократное рассеяние электронов в среде. При прохождении электронного пучка сквозь среду толщиной $T$ это влияние можно оценить как $[41,56]$ : $\Delta \theta_{a} \approx \sqrt{\theta_{\mathrm{ms}}^{2}+\theta_{\mathrm{e}}^{2}}$, где $\theta_{\mathrm{ms}}-$ среднеквадратичный угол многократного рассеяния на длине $T / 2, \theta_{\mathrm{e}}$ - начальная расходимость электронного пучка. При больших энергиях электронов, а также при малых значениях $T$ и расходимости электронного пучка $\Delta \theta_{a} \rightarrow 0$.

За счет дисперсии показателя преломления излучение на разных длинах волн будет приходить в точку наблюдения $P$ в разное время (рис. 2, $a$ ) - при движении электрона, находящегося в точке $O$, вдоль траектории $M O$ фронт, соответствующий фиолетовой области спектра $(O K)$, будет приходить позже фронта, соответствующего красной области спектра $(O P)$. Запаздывание будет определяться временем, за которое фиолетовый фронт сместится вдоль направления $K P$ на расстояние, равное длине отрезка $K P$. Поскольку скорость перемещения фиолетового (и красного) фронта 
вдоль направления $K P$ равна скорости движения электрона $(K P \| M O)$, то время запаздывания определяется как

$$
\Delta t=\frac{K P}{v}=\frac{M O-N O}{v}=\frac{r}{v}\left(\operatorname{tg} \theta_{\phi}-\operatorname{tg} \theta_{\kappa}\right),
$$

с учетом, что $K M \perp M O, P N \perp M O$.

В общем случае

$$
\Delta t=\frac{r}{v}\left(\operatorname{tg} \theta_{2}-\operatorname{tg} \theta_{1}\right)
$$

где $\theta_{1}$ и $\theta_{2}-$ углы, соответствующие граничным длинам волн ИВЧ (определяемым областью прозрачности среды). Величина $\Delta t$ оценивается [57] как $\sim 10^{-12}-10^{-11} \mathrm{~s}$. Таким образом, эффект Вавилова-Черенкова способен обеспечить очень высокое временное разрешение. Это отличает ИВЧ от люминесценции, имеющей, как правило, несопоставимо большее время затухания.

При движении в веществе электрон тратит часть своей энергии на ИВЧ, хоть эта часть и мала $(\sim 0.1 \%)[58]$ по сравнению с потерями на ионизацию атомов вещества. Потери энергии электрона на ИВЧ в интервале частот $d \omega$ можно определить через эффективную силу радиационного торможения $d F$ [57] (формула ТаммаФранка):

$$
d F=\frac{d W}{d t}=\frac{e^{2}}{c^{2}}\left(1-\frac{1}{\beta^{2} n(\omega)^{2}}\right) \omega d \omega,
$$

где $\frac{d W}{d t}-$ потери энергии электроном на ИВЧ на единице пути, $e-$ заряд электрона, $\omega-$ циклическая частота.

Для многозарядной частицы добавляется сомножитель $Z^{2}$, определяющий заряд частицы:

$$
d F=\frac{(Z e)^{2}}{e^{2}}\left(1-\frac{1}{\beta^{2} n(\omega)^{2}}\right) \omega d \omega .
$$

Можно перейти в уравнении (3) от циклической частоты $\omega$ к длине волны $\lambda$ с помощью формулы $\omega=2 \pi c / \lambda$. Тогда спектральную плотность мощности ИВЧ $d P(\lambda) / d \lambda$ для одного электрона можно определить из выражения

$$
d P(\lambda)=v d F=4 \pi^{2} e^{2} v\left(1-\frac{1}{\beta^{2} n^{2}(\lambda)}\right) \frac{d \lambda}{\lambda^{3}} .
$$

Разделив правую и левую части уравнения (5) на $d \lambda$ и умножив их на соответствующий временной интервал $d t$, получим выражение для спектральной плотности энергии излучения $d E / d \lambda$.

Разделив правую и левую части формулы ТаммаФранка (4) на величину энергии кванта $h v$ и пренебрегая дисперсией показателя преломления, нетрудно получить, что в спектральном интервале, определяемом длинами волн $\lambda_{1}$ и $\lambda_{2}$, число квантов ИВЧ, излучаемых заряженной частицей в среде на длине пути $l$ (при условии, что $\beta$ мало меняется на длине $l$ ), равно

$$
\begin{aligned}
N_{h v} & =2 \pi \alpha l Z^{2}\left(\frac{1}{\lambda_{1}}-\frac{1}{\lambda_{2}}\right)\left(1-\frac{1}{\beta^{2} n^{2}}\right) \\
& =2 \pi \alpha l Z^{2}\left(\frac{1}{\lambda_{1}}-\frac{1}{\lambda_{2}}\right) \sin ^{2} \theta,
\end{aligned}
$$

где $\alpha$ - постоянная тонкой структуры $\left(\alpha=\frac{e^{2}}{\hbar c}=\frac{1}{137}\right)$.

В видимой части спектра интенсивность ИВЧ, возбуждаемого электроном, преобладает над интенсивностью тормозного излучения. В [57] на основе анализа основных формул для ИВЧ и тормозного излучения делается вывод о том, что отношение интенсивностей ИВЧ и тормозного излучения в видимом диапазоне спектра составляет $\sim 10^{4}$ практически для любых энергий электронов. В качестве примера в [57] сравнивается число фотонов, испускаемых электроном с энергией $10 \mathrm{MeV}$ в воде за счет тормозного излучения и ИВЧ в спектральном диапазоне $350-700 \mathrm{~nm}$. Число фотонов тормозного излучения, излучаемых на радиационной длине (на которой энергия электрона падает в $e$ раз) в интервале длин волн $\lambda_{1}-\lambda_{2}$ рассчитывается по формуле [57]: $N_{b r}=\frac{4}{3} \ln \frac{\lambda_{2}}{\lambda_{1}}$. Радиационная длина в воде составляет $\sim 34 \mathrm{~cm}$, следовательно, при прохождении $1 \mathrm{~cm}$ воды за счет тормозного излучения электрон излучит $3 \cdot 10^{-2}$ фотонов в спектральном диапазоне 350-700 nm. Количество фотонов, излучаемых электроном за счет ИВЧ в этих же условиях и в этом же спектральном диапазоне, подсчитанное по формуле (6), составляет 263 фотона. Таким образом, в видимой части спектра интенсивность ИВЧ больше интенсивности тормозного излучения примерно в $10^{4}$ раз.

Излучение Вавилова-Черенкова появляется, начиная с некоторой минимальной энергии электрона, определяемой показателем преломления вещества $n$. Эта энергия называется пороговой. Пороговая энергия возникновения ИВЧ на конкретной длине волны $E_{\mathrm{th}}(\lambda)$ определяется из формулы (5) при равенстве нулю сомножителя $\left(1-\frac{1}{\beta^{2} n^{2}(\lambda)}\right)$ и выражении $\beta$ через релятивистскую кинетическую энергию электрона:

$$
E_{\mathrm{th}}(\lambda)=m_{e} c^{2}\left(\frac{n(\lambda)}{\sqrt{n^{2}(\lambda)-1}}-1\right),
$$

где $m_{e}$ - масса покоя электрона.

На практике при определении $E_{\text {th }}$ дисперсией показателя преломления часто пренебрегают, заменив $n(\lambda)$ на значение показателя преломления для длины волны $D$-линии спектра натрия $589.3 \mathrm{~nm}$, измеренное при атмосферном давлении воздуха и температуре $20^{\circ} \mathrm{C}$ [59]. Этот показатель преломления обозначают $n_{D}$ или же просто $n$, подразумевая, что $n=n_{D}$. Чем выше показатель преломления $n$, тем ниже пороговая энергия возникновения ИВЧ $E_{\text {th }}$ (рис. $\left.2, b\right)$. Так, например, для алмаза, у которого показатель преломления $n=2.42$, пороговая энергия возникновения ИВЧ $E_{\mathrm{th}}=50 \mathrm{keV}$. 

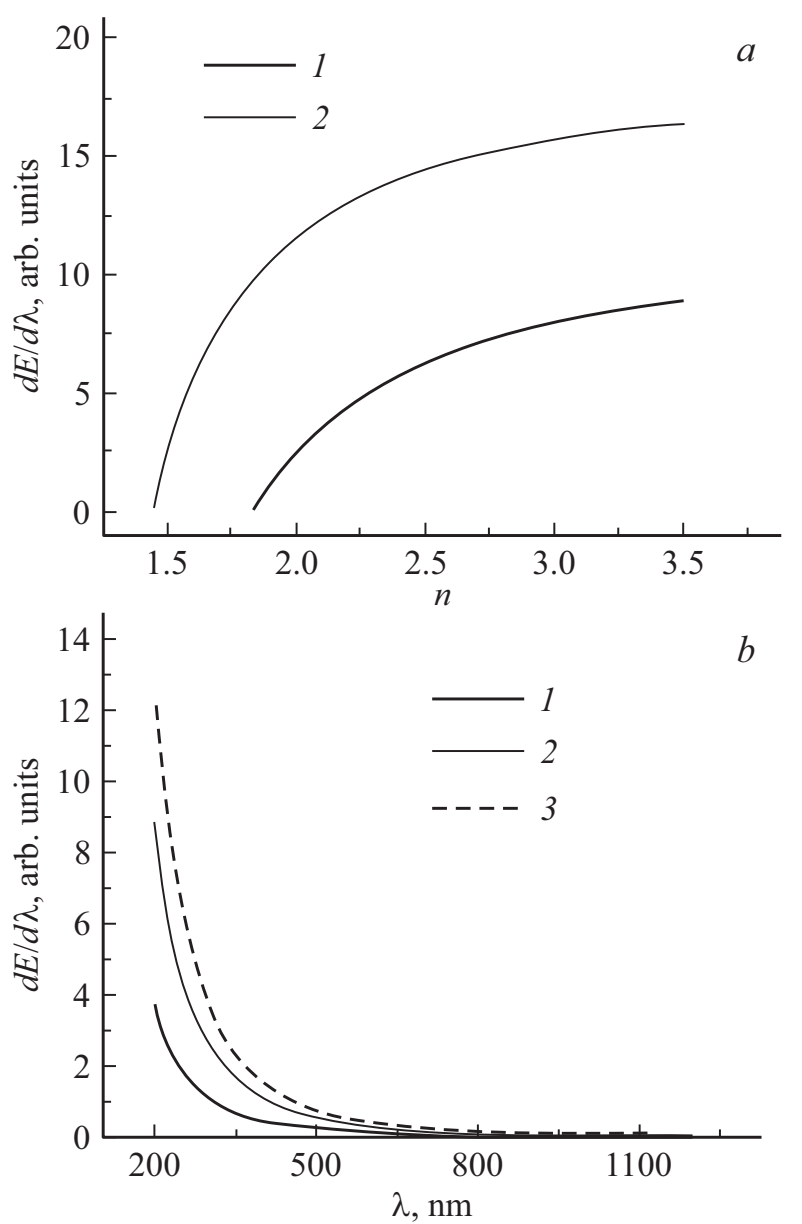

Рис. 3. (a) Зависимость спектральной плотности мощности/энергии ИВЧ от показателя преломления для энергий электронов $100(1)$ и $200 \mathrm{keV}(2)$. (b) Зависимость спектральной плотности мощности/энергии ИВЧ в алмазе от длины волны для энергий электронов 100 (1), 200 (2) и 300 (3) keV.

Из уравнения (5) также следует, что интенсивность ИВЧ увеличивается при уменьшении длины волны несколько быстрее, чем $1 / \lambda^{3}$, так как сомножитель $\left(1-\frac{1}{\beta^{2} n^{2}(\lambda)}\right)$ тоже растет с уменьшением $\lambda$, хотя и достаточно медленно. По этой причине человеческий глаз воспринимает ИВЧ как сине-фиолетовое свечение.

Интенсивность (а также спектральная плотность энергии) ИВЧ увеличивается и с увеличением кинетической энергии электронов, а также с увеличением показателя преломления среды (рис. 3). Из рис. $3, b$ видно, что наибольшая доля энергии ИВЧ сосредоточена в УФ области спектра. Поэтому зарегистрировать ИВЧ проще всего в таких средах, которые прозрачны в УФ области спектра и обладают сравнительно высоким показателем преломления.

Необходимо отметить, что ИВЧ поляризовано. Вектор напряженности электрического поля направлен перпендикулярно поверхности черенковского конуса, а вектор напряженности магнитного поля - по касательной.
Поляризацию излучения экспериментально обнаружил П.А. Черенков [1], а затем она получила объяснение в теории Тамма и Франка [55]. Анализ основных формул, описывающих теорию излучения Вавилова-Черенкова, позволяет сформулировать его основные свойства:

- ИВЧ имеет пороговый (по энергии/скорости) характер;

- ИВЧ в отличие от люминесценции является практически безынерционным;

- ИВЧ имеет выраженную направленность - распространяется под определенным углом к направлению движения заряженной частицы;

- Имеется максимальный угол распространения ИВЧ для частиц со скоростью, близкой к скорости света в среде;

- ИВЧ поляризовано;

- ИВЧ имеет непрерывный спектр;

- Энергия ИВЧ сосредоточена в основном в коротковолновой области спектра;

- ИВЧ в отличие от люминесценции не подвержено ни примесному, ни температурному тушению.

\section{3. Экспериментальное оборудование и методики измерений}

\section{1. Ускорители электронов, используемые в экспериментах}

Для исследования спектральных, амплитудно-временных и пространственных характеристик ИВЧ и ИКЛ, возбуждаемых в прозрачных диэлектриках и полупроводниках электронным пучком с энергией в сотни $\mathrm{keV}$, применялись различные ускорители, причем режимы работы части ускорителей можно было изменять. Это позволяло варьировать параметры электронного пучка в широких пределах и охватить область энергий электронов от $\sim 40$ до $\sim 400 \mathrm{keV}$. Параметры субнаносекундных и наносекундных ускорителей, которые будем называть по имени используемого генератора, приведены в табл. 1 с указанием режимов работы.

Каждый ускоритель состоял из высоковольтного импульсного генератора и диода, который мог заполняться различными газами при давлениях от долей до 760 Torr или откачиваться форвакуумным насосом. Конструкция катода и газового диода, а также давление и сорт рабочего газа позволяли изменять параметры электронного пучка в широких пределах. Отметим, что пучок электронов, формируемый в газовом диоде, мы обычно называем СЛЭП - сверхкороткий лавинный электронный пучок [65]. Электронный пучок для облучения исследуемых образцов выводился из ускорителя через тонкую анодную фольгу. На рис. 4 показаны примеры осциллограмм импульсов тока пучка с ускорителем на базе генератора СЛЭП-150М при различных давлениях гелия $p$ в газовом диоде.

Важным параметром в данных исследованиях является спектр электронов, который возбуждают образцы. 
Таблица 1. Параметры субнаносекундных и наносекундных ускорителей

\begin{tabular}{l|c|c|c|c}
\hline Ускоритель и его режим & $\begin{array}{c}\text { Максимальная } \\
\text { энергия } \\
\text { электронов, } \\
\mathrm{keV}\end{array}$ & $\begin{array}{c}\text { Плотность } \\
\text { тока } \\
\text { пучка } j, \\
\mathrm{~A} / \mathrm{cm}^{2}\end{array}$ & $\begin{array}{c}\text { Длительность им- } \\
\text { пульса тока на } \\
\text { полувысоте } \\
\tau_{0.5, \mathrm{~ns}}\end{array}$ & $\begin{array}{c}\text { Частота } \\
\text { следования } \\
\text { импульсов } f, \\
\mathrm{~Hz}\end{array}$ \\
\hline ГИН-55-01 [60] & 80 & 1.6 & 0.1 & 100 \\
СЛЭП-150 [61] & 250 & $10-230$ & $0.1-0.6$ & 1 \\
СЛЭП-150М [62] & 250 & $10-230$ & $0.1-0.6$ & 1 \\
ГИН-500 [63] & 350 & 100 & 1.3 & 0.2 \\
ГИН-600 [52] & 420 & 75 & 0.18 & 0.1 \\
РАДАН-220 [64] (режим 1) & 200 & 1.1 & 0.1 & 1 \\
РАДАН-220 (режим 2) & 210 & 120 & 0.3 & 1 \\
РАДАН-220 (режим 3) & 200 & & 1
\end{tabular}
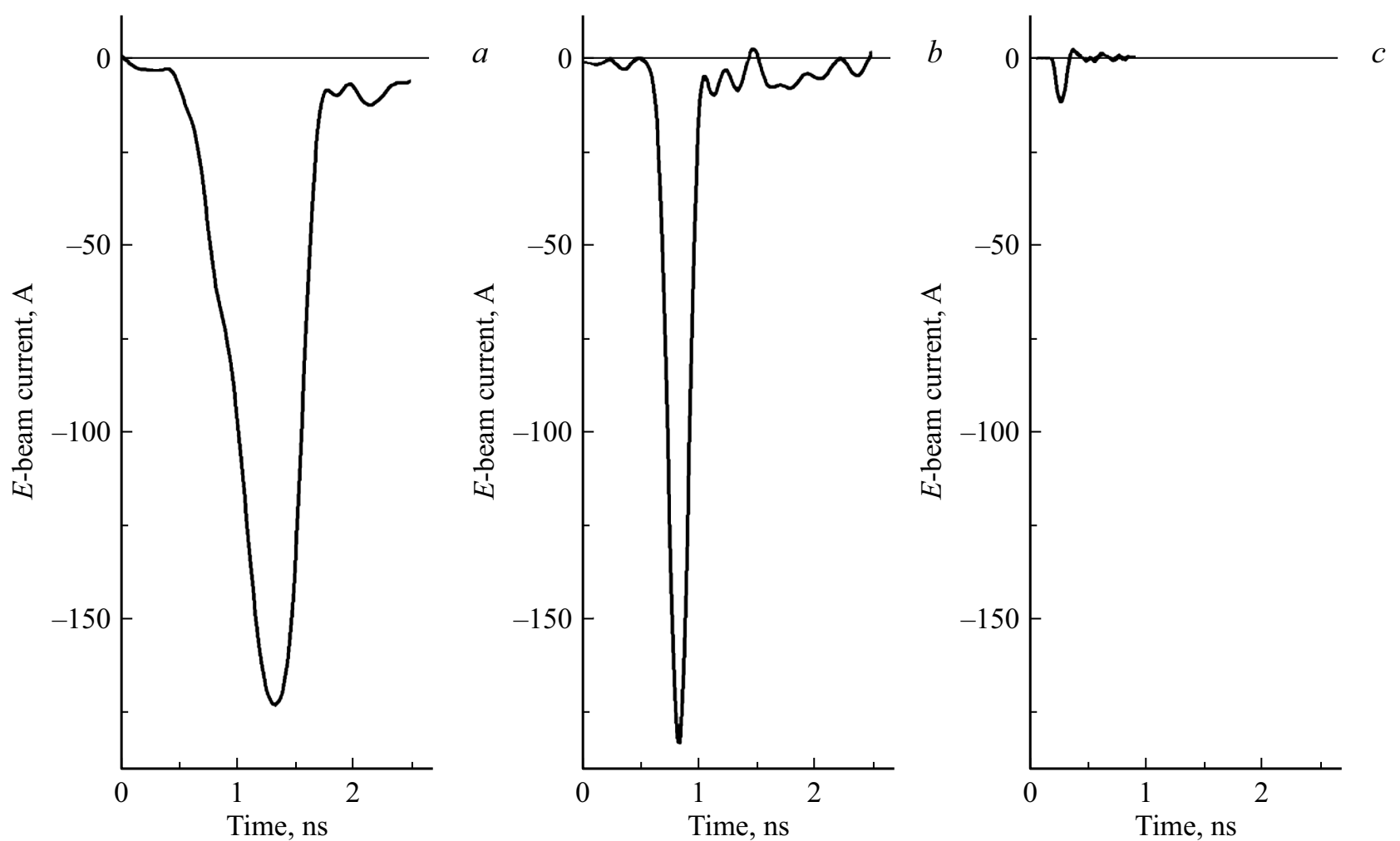

Рис. 4. Импульсы тока электронного пучка, используемые для воздействия на образцы, при разных давлениях газа в диоде за алюминиевой фольгой и диафрагмой диаметром $1 \mathrm{~cm}$. Давление газа в диоде $p=9(a), 60(b)$ и 760 Torr $(c)$. Трубчатый катод, межэлектродный зазор $d=14 \mathrm{~mm}$.

Распределение электронов пучка по энергиям обычно определялось по ослаблению тока СЛЭП за фильтрами из алюминиевой фольги различной толщины $[65,66]$. Для определения энергии основных групп электронов, кроме метода фильтров, также использовался времяпролетный спектрометр, который состоял из отрезка трубы с двумя диафрагмами на торцевых фланцах [67]. Распределения электронов по энергиям для различных ускорителей с трубчатыми катодами приведены на рис. 5.

Поскольку данный обзор посвящен исследованиям спектральных и амплитудно-временных характеристик ИВЧ и ИКЛ, мы подробно опишем конструкцию только одного из ускорителей - ГИН-500, который был создан в 2019 г. [63]. Подробную информацию о конструкциях других ускорителей, а также условиях получения различных режимов тока пучка можно найти в работах [50-52,60-67].

Схематичное изображение конструкции ускорителя ГИН-500, состоящего из двухсекционного высоковольтного блока и газонаполненного диода, показано на рис. 6. В первой секции ускорителя, как и в генераторе РАДАН-303 [68], использовалась двойная формирующая линия. Однако вместо разрядника с регулируемым зазором, который располагался в [68] между средним и 

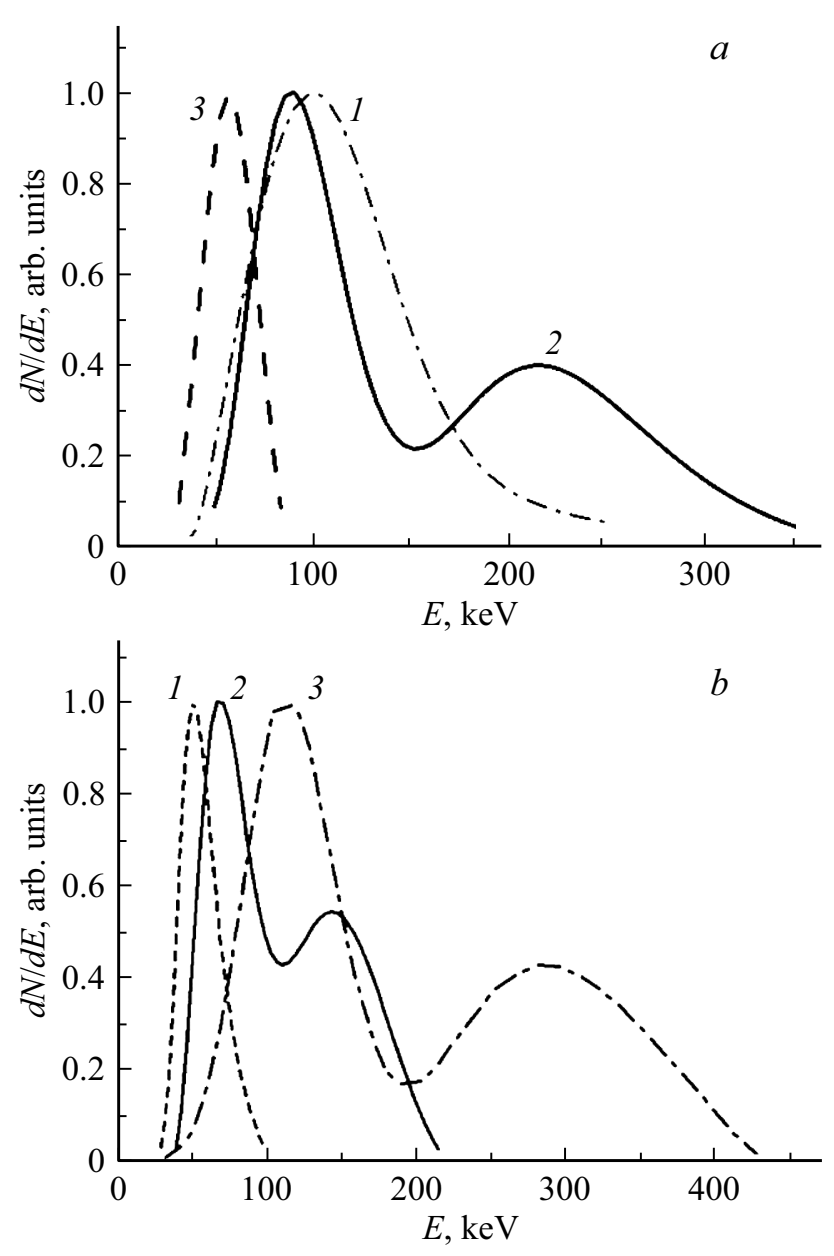

Рис. 5. (a) Распределения электронов пучка по энергиям для ускорителя на основе СЛЭП-150М (1) [51], а также для первого (2) и второго (3) импульсов тока пучка электронов ускорителя на основе ГИН-500 при $d=11.5 \mathrm{~mm}$, $p \sim 0.8$ Torr [63]. (b) Распределения электронов пучка по энергиям для ускорителей на основе генераторов ГИН-55-01 (1), РАДАН-220 (2) [2] и ГИН-600 (3) [40]. Все распределения нормированы на единицу.

заземленным коаксиальными электродами, применялся промышленный двухэлектродный разрядник высокого давления Р-49, соединенный с внутренним электродом. Волновые сопротивления каждой из двух формирующих линий первой секции равнялись $\sim 20 \Omega$. Сопротивление короткой передающей линии, следующей за двойной формирующей линией, составляло $50 \Omega$. На заземленном и среднем электродах в секции I располагались магнитопроводы, которые были взяты из генератора РАДАН-220 [64]. После короткой передающей линии устанавливалась вторая секция ускорителя, которая состояла из неоднородной передающей линии, волновое сопротивление которой плавно изменялось от 50 до $100 \Omega$. Применение второй секции позволяет простым способом увеличить амплитуду импульса напряжения. Диаметр внутреннего электрода на входе неоднородной линии в газонаполненный диод составлял $8 \mathrm{~mm}$, а внут- ренний диаметр внешнего электрода коаксиальной линии равнялся $102 \mathrm{~mm}$. Это обеспечивало сравнительно высокую электрическую прочность изолятора газового диода.

Трубчатый катод с внутренним диаметром $8 \mathrm{~mm}$ был изготовлен из фольги из нержавеющей стали толщиной $100 \mu \mathrm{m}$. Межэлектродный зазор мог изменяться от 2 до $13 \mathrm{~mm}$. Вывод тока пучка осуществлялся через фольгу $\mathrm{AlMg}$ толщиной $40 \mu \mathrm{m}$. Ток пучка регистрировался с помощью конического коллектора с временным разрешением не хуже 100 ps [69]. Измерения импульсов напряжения на выходе из первой и второй секций ускорителя осуществлялись с помощью емкостных делителей.

Зарядка двойной формирующей линии осуществлялась от вторичной обмотки импульсного трансформатора, который был расположен между двумя коаксиальными цилиндрами со встроенными магнитными сердечниками, при разряде конденсатора через первичную обмотку трансформатора (на рисунке не показаны). Далее при срабатывании разрядника высокого давления P-49 в секции I формировался наносекундный импульс напряжения с амплитудой $\sim 190 \mathrm{kV}$, который по короткой передающей линии и линии с переменным волновым сопротивлением подавался на трубчатый катод. Это позволяло получать импульсы напряжения длительностью $2.5 \mathrm{~ns}$ на полувысоте с амплитудой в режиме холостого хода $\sim 500 \mathrm{kV}$. Давление газа в диоде могло изменяться от 0.1 до 760 Torr. В данном ускорителе для заполнения газового диода применялся воздух. Как было показано в работе [70], оптимальные давления в диоде для получения максимальных амплитуд тока пучка в гелии, водороде и азоте отличаются.

Осциллограммы импульсов напряжения и тока пучка в режиме, близком к оптимальному для проведения экспериментов по изучению параметров ИВЧ, показаны на рис. 7. Амплитуда импульса напряжения на диоде составляла не менее $350 \mathrm{kV}$, а ток, регистрируемый коллектором с диаметром приемной части $15 \mathrm{~mm}$, составлял $\sim 700 \mathrm{~A}$. Плотность тока пучка за фольгой с центральной площадки диаметром $3 \mathrm{~mm}$ равнялась $\sim 220 \mathrm{~A} / \mathrm{cm}^{2}$. Осциллограммы импульсов напряжения и тока пучка в этом режиме состояли из двух импульсов. Длительность первого (основного) импульса на полувысоте была $\tau_{0.5} \sim 1.3 \mathrm{~ns}$. Второй импульс тока пучка имел меньшую амплитуду. Он возникал из-за различий сопротивлений генератора и газонаполненного диода, которое увеличивалось при увеличении сопротивления диода. Для первого импульса напряжения на распределении электронов по энергиям имелись две группы в диапазонах энергий 50-150 и $180-350 \mathrm{keV}$. Bo втором импульсе в этих же условиях энергия электронов не превышала $100 \mathrm{keV}$ и распределение имело один максимум (рис. 5,a). Свечение образцов из кварца и сапфира под воздействием пучка электронов от ускорителя ГИН-500 при длительности импульсов на полувысоте 1.3 ns показано на рис. 8. Созданный ускоритель был 


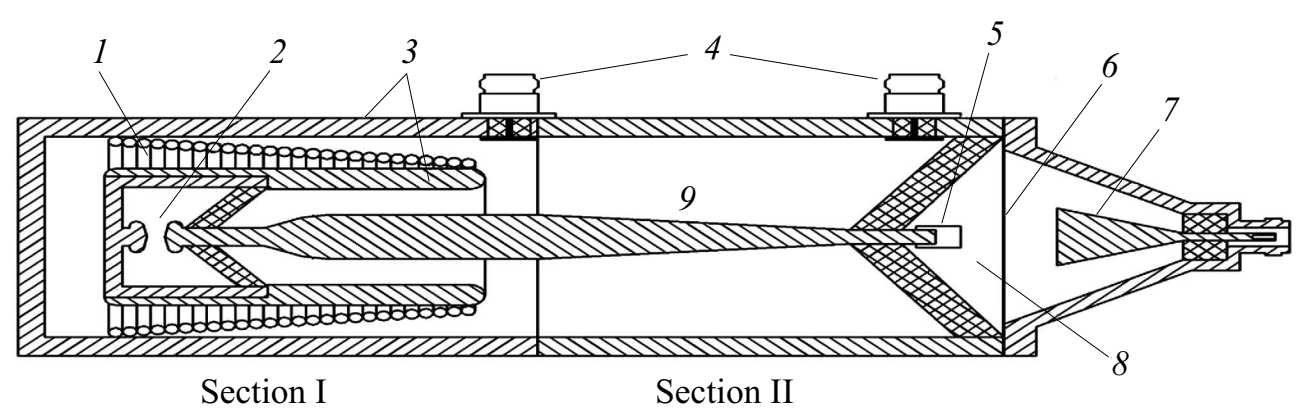

Pис. 6. Схематичное изображение высоковольтного блока ускорителя, состоящего из двух секций, а также газонаполненного диода, к которому подключен конический коллектор [63]. Обе секции ускорителя заполнены трансформаторным маслом. $1-$ вторичная обмотка, 2 - разрядник, 3 - электроды коаксиальной линия, 4 - емкостные делители напряжения, 5 - катод, 6 анодная фольга, 7 - коллектор, 8 - диод, 9 - передающая неоднородная линия.

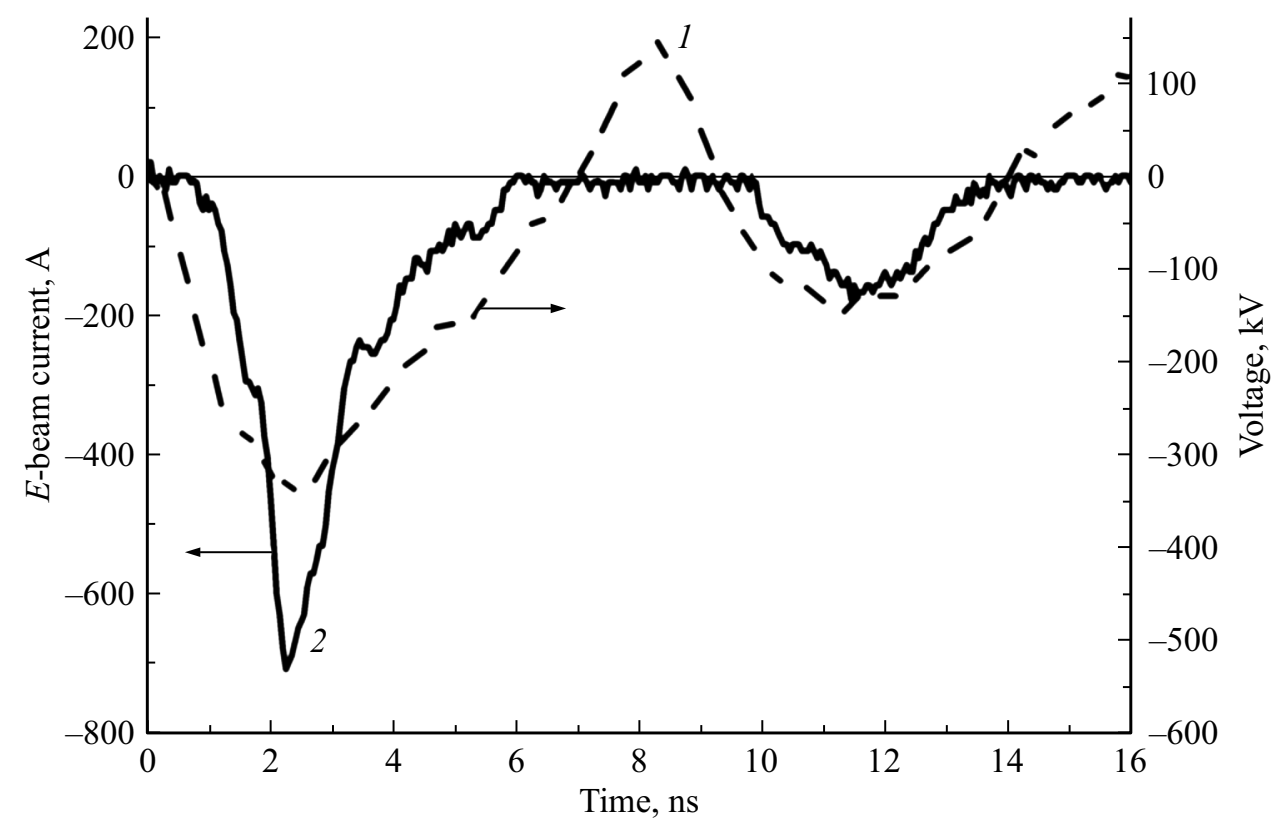

Рис. 7. Осциллограммы импульса напряжения на диоде $(1)$ и тока пучка за фольгой $(2)$ при межэлектродном зазоре $d=11.5 \mathrm{~mm}$ и давлении воздуха в диоде $p \sim 0.8$ Torr [63].

использован для возбуждения ИВЧ в кварцевом стекле КУ-1, лейкосапфире, сапфире, синтетическом алмазе типа IIa, керамике из оксида иттрия, а также в других материалах. Результаты приведены в разд. 4.

В экспериментах по исследованию повреждения ПММА более удобно было использовать значения плотности энергии электронного пучка. Диапазон плотностей энергии электронного пучка при варьировании зарядных напряжений генератора ГИН-600 составлял $0.01-0.4 \mathrm{~J} / \mathrm{cm}^{2}$. С генератором СЛЭП-150М максимальная плотность энергии электронного пучка составляла $0.01 \mathrm{~J} / \mathrm{cm}^{2}$, а минимальные, при которых еще удавалось регистрировать осциллограммы СЛЭП, были на три порядка меньше. Изменение достигалось за счет вариации давления и сорта газа в диоде.

Кроме ускорителей, параметры которых приведены в табл. 1, для исследования зависимости спектрально- го состава излучения кварцевой пластины от ее угла наклона к направлению распространения электронного пучка в качестве ускорителя электронов использовался микротрон Томского политехнического университета [71]. Исследование пространственных характеристик ИВЧ расширяет заявленный в названии обзора диапазон энергий электронов пучка. Использование микротрона оправдано тем, что приближает энергию электронов пучка к верхней границе энергий УЭ в ТОКАМАКах. Энергия электронов пучка равнялась $6 \mathrm{MeV}$. Средний ток пучка составлял $25 \mathrm{~mA}$, длительность импульса тока $-4 \mu \mathrm{s}$. При этом пучок состоял из $10^{4}$ сгустков с длительностью каждого сгустка $\sim 10 \mathrm{ps}$ и подавался на образцы с частотой $3 \mathrm{~Hz}$. Расходимость пучка после вывода из камеры соответствовала $\theta_{\mathrm{e}} \sim 6^{\circ}$. Длительность отдельных электронных сгустков и соответствующих 


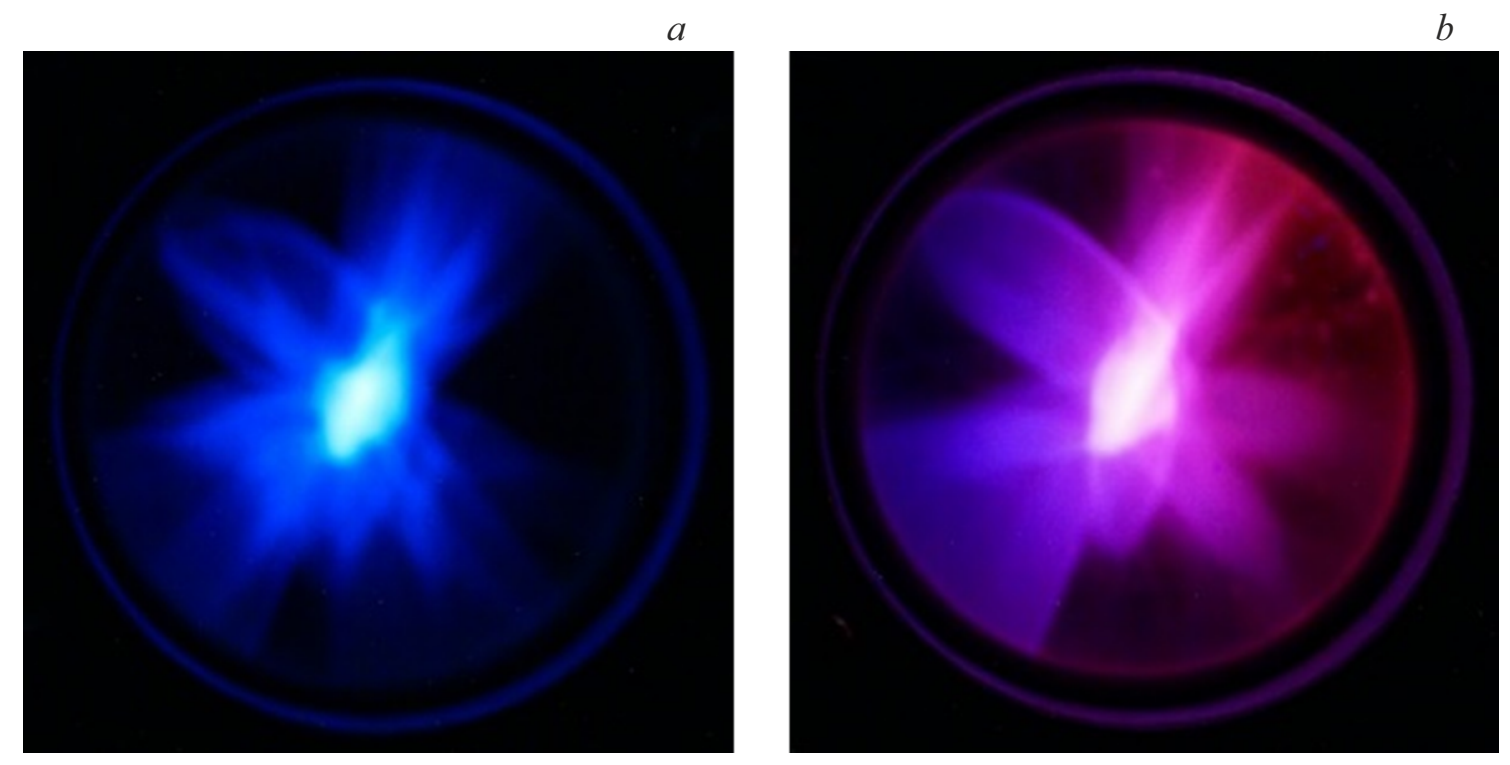

Рис. 8. Фотографии свечения пластинок (радиаторов, расположенных перпендикулярно направлению распространения пучка электронов) из кварцевого стекла КУ-1 толщиной $8 \mathrm{~mm}(a)$ и сапфира толщиной $5 \mathrm{~mm}(b)$ [42]. Размер фотографий $65 \times 65 \mathrm{~mm}$. Фотографии свечения образцов выполнялись с помощью цифрового зеркального фотоаппарата Sony $\alpha 100$.

импульсов ИВЧ была меньше временного разрешения используемой в данных экспериментах аппаратуры.

Для всех ускорителей, за исключением ускорителя на основе ГИН-600 и микротрона, электрические сигналы с емкостных делителей и коллекторов подавались на цифровой осциллограф Agilent DSO-X6004A (6 GHz, $20 \mathrm{~S} / \mathrm{ns}$ ) через высокочастотные кабели 5D-FB PEEG (Radiolab) длиной $1.2 \mathrm{~m}$. Для ослабления сигналов использовались ослабители 142-NM (Barth Electronics, $30 \mathrm{GHz}$ ). При работе с ускорителем ГИН-600 и микротроном использовался цифровой осциллограф Tektronix DPO 3034 (300 MHz, 5 S/ns).

\section{2. Схемы экспериментов и характеристики материалов образцов}

Исследование свечения образцов из различных материалов под действием электронного пучка от вышеописанных ускорителей проводилось на нескольких экспериментальных стендах. Типичные схемы экспериментов по изучению спектральных и амплитудно-временных характеристик свечения различных образцов с возбуждением пучком электронов от ускорителей, описанных в табл. 1, а также данные о пропускании фильтров УФС и чувствительности фотодиода PD025 представлены на рис. 9.

Образцы обычно располагались перпендикулярно направлению распространения пучка электронов или направлению излучения эксилампы. Как было показано в [40], при энергиях электронов в десятки-сотни $\mathrm{keV}$ значительная часть ИВЧ из-за многократного рассеяния электронов, а также изменения угла $\theta$ (рис. $1, b$ ) между направлением движения электрона и направлением ИВЧ при уменьшении их энергии в процессе торможения, выходит перпендикулярно поверхности образца. Это подтверждают и фотографии свечения пластинок из кварцевого стекла КУ-1 и сапфира на рис. 8.

Спектры излучения образцов, а также спектры их пропускания измерялись с помощью спектрометра $\mathrm{HR} 2000$ + ES (спектральный диапазон 190-1100 nm, спектральное разрешение $9 \AA$, Ocean Optics, Inc.) c известной спектральной чувствительностью. Образцы обычно устанавливались на расстоянии $2.5 \mathrm{~mm}$ от фольги. Излучение подавалось на спектрометр по световоду P600-1-SR (спектральный диапазон 200-1100 nm, диаметр сердцевины $600 \mu \mathrm{m}$, Ocean Optics, Inc.). При проведении спектральных измерений с возбуждением свечения образцов электронным пучком от ускорителя ГИН-600 использовался оптоволоконный спектрометр AvaSpec-3648 (диапазон 200-1100 nm, спектральное разрешение $\sim 3 \mathrm{~nm}$ ) [72].

При высоком временном разрешении в области длин волн 200-700 nm амплитудно-временные характеристики излучения регистрировались с помощью фотодиода PD025 компании Photek (катод LNS20, время нарастания переходной характеристики $\sim 80 \mathrm{ps}$ ) с установкой оптического фильтра УФС-1 (УФС-2) и без него (рис. 9, $b$ ). Коротковолновая граница определялась поглощением образцов или воздуха, а длинноволновая - уменьшением чувствительности фотодиода, начиная с $500 \mathrm{~nm}$. Для уменьшения влияния электромагнитных наводок фотодиод PD025 помещался в алюминиевый стакан. Bo всех экспериментах сигналы с фотодиода PD025 регистрировались с помощью цифрового осциллографа Agilent DSO-X6004A (6 GHz, 20 S/ns). 

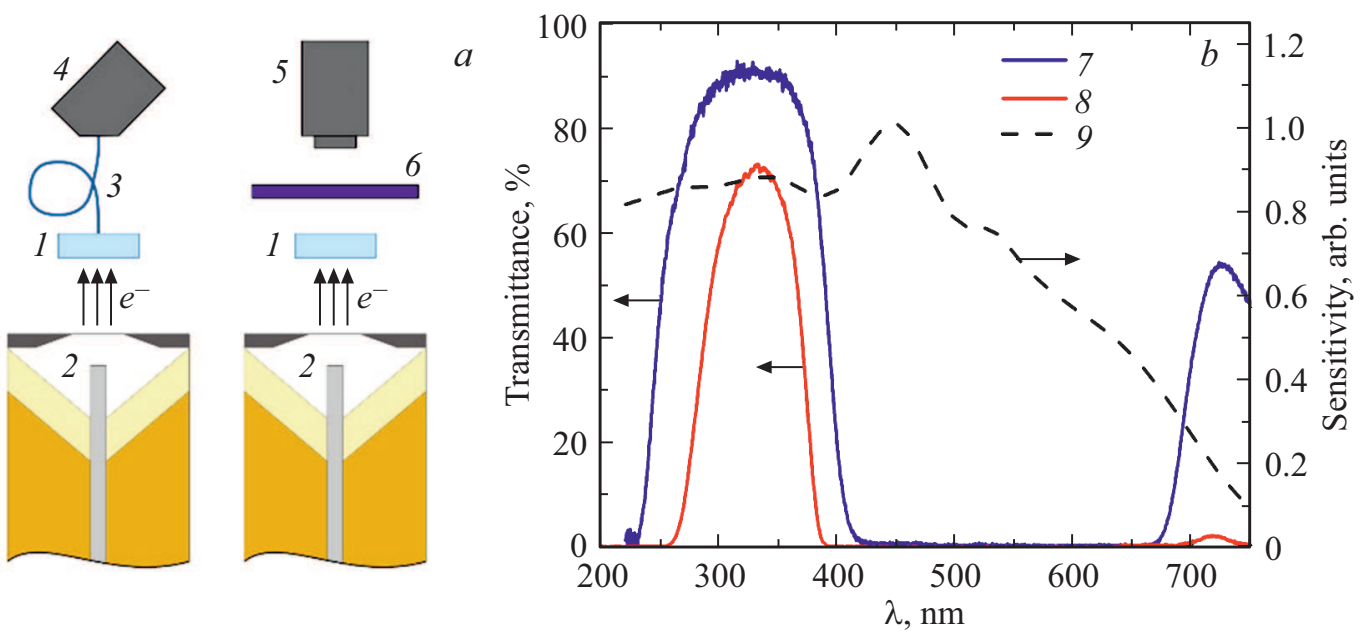

Рис. 9. Схемы систем регистрации параметров излучения с помощью спектрометра и фотодиода $(a)$, а также данные о пропускании фильтров УФС и чувствительности фотодиода $\mathrm{PD} 025(b): 1$ - образец, 2 - газовый или вакуумный диод, 3 оптический световод, 4 --спектрометр, 5 - фотодиод PD025, 6 - оптический фильтр УФС-1 или УФС-2, 7 - кривая пропускания фильтра УФС-1, 8 - кривая пропускания фильтра УФС-2, 9 - кривая чувствительности фотодиода PD025.

Амплитудно-временные характеристики излучения на определенной длине волны регистрировались с помощью дифракционного монохроматора МДР-23 (решетка 1200 grooves $/ \mathrm{mm}$, обратная линейная дисперсия $1.3 \mathrm{~nm} / \mathrm{mm}$, ширина входной и выходной щели $400 \mu \mathrm{m}$ ) и ФЭУ-97 (рабочий диапазон длин волн 250-650 nm, время нарастания переходной характеристики $\sim 7 \mathrm{~ns}$ ) [73], либо ФЭУ-84 (рабочий диапазон длин волн 300-800 nm, время нарастания переходной характеристики $\sim 5 \mathrm{~ns}$ ) [40], либо ФЭУ Н7732-10 Hamamatsu (рабочий диапазон длин волн 185-900 nm, диапазон изменения чувствительности ФЭУ $10^{3}-10^{7}$, время нарастания переходной характеристики $2.2 \mathrm{~ns}$ ) с известной спектральной чувствительностью [72], а также цифрового осциллографа Tektronix DPO $3034(300 \mathrm{MHz})$ или Tektronix TDS3054B $(500 \mathrm{GHz}, 5 \mathrm{~S} / \mathrm{ns})$, связанных c компьютером. Образцы устанавливались перпендикулярно или под углом $45^{\circ}$ к оси монохроматора, излучение фокусировалось линзой на щель монохроматора.

В [72] использовались два метода регистрации спектров свечения кристаллов $\mathrm{Ga}_{2} \mathrm{O}_{3}$ : „спектр по точкам“ и „спектр за импульс“. Первый метод позволял с временным разрешением регистрировать спектры свечения с помощью импульсного спектрометра на основе дифракционного монохроматора МДР-23,ФЭУ-97 и осциллографа Tektronix DPO 3034, связанного с компьютером. Временное разрешение всей системы регистрации спектральных характеристик свечения образцов составляло $\sim 15 \mathrm{~ns}$. Во втором методе суммарные за импульс возбуждения спектры свечения (без временного разрешения) регистрировались с помощью оптоволоконного спектрометра AvaSpec-3648.

Характеристики исследованных образцов приведены в табл. 2 и 3. Для кристаллов с двойным лучепре- ломлением указаны значения показателя преломления обыкновенного луча. Для кристаллов $\mathrm{CdS}$ и $\mathrm{Ga}_{2} \mathrm{O}_{3}$, а также для керамики из оксида иттрия не удалось найти точные данные о длинноволновой границе области прозрачности, поэтому в табл. 3 указана длинноволновая граница рабочего диапазона спектрометра HR2000 + ES $(\sim 1 \mu \mathrm{m})$. Однако, как и в случае с алмазом, точное значение длинноволновой границы области прозрачности для дальнейшего изложения не имеет значения.

Оксид галлия (III) имеет несколько модификаций, наиболее стабильной считается $\beta$-фаза. В экспериментах $[72,74]$ использовались два образца $\beta-\mathrm{Ga}_{2} \mathrm{O}_{3}$ (№ 1 и № 2): легированный $\mathrm{Sn}$ (№ 1), который является полупроводником, и легированный $\mathrm{Fe}$ - полуизолятор (№ 2). Исследовались характеристики монокристаллических пластин $\beta$ - $\mathrm{Ga}_{2} \mathrm{O}_{3}$, выращенных методом Степанова (EFG-метод, производитель - Tamura Corp. [75]). В [76] в экспериментах использовался образец керамики из оксида иттрия $\left(\mathrm{Y}_{2} \mathrm{O}_{3}\right)$ с добавления 0.05 мольных долей $\mathrm{ZrO}_{2}$. Образцы керамики изготавливались в Институте электрофизики УрО РАН из нанопорошка, полученного методом лазерного синтеза [77].

Значения показателей преломления $n_{D}$ для разных кристаллов были взяты из базы данных показателей преломления [78]. Коротковолновая граница области прозрачности для ряда кристаллов определялась с помощью спектрометра HR2000 + ES, имеющего чувствительность в диапазоне длин волн 190-1100 nm, а данные о длинноволновой границе области прозрачности ряда кристаллов были взяты из различных источников $[79,80]$. Из этих же источников были взяты данные о коротковолновой границе области прозрачности для кристаллов, у которых она лежала в области короче $190 \mathrm{~nm}$. Исследования по определению 
Таблица 2. Характеристики наиболее перспективных образцов

\begin{tabular}{l|c|c|c}
\hline \multicolumn{1}{c|}{ Параметры образцов } & $\begin{array}{c}\text { Полоса } \\
\text { пропускания, } \\
\text { Тип материала образца } \\
\text { (обозначение образца) }\end{array}$ & $\begin{array}{c}\text { Показатель } \\
\text { преломления } \\
\text { луча }\left(n_{D}\right)\end{array}$ & $\begin{array}{c}\text { Пороговая энергия } \\
\text { электронов } \\
\left(E_{\mathrm{th}}\right), \mathrm{keV}\end{array}$ \\
\hline Алмаз, тип IІа, синтетический, CVD $(\mathrm{C} 5)$ & $0.225-(>5)$ & 2.42 & 50 \\
Алмаз, тип IIа, синтетический, CVD $(\mathrm{C6})$ & $0.225-(>5)$ & 2.42 & 50 \\
Сапфир, $\mathrm{Al}_{2} \mathrm{O}_{3}$ & $0.18-2.3$ & 1.77 & 108 \\
Лейкосапфир, $\mathrm{Al}_{2} \mathrm{O}_{3}$ & $0.18-2.3$ & 1.77 & 178 \\
ПММА & $0.35-2.0$ & 1.46 & 190
\end{tabular}

Примечание. Длинноволновая граница полосы пропускания алмазов указана условно (более $5 \mu \mathrm{m})$. Ее точное значение для дальнейшего изложения не имеет значения, так как она лежит в ИК области спектра, а исследованная спектральная область возбуждения ИВЧ ограничивается УФ и видимым диапазонами.

Таблица 3. Характеристики образцов

\begin{tabular}{|c|c|c|c|}
\hline Параметры образцов & Полоса & Показатель & Пороговая энергия \\
\hline $\begin{array}{l}\text { Тип материала образца } \\
\text { (обозначение образца) }\end{array}$ & $\mu \mathrm{m}$ & луча $\left(n_{D}\right)$ & $\left(E_{\mathrm{th}}\right), \mathrm{keV}$ \\
\hline $\begin{array}{l}\text { Алмаз, ІІа тип, природный }(\mathrm{C} 4) \\
\text { Алмаз, ІІа тип, синтетический, НРНТ (CN3) } \\
\mathrm{ZnSe} \\
\mathrm{CdS} \\
\mathrm{ZnS} \\
\mathrm{ZiO}_{2} \\
\mathrm{Ga}_{2} \mathrm{O}_{3} \\
\mathrm{Kepaмика} \mathrm{из} \mathrm{оксида} \mathrm{иттрия}_{\mathrm{CsI}} \\
\mathrm{CaCO}_{3} \\
\mathrm{CaF}_{2} \\
\mathrm{MgF}_{2}\end{array}$ & $\begin{array}{l}0.225-(>5) \\
0.225-(>5) \\
0.475-20 \\
0.52-1 \\
0.37-13.5 \\
0.35-7 \\
0.26-1 \\
0.25-1 \\
0.3-35 \\
0.25-2.5 \\
0.125-12 \\
0.11-7.5\end{array}$ & $\begin{array}{c}2.42 \\
2.42 \\
2.4 \\
2.4 \\
2.2 \\
2.16 \\
1.97 \\
1.93 \\
1.74 \\
1.57 \\
1.434 \\
1.38\end{array}$ & $\begin{array}{c}50 \\
50 \\
51 \\
51 \\
63 \\
65 \\
82 \\
86 \\
113 \\
152 \\
202 \\
230\end{array}$ \\
\hline
\end{tabular}

Примечание. Данные взяты из работы [34]. Длинноволновая граница полосы пропускания алмазов указана условно (более 5 значение для дальнейшего изложения не имеет значения, так как она лежит в ИК области спектра, а исследованная спектральная область возбуждения ИВЧ ограничивается УФ и видимым диапазонами.

пространственных характеристик излучения кварцевых пластин с использованием микротрона [41] проводились на установке, схема которой представлена на рис. 10. Для экспериментов использовались плоскопараллельные пластинки из кварцевого стекла марки GE-014 и КУ-1. Выбор данных сортов кварцевого стекла был обусловлен малой интенсивностью ИКЛ в них и малым поглощением в области длин волн 200-800 nm. Основные эксперименты были проведены с пластинкой из кварцевого стекла марки GE-014, которая имела наименьшую толщину. Для указанной толщины угол многократного рассеяния составлял $\theta_{\mathrm{ms}} \sim 23^{\circ}$. Спектры излучения регистрировались спектрометром Ocean Optics HR2000+, который был удален от траектории пучка электронов и защищался от их попадания, a также от рентгеновского излучения. Отметим, что рентгеновское излучение имело наибольшую интенсивность у ускорителя и рядом с облучаемой пластинкой и траекторией пучка электронов. Световое излучение от образцов к спектрометру подавалось с помощью световода длиной $2 \mathrm{~m}$, который также защищался от рентгеновского излучения и прямого попадания пучка электронов.

Кроме пучков электронов от различных ускорителей для воздействия на образцы использовались эксилампы с излучением на длинах волн 172, 206, 222, 282 и $308 \mathrm{~nm}$ [81,82,83]. Основные эксперименты были проведены с $\mathrm{KrCl}$-эксилампой (длина волны излучения $\lambda=222 \mathrm{~nm})$. Средняя плотность мощности излучения при частоте следования импульсов $f=43 \mathrm{kHz}$ состав- 


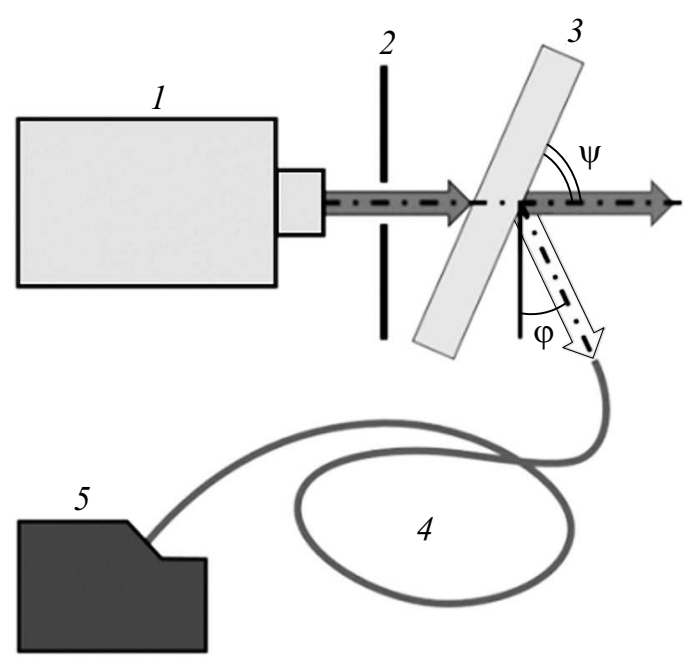

Рис. 10. Схема экспериментальной установки [41]: 1 микротрон, 2 - диафрагма, 3 - кварцевая пластина, 4 световод, 5 - спектрометр.

ляла $7 \mathrm{~mW} / \mathrm{cm}^{2}$, длительность импульса излучения на полувысоте $\tau_{0.5} \sim 200 \mathrm{~ns}$. Спектральные и амплитудновременные характеристики свечения образцов регистрировались на той же аппаратуре, что и при возбуждении пучком электронов.

\section{4. ИВЧ и ИКЛ, наблюдаемые в различных материалах при возбуждении пучком электронов}

\section{1. Спектральные и амплитудно-временные характеристики ИВЧ и ИКЛ}

Исследованию ИКЛ, возникающей при облучении различных материалов электронными пучками с энергией электронов в десятки-сотни $\mathrm{keV}$, посвящено большое число работ (например, монографии [31,37]). В некоторых публикациях проводился подробный анализ спектрального состава люминесценции образцов. Однако при энергиях электронов в сотни $\mathrm{keV}$, как будет показано в данном разделе, возникает и излучение ВавиловаЧеренкова. Далее приведены результаты исследований, которые были направлены на поиск материалов (диэлектриков и полупроводников) и условий их возбуждения, подходящих для регистрации ИВЧ, возникающего при облучении образцов электронными пучками с энергией электронов в диапазоне десятков-сотен $\mathrm{keV}$. Используемые образцы имели различную форму и размеры, но их толщина была достаточной для того, чтобы электроны пучка полностью поглощались в образце.

В $[34,35,82,83]$ воздействию СЛЭП и УФ излучения подвергались материалы с различными показателями преломления. Использовались ускорители РАДАН-220 и

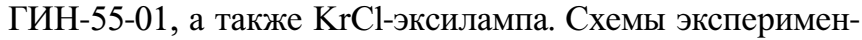

тов приведены на рис. 9, $a$. В качестве образцов были выбраны природный и синтетический алмазы типа IIa, иодид цезия (CsI), сульфид цинка $(\mathrm{ZnS})$, лейкосапфир $\left(\mathrm{Al}_{2} \mathrm{O}_{3}\right)$, флюорит $\left(\mathrm{CaF}_{2}\right)$, диоксид циркония $\left(\mathrm{ZrO}_{2}\right)$, оксид галлия (III) $\left(\mathrm{Ga}_{2} \mathrm{O}_{3}\right)$, кальцит $\left(\mathrm{CaCO}_{3}\right)$, сульфид кадмия $(\mathrm{CdS})$ и селенид цинка $(\mathrm{ZnSe})$. Наибольшие показатели преломления имели алмаз, $\mathrm{ZnSe}, \mathrm{CdS}, \mathrm{ZnS}$ и $\mathrm{ZrO}_{2}$. Однако образцы $\mathrm{CdS}$ и $\mathrm{ZnSe}$ не подходят для создания черенковских датчиков, поскольку имеют заметное пропускание только в длинноволновой области спектра $(>500 \mathrm{~nm})$. Образцы $\mathrm{CaF}_{2}$ и $\mathrm{Al}_{2} \mathrm{O}_{3}$ (лейкосапфир) хорошо пропускают свет не только в УФ области спектра, но и в ВУФ диапазоне, однако имеют малые коэффициенты преломления. Также сравнительно малые коэффициенты преломления имеют $\mathrm{CsI}$ и $\mathrm{CaCO}_{3}$.

Спектры ИКЛ под действием СЛЭП были зарегистрированы во всех исследованных образцах. На фоне катодолюминесценции с помощью стандартных спектрометров ИВЧ ни в одном из образцов не было зарегистрировано из-за его низкой интенсивности. Это согласуется с данными работ $[31,37,84]$. Полученные
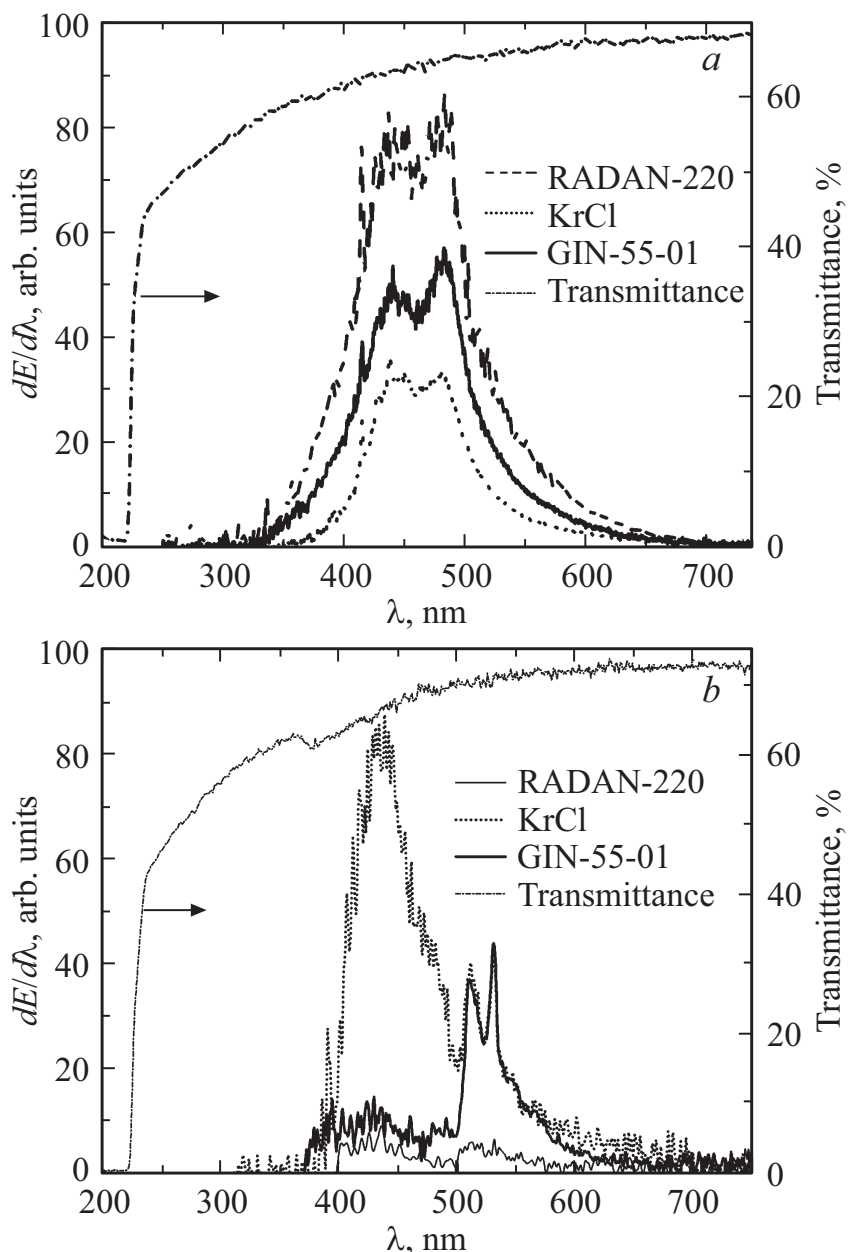

Рис. 11. Спектры пропускания и излучения природного $(a)$ и синтетического алмаза $(b)$, при возбуждении СЛЭП от генератора ГИН-55-01 и от генератора РАДАН-220 в режиме 1, а

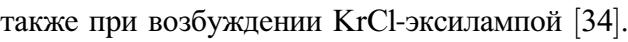


спектры для ряда образцов с различными коэффициентами преломления и пропускания представлены на рис. 11, 12. На этих же рисунках представлены спектры пропускания, а для ряда образцов - полосы их фотолюминесценции. Особое внимание в этих исследованиях было уделено образцам природного и синтетического алмазов типа IIa, так как алмазы обладают рядом уникальных физических характеристик и используются в качестве радиаторов черенковских детекторов, позволяющих определять присутствие потоков электронов начиная с энергий $\sim 50 \mathrm{keV}[16-18,29,85]$.

В спектрах ИКЛ природного алмаза (рис. 11,a) в области 330-650 nm при возбуждении электронным пучком как от ускорителя РАДАН-220 (в режимах 1 и 2), так и от ГИН-55-01 видна хорошо известная суперпозиция бесструктурной А-полосы и электронноколебательной системы (ЭКС) N3 [38,86]. А-полоса при 430-460 nm обусловлена собственными дефектами - $s p^{2}$-гибридизированными углеродными связями [87]. Центрами ЭКС N3 являются комплексные дефекты, включающие три замещающих атома азота в соседних узлах решетки в плоскости $\langle 111\rangle$, связанные с общей вакансией - $\mathrm{N}_{3} \mathrm{~V}$-дефекты [88]. Бесфононная линия (БФЛ) ЭКС N3 наблюдается при $415 \mathrm{~nm}$, ее основные фононные повторения - при 428, 439 и $452 \mathrm{~nm}$. В области 225-310 nm, которая попадает в область пропускания используемых кристаллов алмаза и в которой должно наблюдаться ИВЧ, излучение на спектрограммах имело малую интенсивность и надежно не регистрировалось.

В спектрах ИКЛ синтетического алмаза (рис. 11, b) интенсивность излучения в области $350-650 \mathrm{~nm}$ уменьшилась, изменилось распределение энергии излучения по спектру в данной области и проявилась зависимость спектра от режима возбуждения. Наиболее сильное уменьшение регистрируемой интенсивности излучения в области 330-650 nm было получено при малой частоте следования импульсов $(1 \mathrm{~Hz})$. Причем при работе РАДАН-220 в режиме 2 из-за уменьшения плотности тока СЛЭП более чем на порядок зарегистрировать спектр излучения синтетического алмаза не удалось. При возбуждении в импульсно-периодическом режиме с частотой $60 \mathrm{~Hz}$ уменьшение интенсивности излучения в области 330-650 nm было меньше, чем в режиме однократных импульсов. Кроме того, при использовании ускорителя ГИН-55-01 изменилось распределение энергии оптического излучения по спектру. В спектре свечения ИКЛ помимо А-полосы при 430-440 nm наблюдались ЭКС $389 \mathrm{~nm}$ и $3 \mathrm{H} \mathrm{[31].} \mathrm{Электронно-колебательная}$ система $389 \mathrm{~nm}$ названа по спектральному положению БФЛ, ее фононные повторения наблюдаются при 400, 410 и $420 \mathrm{~nm}$. Бесфононная линия ЭКС $3 \mathrm{H}$ при $503 \mathrm{~nm}$ характеризуется низкой интенсивностью при комнатной температуре, ее основные фононные повторения наблюдаются при 510 и $530 \mathrm{~nm}$. На данный момент еще не предложены модели центров ЭКС $389 \mathrm{~nm}$ и $3 \mathrm{H}$, которые бы описывали все наблюдаемые данные, но можно утверждать, что данные ЭКС обусловлены междоузельными атомами, т.е. радиационными дефектами [31]. В области 225-350 nm излучение на спектрограммах было слабым и надежно не регистрировалось, как и при работе ускорителя РАДАН-220 в режиме 1. Соответственно при увеличении частоты следования импульсов тока СЛЭП интенсивность излучения синтетического алмаза в области 330-650 nm увеличивается, что может быть обусловлено накоплением радиационных дефектов, которые не успевают релаксировать в паузах между импульсами возбуждения.

При возбуждении импульсами УФ излучения $(\lambda \sim 222 \mathrm{~nm})$ длительностью $\sim 200 \mathrm{~ns}$ от $\mathrm{KrCl}-$ эксилампы, которые следовали с частотой $43 \mathrm{kHz}$ и обеспечивали на образцах среднюю плотность мощности излучения $7 \mathrm{~mW} / \mathrm{cm}^{2}$, также наблюдались ЭКС $389 \mathrm{~nm}$ и $3 \mathrm{H}(500-540 \mathrm{~nm})$. Интенсивность Аполосы в области 400-500 nm значительно увеличилась. Из этих результатов следует, что при облучении алмазов коротковолновым УФ излучением интенсивность излучения алмазов в области 350-650 nm увеличивается. Соответственно ИВЧ при его достаточной интенсивности может давать вклад в интегральное свечение алмаза за счет фотолюминесценции.

В природном и синтетическом алмазах (рис. 11), в $\mathrm{CaCO}_{3}$ (рис. 12,a), а также в $\mathrm{ZnS}$ и $\mathrm{Ga}_{2} \mathrm{O}_{3}$ имеется достаточно большая область спектра между краем полосы поглощения и краем полосы люминесценции, в которой отсутствует излучение, заметное на уровне шумов на спектрограммах. В кристаллах CsI коротковолновые края полос поглощения и катодолюминесценции практически совпадают, что затрудняет регистрацию в этой области ИВЧ. В $\mathrm{CaF}_{2}$ (рис. $\left.12, b\right)$, несмотря на то, что коротковолновый край полосы поглощения лежит в ВУФ области спектра, край полосы люминесценции достигает $225 \mathrm{~nm}$, а в области короче $225 \mathrm{~nm}$ существенно возрастает поглощение кварцевых световодов. В области короче $200 \mathrm{~nm}$, кроме этого, резко возрастает поглощение воздуха. Таким образом, на основе полученных спектров излучения можно было ожидать регистрацию ИВЧ при использовании более чувствительных методов измерений прежде всего в синтетическом алмазе.

При возбуждении $\mathrm{KrCl}$-эксилампой фотолюминесценция, как уже отмечалось выше, была зарегистрирована в природном и синтетическом алмазах, а также в CsI, ZnS, $\mathrm{ZrO}_{2}$ и $\mathrm{Ga}_{2} \mathrm{O}_{3}$. В лейкосапфире и $\mathrm{CaF}_{2}$ из-за их малого поглощения в области 200-250 nm фотолюминесценция не регистрировалась. Из-за сильного поглощения в области спектра короче $500 \mathrm{~nm}$ фотолюминесценцию не удалось зарегистрировать в $\mathrm{CdS}$ и $\mathrm{ZnSe}$, а в $\mathrm{CaCO}_{3}-$ из-за неправильной формы исследуемых образцов. Из экспериментов с KrCl-эксилампой следует, что коротковолновое излучение дает вклад в полосы катодолюминесценции большинства исследованных образцов и что полосы катодолюминесценции и фотолюминесценции подобны. Следовательно, ИВЧ, интенсивность которого увеличивается с уменьшением длины волны, может 


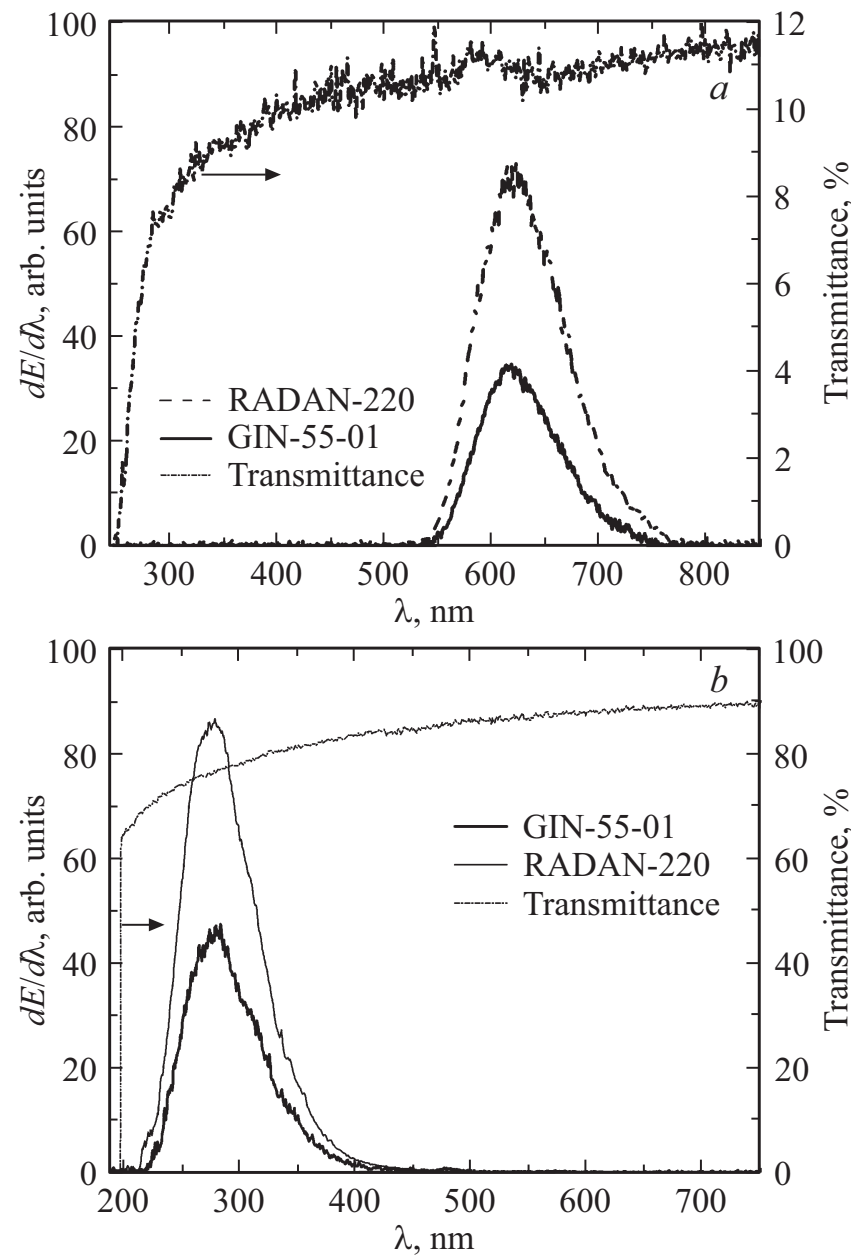

Рис. 12. Спектры пропускания и излучения $\mathrm{CaCO}_{3}(a)$ и $\mathrm{CaF}_{2}(b)$ при возбуждении СЛЭП от генератора ГИН-55-01 и от генератора РАДАН-220 в режиме 1 [34].

давать вклад в излучение образцов за счет фотолюминесценции при возбуждении ИВЧ в области спектра, где имеется сильное поглощение в образце.

Амплитудно-временные характеристики снимались с помощью фотодиода PD025 компании Photek, который обладал субнаносекундным временным разрешением, но имел малую чувствительность, и с помощью ФЭУ H7732-10 Hamamatsu, который устанавливался за монохроматором. Во втором случае за счет высокой чувствительности ФЭУ измерения амплитудно-временных характеристик импульсов излучения проводились на определенных длинах волн даже при малой интенсивности излучения на этих длинах волн. Однако временное разрешение при этом было хуже, чем у фотодиода PD025 и определялось в основном временем спада импульсной характеристики, составлявшим $10 \mathrm{~ns}$ по уровню $0.9-0.1$. На рис. 13 приведены осциллограммы катодолюминесценции синтетического алмаза при возбуждении СЛЭП с длительностью на полувысоте $\sim 100$ ps. Длительность импульса излучения составила около $2 \mathrm{~ns}$ на полувысоте при его фронте 1 ns. Отметим наличие изгиба на
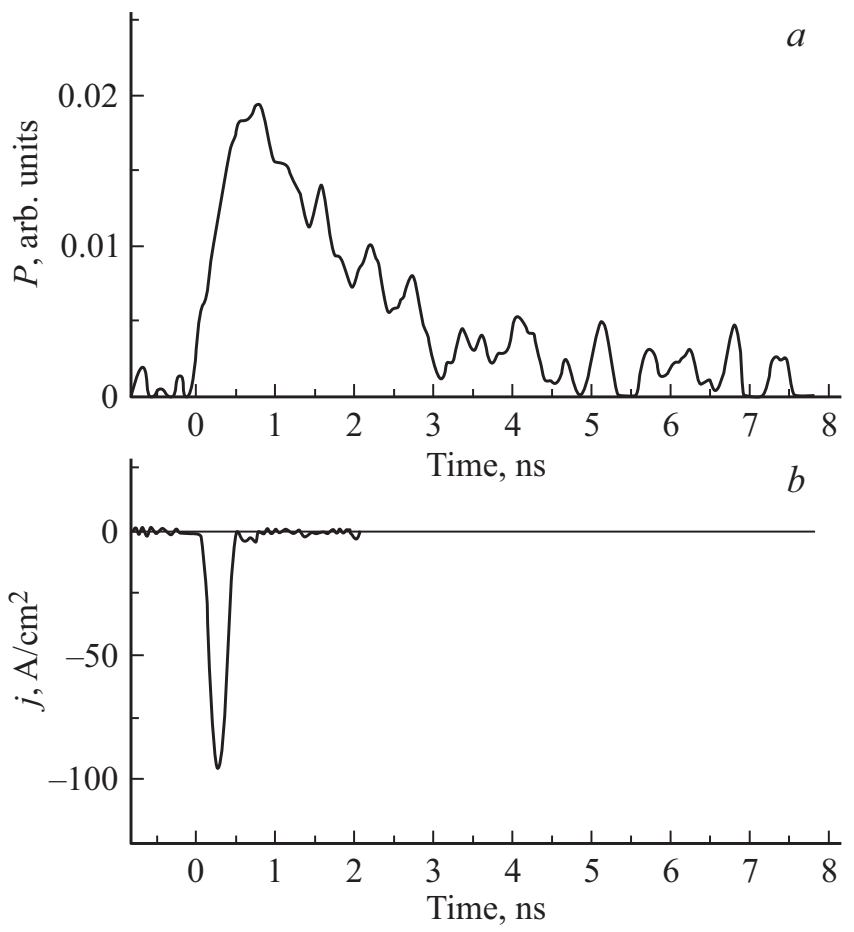

Рис. 13. Осциллограммы катодолюминесценции синтетического алмаза $(a)$ и плотности тока пучка $(b)$ [84].

фронте импульса излучения, что может быть связано с регистрацией ИВЧ во время импульса тока пучка. Однако в данном случае регистрируется в основном катодолюминесценция. Временное разрешение системы регистрации в этих условиях было не хуже $0.3 \mathrm{~ns}$.

Как отмечено выше, для регистрации ИВЧ наиболее подходит область между коротковолновым краем полосы поглощения материалов и коротковолновой границей катодолюминесценции. При использовании ФЭУ и монохроматора при возбуждении от ускорителя РАДАН-220 в этой области было зарегистрировано ИВЧ в алмазе (природном и синтетическом), $\mathrm{ZnS}, \mathrm{ZrO}_{2}, \mathrm{Ga}_{2} \mathrm{O}_{3}$, лейкосапфире и даже в CsI. Чувствительность используемого ФЭУ оказалась достаточной для достоверной регистрации ИВЧ в этих образцах. Для регистрации ИВЧ в $\mathrm{CaF}_{2}$ и $\mathrm{CaCO}_{3}$ следует использовать пучок электронов с более высокой энергией $(>200 \mathrm{keV})$. Образцы $\mathrm{CdS}$ и $\mathrm{ZnSe}$ изза большого поглощения в области спектра $<500 \mathrm{~nm}$ непригодны для создания датчиков ИВЧ.

Упоминая о $\mathrm{CdS}$ и $\mathrm{ZnSe}$, отметим также работы А.С. Насибова, суммированные в обзоре [89], в которых сообщалось о получении лазерного излучения в полупроводниковых соединениях $\mathrm{CdS}_{x} \mathrm{Se}_{1-x}, \mathrm{ZnSe}$, а также других кристаллах. Было показано, что даже при атмосферном давлении плотность тока пучка УЭ может достигать значения, достаточного для возникновения стимулированного излучения.

Исследования с помощью монохроматора и ФЭУ показали, что в области 225-310 nm для природного 
алмаза и в области 225-350 nm для синтетического алмаза спектральная плотность энергии увеличивается с уменьшением длины волны [34]. В этих областях можно ожидать свечения экситонной полосы с максимумом на длине волны $235 \mathrm{~nm}$, однако время затухания люминесценции экситонной полосы в алмазе типа ІІа составляет десятки наносекунд [90]. Регистрируемая длительность импульсов излучения образцов алмаза в этих областях не изменяется и соответствует временному разрешению ФЭУ Н7732-10 Hamamatsu, т. е. в несколько раз меньше, чем время затухания люминесценции экситона. Также при этом наблюдается минимальная задержка импульсов излучения образцов алмаза относительно фронта импульса напряжения. Соответственно зарегистрированное оптическое излучение в данной области можно отнести к ИВЧ. Начиная с длины волны $310 \mathrm{~nm}$ для природного алмаза и $350 \mathrm{~nm}$ для синтетического алмаза, наблюдается рост мощности и увеличение длительности импульсов излучения в несколько раз по мере увеличения длины волны. Кроме того, в этом диапазоне длин волн появляется задержка импульсов излучения относительно импульсов излучения, ассоциируемых с ИВЧ, которая плавно увеличивается до 4-5 ns.

Подобные малые задержки и увеличение длительности импульса излучения при регистрации в области катодолюминесценции относительно излучения в области между коротковолновым краем поглощения и коротковолновой границей катодолюминесценции при использовании ФЭУ с высокой чувствительностью и монохроматора были получены для образцов $\mathrm{ZnS}, \mathrm{ZiO}_{2}$, $\mathrm{Ga}_{2} \mathrm{O}_{3}, \mathrm{Al}_{2} \mathrm{O}_{3}$ и CsI. Соответственно в этих материалах также регистрировалось ИВЧ.

В [72,74] было проведено углубленное исследование свечения кристаллических образцов оксида галлия (III) с целью определения пригодности кристаллов $\mathrm{Ga}_{2} \mathrm{O}_{3}$ для регистрации ИВЧ при создании датчиков УЭ для установок типа ТОКАМАК. Для возбуждения кристаллов $\mathrm{Ga}_{2} \mathrm{O}_{3}$ электронным пучком использовались ускорители РАДАН-220 в режимах 1 и 2, а также ГИН-55-01. Спектры свечения кристаллов $\mathrm{Ga}_{2} \mathrm{O}_{3}$, возбуждаемых пучком электронов и УФ излучением, существенно зависят от вида легирования. Наибольшую интенсивность при возбуждении пучком электронов имеет полоса катодолюминесценции в области 300-450 nm. Данная полоса также регистрируется при возбуждении кристалла, легированного $\mathrm{Sn}$, УФ излучением эксилампы $\mathrm{KrCl}$. В кристалле, легированном $\mathrm{Fe}$, при обоих способах возбуждения появляется вторая полоса в области 650-900 nm. Однако в этом кристалле фотолюминесценция в области $300-450 \mathrm{~nm}$ была слабой и не регистрировалась на фоне шумов. Отметим, что в этом кристалле интенсивность полосы в области 300-450 nm была существенно меньше, чем в кристалле, легированном Sn. Это может быть обусловлено тем, что концентрация свободных носителей заряда с легирующей примесью Fe была существенно меньше, чем с Sn. C помощью спектрометра на ускорителях ГИН-55-01 и РАДАН-220 ИВЧ не было зарегистрировано.

Излучение Вавилова-Черенкова в области 250-300 nm было зарегистрировано на ускорителе РАДАН-220 только при использовании монохроматора и ФЭУ. Это удалость сделать как в режиме 1 при плотности тока пучка $75 \mathrm{~A} / \mathrm{cm}^{2}$, так и в режиме 2 при плотности тока пучка $1.1 \mathrm{~A} / \mathrm{cm}^{2}$. Излучение на длине волны $265 \mathrm{~nm}$ имеет минимальную задержку относительно импульса напряжения, а его длительность и форма соответствуют импульсной характеристике используемого ФЭУ. При регистрации излучения в области ИКЛ амплитуда импульсов излучения и длительность импульсов с ФЭУ возрастала, что соответствовало наблюдаемым спектрам излучения. Таким образом, кристаллы $\mathrm{Ga}_{2} \mathrm{O}_{3}$ можно использовать для регистрации УЭ с энергией более $82 \mathrm{keV}$, используя ИВЧ. Однако существенно большей чувствительностью к возбуждению пучками электронов обладает ИКЛ при длинах волн > $300 \mathrm{~nm}$, особенно в кристаллах, легированных Sn. Причем катодолюминесценция наблюдается и при энергиях электронов, меньших $82 \mathrm{keV}$.

Применение фотодиода с высоким временным разрешением для регистрации излучения позволило зарегистрировать на ускорителе РАДАН-220 (работавшем в режиме 1) интегральные импульсы излучения в области 250-700 nm, а также импульсы ИВЧ в области 250-300 nm [34,74]. В этой области исследованные кристаллы $\mathrm{Ga}_{2} \mathrm{O}_{3}$ были еще прозрачны, а катодолюминесценция имела малую интенсивность.

Ряд экспериментов $[40,73,72]$ по исследованию свечения образцов алмаза, лейкосапфира, кварцевого стекла и $\mathrm{MgF}_{2}$ был проведен на ускорителе ГИН-600, энергия электронов в котором достигала $400 \mathrm{keV}$ (рис. 5,b). Схемы экспериментов приведены на рис. 9, $a$. При проведении этих измерений возбуждение осуществлялось при плотности тока пучка $\sim 100 \mathrm{~A} / \mathrm{cm}^{2}$. Максимальная энергия электронов в два раза превышала энергию электронов ускорителя РАДАН-220. На рис. 14 показаны спектры излучения и пропускания света алмазов, природного и синтетических, полученных разными способами. Как хорошо известно, спектры излучения алмазов зависят от способа их получения, а также от состава примесей в них [31,37]. Поэтому полученные спектры излучения существенно отличаются, кроме спектров алмазов высокой чистоты (С5 и С6, табл. 2), полученных методом газохимического осаждения. Для образцов С5 и С6 было зарегистрировано увеличение интенсивности излучения в области спектра 250-400 nm при уменьшении длины волны излучения, что является одним из главных признаков ИВЧ. Для природного алмаза С4 существенный вклад в излучение в этой обрасти давала катодолюминесценция, а для алмаза CN3 на спектр излучения повлияло поглощение. Формы кривой поглощения кристаллов С4, С5 и С6 существенно не отличались, но высокая интенсивность катодолюминесценции в кристалле C4 не позволяла с помощью спектрометра 


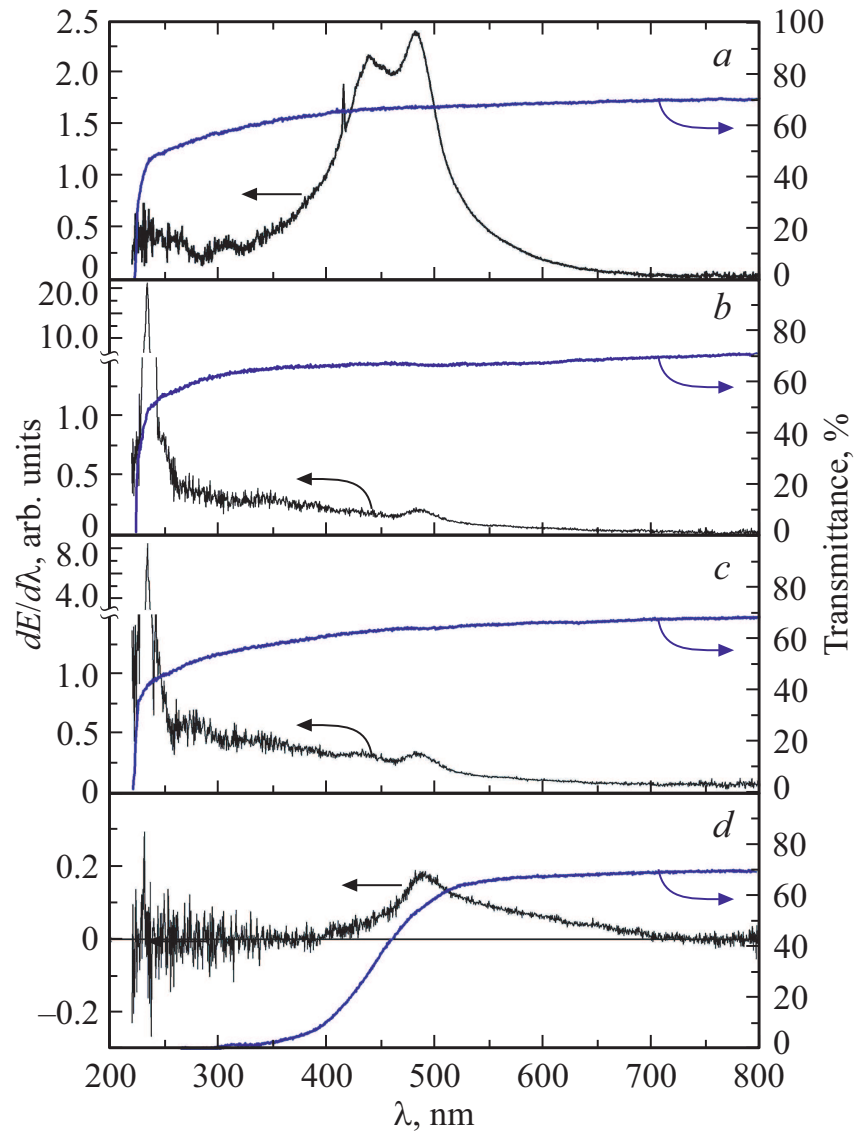

Рис. 14. Спектры излучения и пропускания четырех образцов алмаза, полученных различными способами: $(a)-\mathrm{C} 4,(b)-$ C5, $(c)-\mathrm{C} 6,(d)-\mathrm{CN} 3[40]$. Ускоритель ГИН-600.

достоверно выделить ИВЧ. Сильное поглощение в кристалле CN3 (ввиду наличия дисперсно распределенных атомов азота, замещающих атомы решетки), начиная с $500 \mathrm{~nm}$, объясняет отсутствие ИВЧ в его спектре.

Кроме ИВЧ, на ускорителе ГИН-600, а также на ускорителях РАДАН-220 при увеличении плотности тока пучка и длительности импульса для образцов С5 и С6 с помощью спектрометра была зарегистрирована полоса с высокой спектральной плотностью энергии излучения в области $220-350 \mathrm{~nm}$. Данная полоса отсутствовала в природном алмазе (образец С4) и в образце $\mathrm{CN} 3$. Как показали исследования катодолюминесценции в работе [91], полоса в области $220-350 \mathrm{~nm}$ относится к излучению экситонов в алмазе. При уменьшении температуры образца интенсивность данной полосы возрастает.

Как следует из результатов [40], ИВЧ уверенно регистрировалось на установке с ускорителем ГИН-600, которая имела большие энергии электронов и длительность тока пучка по сравнению с используемыми в работе [34]. Увеличение на установке с ускорителем РАДАН-220 плотности тока пучка с 75 до $120 \mathrm{~A} / \mathrm{cm}^{2}$ и длительности импульса на полувысоте со 180 до 300 ps также позволило с помощью стандартного спектрометра зарегистрировать увеличение интенсивности излу- чения в области $240-300 \mathrm{~nm}$ при уменьшении длины волны излучения. Это, как уже отмечалось, является признаком регистрации ИВЧ в этой области. Кроме того, и на этой установке при энергии электронов до $200 \mathrm{keV}$ удалось зарегистрировать экситонную полосу в области $220-350 \mathrm{~nm}$ с максимумом на длине волны $235 \mathrm{~nm}$. На рис. 15 для сравнения приведены спектры излучения кристалла алмаза $\mathrm{C} 5$, полученные на установках ГИН-600 и РАДАН-220. Кроме ИВЧ и ИКЛ, при длительности импульса тока пучка $0.3 \mathrm{~ns}$, на спектре излучения в области $300-400 \mathrm{~nm}$ хорошо видны полосы второй положительной системы азота (рис. $15, a$ ). Наибольшую интенсивность имела линия с длиной волны $337.1 \mathrm{~nm}$. Однако эти полосы отсутствовали при длительности импульса $12 \mathrm{~ns}$ и плотности тока пучка $100 \mathrm{~A} / \mathrm{cm}^{2}$. Причем полосы азота в спектре излучения при возбуждении алмаза отсутствовали как в первой серии экспериментов (рис. 14, $b$ ), так и во второй (рис. $15, b$ ). Можно предположить, что во втором случае интенсивность излучения второй положительной системы азота сильно уменьшается за счет тушения плазменными электронами возбужденных уровней мо-

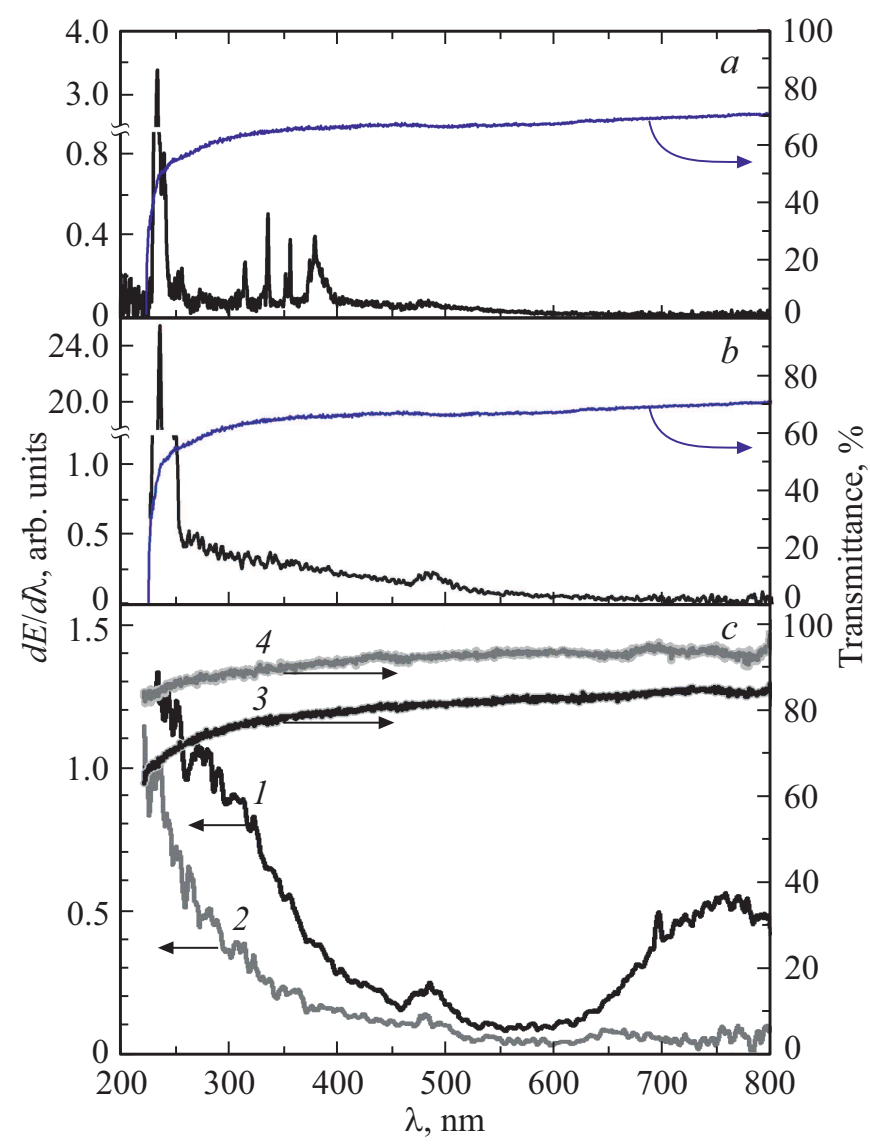

Рис. 15. Спектры излучения и пропускания образца алмаза С5 при возбуждении пучком электронов от ускорителя РАДАН$220(a)$ и от ускорителя ГИН-600 $(b)$, спектры излучения и пропускания лейкосапфира $(1,3)$ и кварцевого стекла КУ$1(2,4)$ при возбуждении пучком электронов на ускорителе ГИН-600 (c) [40]. 
лекулы азота. В результате спектральная плотность энергии излучения полос азота, регистрируемая спектрометром, оказывается на установке ГИН-600 меньше, чем спектральная плотность энергии ИВЧ.

Таким образом, на двух установках удалось зарегистрировать с помощью спектрометра спектры излучения алмаза, на которых было заметно увеличение плотности энергии излучения в области 250-340 nm. Также на этих спектрах регистрировалась узкая полоса с максимумом на длине волны $235 \mathrm{~nm}$ с высокой спектральной плотностью энергии излучения, которая отсутствовала при использовании установки РАДАН-220 с меньшей плотностью тока пучка.

Спектры излучения также были зарегистрированы с помощью спектрометра в лейкосапфире и кварцевом стекле КУ-1 (рис. 15,c) [40]. Данные материалы были выбраны для исследований, поскольку они имеют сравнительно малую интенсивность катодолюминесценции в УФ области спектра, а край фундаментального поглощения находится в ВУФ области. Как видно из рис. $15, c$, оба образца имеют полосу в области длин волн $220-450 \mathrm{~nm}$, интенсивность которой растет с уменьшением длины волны. Такое увеличение интенсивности можно объяснить только наличием ИВЧ. Для дополнительной проверки данного вывода было проведено измерение амплитудно-временных характеристик излучения в алмазе (образец С6), лейкосапфире и кварцевом стекле КУ-1.

Важным признаком ИВЧ является соответствие его длительности продолжительности электронного пучка. Исследования амплитудно-временных характеристик излучения были проведены на установках с ускорителями ГИН-600 и РАДАН-220 с помощью фотодиода PD025 (рис. 9, b). Импульсы излучения сравнивались с осциллограммами тока пучка. Импульсы излучения регистрировались за светофильтром УФС-1, который пропускал излучение в спектральной области, где наблюдалось ИВЧ $(230-400 \mathrm{~nm})$. Кривая пропускания светофильтра приведена на рис. 9, c. В области второй полосы пропускания светофильтра УФС-1 (> $670 \mathrm{~nm})$ чувствительность фотодиода существенно уменьшается, а пропускание светофильтра даже в максимуме полосы на длине волны $720 \mathrm{~nm}$ не превышает 55\%.

Для алмаза (образец С5) форма импульса излучения примерно соответствует форме тока пучка вплоть до его максимума. Далее наблюдается увеличение интенсивности излучения и длительности импульса как с применением фильтра УФС-1, так и без него. Из этого следует, что катодолюминесценция наряду с излучением Вавилова-Черенкова дает вклад в регистрируемое излучение. Однако вклад полосы экситонного излучения в области 220-350 nm в регистрируемый фотоприемником сигнал в первые $20 \mathrm{~ns}$ относительно мал изза большой длительности импульса излучения, соответствующего этой полосе ( 80 ns на полувысоте) при возбуждении от ускорителя ГИН-600. Интенсивность излучения после 12-й наносекунды быстро спадала. Длительность импульса экситонной полосы была определена с помощью монохроматора и ФЭУ.

Для сапфира и лейкосапфира наблюдалось наилучшее соответствие между осциллограммами тока пучка и излучения. Вклад ИКЛ сапфира в длинноволновой области спектра $(>650 \mathrm{~nm})$ в регистрируемый сигнал был незначительным. Для кварцевого стекла КУ-1 импульсы излучения по суммарной длительности примерно соответствовали длительности импульсов тока пучка, но состояли из трех последовательных пиков. Эти пики появлялись из-за колебания напряжения на вакуумном диоде, которые приводили к изменению плотности тока пучка и энергии электронов. При этом по три пика наблюдались как при наличии фильтра, так и без него. В эти импульсы основной вклад дает ИВЧ, но из-за малого показателя преломления у половины электронов пучка не хватало энергии для превышения порога $\left(E_{\mathrm{th}}=190 \mathrm{keV}\right)$.

Данный вывод подтверждают эксперименты на установке с ускорителем ГИН-500 [42]. Эксперименты были проведены с синтетическим алмазом С5, сапфиром и кварцевым стеклом КУ (табл. 2). Исследования показали, что в спектрах излучения всех образцов обнаруживается полоса в области $220-400 \mathrm{~nm}$, а ее интенсивность увеличивается с уменьшением длины волны. Это излучение соответствует расчетному спектру и относится к ИВЧ. При расчете спектров ИВЧ использовалась известная формула (5) спектральной плотность мощности ИВЧ, приведенная в разд. 2. Спектры излучения и пропускания синтетического алмаза представлены на рис. $16, a$. В спектре излучения синтетического алмаза высокой чистоты можно выделить несколько полос. Спектральная плотность энергии излучения $d E / d \lambda$ в области 260-450 nm увеличивается с уменьшением длины волны, что характерно для ИВЧ. При этом в спектре заметно выделяется узкая и интенсивная полоса в коротковолновом диапазоне 230-240 nm. Поскольку спектр излучения является интегрированной по времени характеристикой, высокие значения $d E / d \lambda$ в диапазоне 230-240 nm также могут быть определены по длительности излучения алмаза в этом спектральном диапазоне. Излучение этой узкой полосы с максимумом на длине волны $235 \mathrm{~nm}$, как и в [73,82], обусловлено излучательной рекомбинацией свободных экситонов [31]. В области 400-600 nm наблюдаются полосы катодолюминесценции алмаза, которые также наблюдались в [34] для синтетического алмаза.

Спектры излучения и пропускания кварцевого стекла КУ-1 представлены на рис. 16, $b$. В кварцевом стекле спектральная плотность энергии $d E / d \lambda$ монотонно возрастает с уменьшением длины волны в диапазоне 220-450 nm. Это также связано с ИВЧ. При энергиях электронов менее $200 \mathrm{keV}$ эта полоса отсутствует, поскольку пороговая энергия электронов для генерации ИВЧ в кварцевом стекле составляет $190 \mathrm{keV}$. 

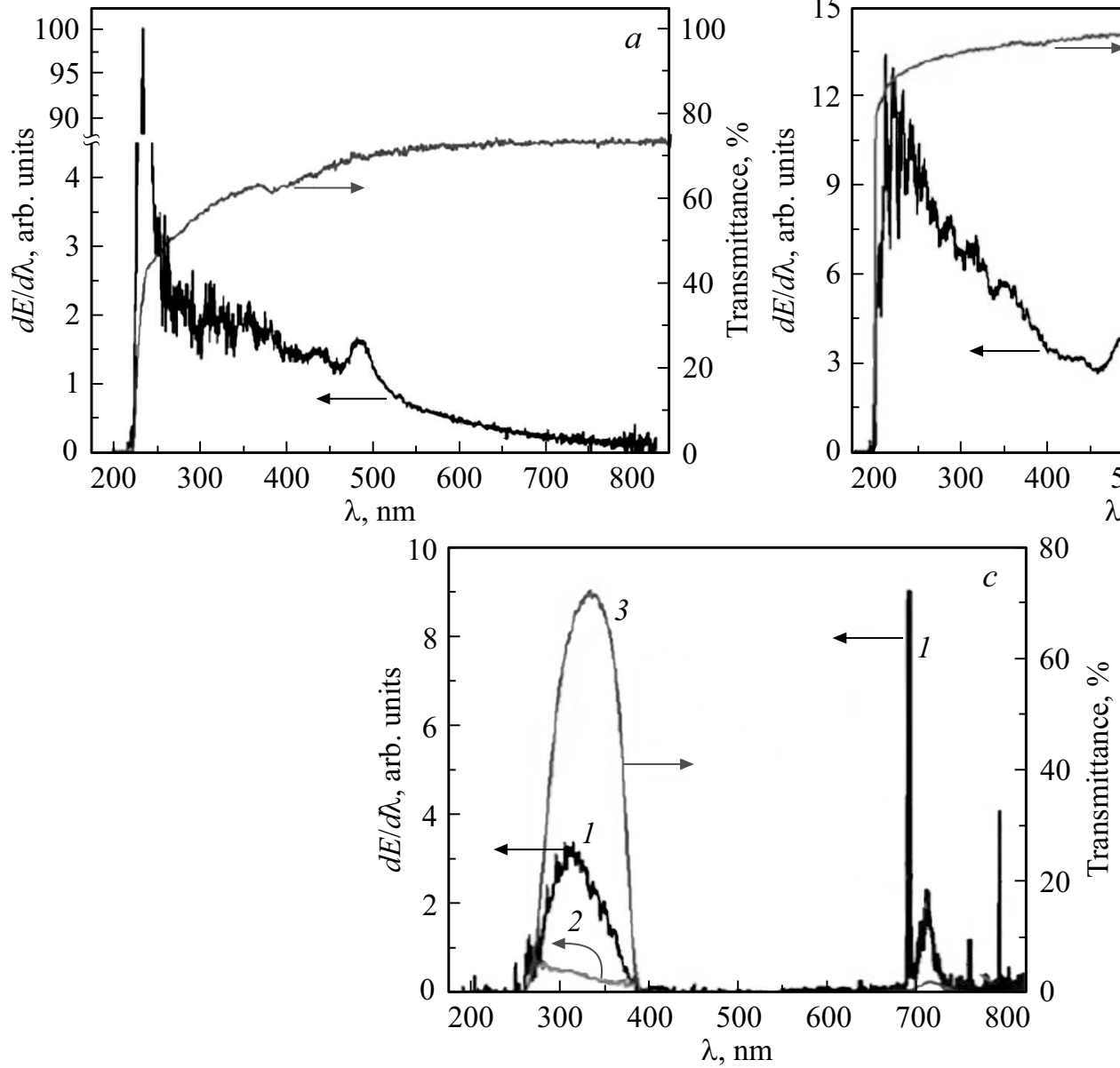

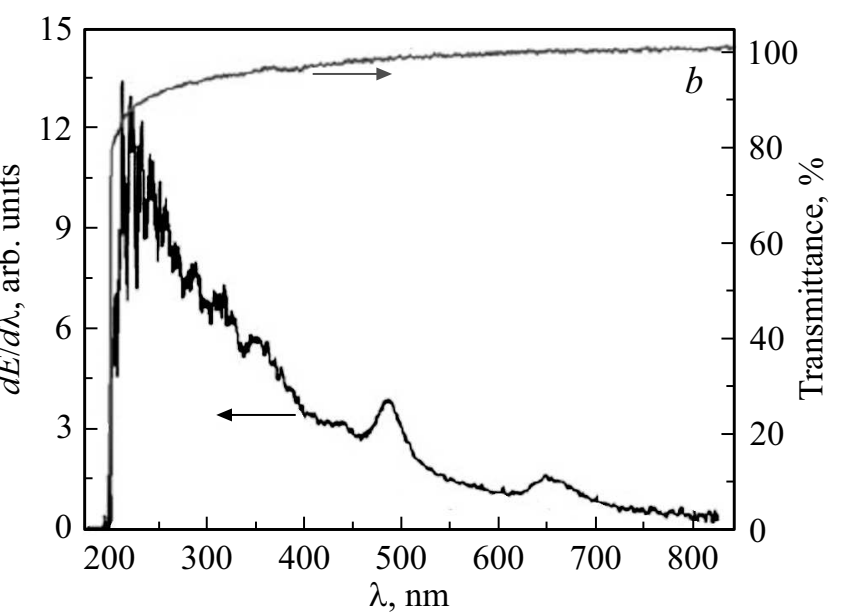

泀

Рис. 16. Спектр излучения и пропускания образца синтетического алмаза С5 (a), кварцевого стекла КУ-1 (b) и сапфира (c), где 1 - спектр излучения, полученный с фильтром УФС-2, 2 - спектр излучения сапфира в диапазоне 260-380 nm, реконструированный с учетом поглощения излучения в фильтре УФС-2, 3 - спектр пропускания этого фильтра [42]. Ускоритель ГИН-500.

В сапфире такое же поведение $d E / d \lambda$ наблюдалось в диапазоне $250-450 \mathrm{~nm}$. Также были зарегистрированы интенсивная узкая линия с максимумом на длине волны $693 \mathrm{~nm}$ и широкая полоса в области $650-800 \mathrm{~nm}$, которые, вероятно, обусловлены неконтролируемыми примесными ионами $\mathrm{Cr}^{3+}$. На рис. $16, c$ показан спектр излучения сапфира, полученного с использованием фильтра УФС-2, а также показан спектр пропускания этого фильтра и спектр излучения сапфира в диапазоне $260-380 \mathrm{~nm}$, реконструированный с учетом поглощения излучения в фильтре. Из восстановленного спектра видно, что $d E / d \lambda$ увеличивается с уменьшением длины волны в диапазоне $260-380 \mathrm{~nm}$. Пропускание сапфира соответствует пропусканию лейкосапфира (рис. 15,c). Полученные результаты согласуются с результатами работ $[34,35,40,41,92]$.

Для дополнительной идентификации природы излучения в УФ диапазоне были исследованы амплитудновременные параметры излучения с использованием фотодиода РD025 и фильтра УФС-1. Комбинированное использование фотодиода и фильтра позволило регистри- ровать излучение в основном в спектральном диапазоне $240-400 \mathrm{~nm}$. В результате влияние полос катодолюминесценции в видимой и инфракрасной областях спектра было сведено к минимуму. Измерения показывают, что импульс излучения во всех образцах приближается к длительности импульса тока электронного пучка (рис. 17).

На спектре алмаза (рис. 16,a) видно, что полоса излучательной рекомбинации свободных экситонов доминирует в диапазоне $230-245 \mathrm{~nm}$. Спектральная плотность энергии излучения экситонов в $10-50$ раз выше спектральной плотности энергии ИВЧ. Согласно спектру пропускания фильтра УФС-1 (рис. 14, кривая 2), его коэффициент пропускания монотонно увеличивается от 0 до $30 \%$ в диапазоне длин волн от 230 до $245 \mathrm{~nm}$. Фильтр УФС-1 пропускает $\sim 8 \%$ экситонного излучения, которое имеет максимум на длине волны $\lambda=235 \mathrm{~nm}$. Таким образом, как видно из рис. $17, a$, в присутствии фильтра экситонные и другие полосы люминесценции вносят незначительный вклад в свечение алмаза, поскольку они существенно ослабляются фильтром. При 

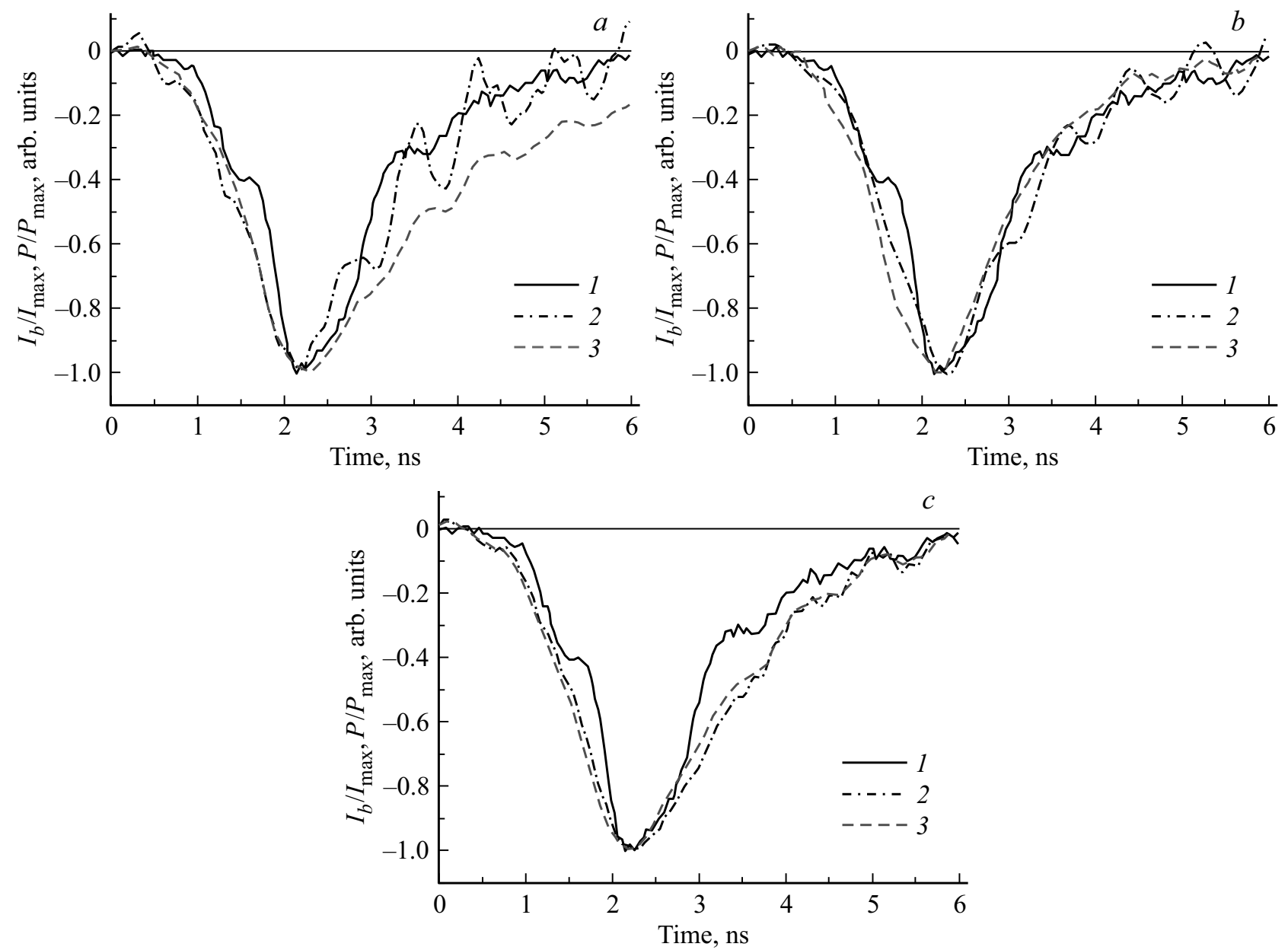

Рис. 17. Временной ход импульсов тока электронного пучка $(1)$ и излучения алмаза $(a)$, кварцевого стекла КУ-1 $(b)$ и сапфира $(c)$, зарегистрированные с фильтром УФС-1 (2) и без него (3) [42]. Ускоритель ГИН-500.

отсутствии фильтра вклад таких полос в излучение в алмазе становится существенным, а импульс излучения, зарегистрированный без фильтра, длиннее, чем импульс, полученный в присутствии фильтра. Соответственно при создании черенковских детекторов следует учитывать вклад экситонной полосы. Отметим, что при температуpax выше $200^{\circ} \mathrm{C}$ люминесценция в алмазах гасится [90] и экситонная зона автоматически подавляется. Для кварцевого стекла (рис. $17, b)$ и сапфира (рис. $17, c$ ) импульсы излучения по длительности приближаются к импульсам тока электронного пучка, что свидетельствует о существенной доле ИВЧ в их свечении.

На установке с ускорителем ГИН-500 также проводились исследования свечения фторидов: $\mathrm{CaF}_{2}, \mathrm{BaF}_{2}-\mathrm{Ce}$ и $\mathrm{MgF}_{2}$ [92]. Целью работы было исследование спектров ИКЛ и ИВЧ в кристаллах $\mathrm{CaF}_{2}, \mathrm{BaF}_{2}, \mathrm{MgF}_{2}$, определение области излучения наиболее интенсивных полос и выяснение, в каких кристаллах интенсивность ИВЧ наибольшая, а также определение длительности импульсов излучения при возбуждении пучком электронов. Спектральные исследования свечения образцов под действием пучка электронов показали, что максималь- ную интенсивность излучения в этих условиях имеют кристаллы $\mathrm{CaF}_{2}$ и $\mathrm{BaF}_{2}-\mathrm{Ce}$. Максимум экситонной полосы катодолюминесценции кристалла $\mathrm{CaF}_{2}$ с шириной на полувысоте $\sim 77 \mathrm{~nm}$ имеет высокую интенсивность и приходится на длину волны $\lambda=280 \mathrm{~nm}$. Кинетика затухания этой полосы описывается экспоненциальной функцией с временем релаксации $\sim 70 \mathrm{~ns}$, что на порядок больше длительности импульса тока пучка УЭ. Соответственно выделить вклад ИВЧ в излучение кристалла $\mathrm{CaF}_{2}$ очень сложно. Также на осциллограммах было видно увеличение интенсивности ИКЛ во время второго импульса тока пучка электронов с энергией, которая меньше пороговой для ИВЧ $\left(E_{\mathrm{th}}=202 \mathrm{keV}\right)$.

Спектр излучения кристалла $\mathrm{BaF}_{2}-\mathrm{Ce}$ состоял из полосы, соответствующей переходам электронов из валентной зоны, образованной $2 p$-состояниями $\mathrm{F}^{-}$, в верхнюю остовную зону кристалла, образованную $5 p$-состоянием $\mathrm{Ba}^{2+}$ (кросс-люминесценция): узкая полоса с максимумом на $\lambda=217 \mathrm{~nm}$ и полушириной $30 \mathrm{~nm}$. Широкая экситонная полоса с максимумом на $\lambda=308 \mathrm{~nm}$ имеет полуширину $90 \mathrm{~nm}$. Интенсивности полос составляют $\sim 600$ и $\sim 1150$ arb. units соответ- 
ственно. Третья полоса с максимумом на $\lambda=483 \mathrm{~nm}$ соответствует переходам с ионов фтора второй координационной сферы, низкая интенсивность которой ( 35 arb. units) связана с малой степенью перекрытия волновых функций катиона и анионов. Сильный спад пропускания в области спектра короче $400 \mathrm{~nm}$ обусловлен поглощением ионами $\mathrm{Ce}^{3+}$ на $f$ - $d$-переходах. Как известно, $\mathrm{BaF}_{2}$ является самым быстрым из известных неорганических сцинтилляторов, что подтверждается хорошим совпадением временного хода его излучения с формой импульсов тока пучка электронов, которое было получено с ГИН-500. Однако увеличение интенсивности излучения во время второго импульса пучка электронов с энергией, которая меньше пороговой для ИВЧ, исключает наличие ИВЧ во время второго импульса. Таким образом, регистрируемое излучение кристаллов $\mathrm{CaF}_{2}$ и $\mathrm{BaF}_{2}-\mathrm{Ce}$ в основном относится к ИКЛ.

$\mathrm{B}$ кристалле $\mathrm{MgF}_{2}$ при низких температурах при импульсном облучении пучком электронов преимущественно создаются автолокализованные экситоны с соответствующими им излучательными переходами на длине волны $\lambda=387 \mathrm{~nm}$ [93]. С ростом температуры интенсивность свечения этой полосы уменьшается, а при температурах выше $100 \mathrm{~K}$ в спектре доминирует краевая полоса с максимумом на $\lambda=295 \mathrm{~nm}$. В экспериментах с ГИН-500 катодолюминесценция кристалла $\mathrm{MgF}_{2}$ имела малую интенсивность, что облегчало регистрацию ИВЧ на фоне ИКЛ. Широкая полоса излучения в области длин волн короче $400 \mathrm{~nm}$, интенсивность которой возрастала с уменьшением длины волны, была связана c ИВЧ. Временной ход излучения кристалла $\mathrm{MgF}_{2}$ и первого импульса тока пучка электронов хорошо совпадали, что также характерно для ИВЧ. Кроме того, во время второго импульса тока пучка электронов с энергией, которая меньше пороговой для ИВЧ $(\sim 200 \mathrm{keV})$, излучение отсутствовало. Таким образом, воздействие пучком электронов с энергией до $350 \mathrm{keV}$ на кристаллы $\mathrm{MgF}_{2}$, которые имеют малую интенсивность ИКЛ в коротковолновой области спектра, позволило зарегистрировать ИВЧ.

Одним из наиболее доступных и относительно дешевых материалов, обладающих хорошей прозрачностью в оптическом диапазоне спектра и достаточно высоким показателем преломления $(\sim 2)$, является керамика из оксида иттрия, применяемая в оптических приборах и лазерах. В [76] на установке с ускорителем ГИН-500 исследовалось свечение керамики из оксида иттрия. В ходе экспериментов был снят спектр излучения образца керамики при облучении его электронным пучком, а также спектр пропускания образца. С уменьшением длины волны интенсивность спектра возрастает вплоть до границы пропускания материала. Такое поведение спектра характерно для ИВЧ $[34,35,94]$. Это подтверждается и хорошим совпадением экспериментального спектра излучения образца с расчетным спектром ИВЧ, рассчитанным [95] с учетом реального распределения электронов пучка по энергиям, дисперсии показателя преломления керамики и ее спектра пропускания. В диапазоне длин волн 450-550 nm наблюдалась полоса, которую можно связать с катодолюминесценцией керамики. Временные характеристики свечения образца керамики соответствуют импульсу тока пучка. Так как эффект ВавиловаЧеренкова является практически безынерционным, то длительность ИВЧ должна совпадать с длительностью тока пучка, что наблюдалось в эксперименте [76]. Анализ полученных данных однозначно свидетельствует о том, что в экспериментах было зафиксировано ИВЧ, и его энергия в керамике из оксида иттрия превышает энергию катодолюминесценции.

\section{2. Пространственные характеристики ИВЧ и ИКЛ}

Для сравнительно низких энергий электронов $\left(E_{\mathrm{e}} \leq 50 \mathrm{keV}, \beta<0.44\right)$ процесс многократного рассеяния приводит к тому, что фотоны ИВЧ испускаются в широком интервале углов даже в тонких радиаторах. По мере увеличения энергии электронов многократное рассеяние уменьшается и угловое распределение ИВЧ становится более направленным. Так, например, для энергии электронов $E_{\mathrm{e}}=1 \mathrm{MeV}$ угол многократного рассеяния $\left\langle\theta_{\mathrm{ms}}\right\rangle$ в кварцевой пластине толщиной $50 \mu \mathrm{m}$ не превышает $25^{\circ}$, тогда как угол ИВЧ $\theta=47^{\circ}$. При дальнейшем росте энергии электронов, чтобы вывести ИВЧ из пластины, необходимо выбирать подходящую геометрию. Только при наклоне пластины на угол $\psi$ относительно вектора скорости электронного пучка часть конуса ИВЧ будет выходить в воздух под углом $\varphi$ (рис. $18, a)$ :

$$
\varphi=\psi+\arcsin [n \cos (\theta+\psi)]
$$

Для не расходящегося электронного пучка вывод ИВЧ из кварцевой мишени в вакуум (или в воздух) возможен только для углов наклона $\psi<86^{\circ}$. Так, например, для угла наклона $\psi=70^{\circ}$ максимальный выход ИВЧ соответствует углу вывода $\varphi=29^{\circ}(8)$. Если выбрать угол наклона $\psi=43^{\circ}$, что соответствует углу $\theta=47^{\circ}$, то ИВЧ будет выходить из кварцевой пластины без преломления, т. е. под углом $\varphi=\frac{\pi}{2}-\theta=43^{\circ}$.

В среде угловое распределение ИВЧ обладает азимутальной симметрией (рис. $18, a$ ) и может быть оценено как $\Delta \theta_{1} \approx \sqrt{\theta_{m s}^{2}+\theta_{\mathrm{e}}^{2}}$, где $\theta_{\mathrm{ms}}-$ среднеквадратичный угол многократного рассеяния на длине $T / 2, \theta_{\mathrm{e}}-$ начальная расходимость пучка. В приближении $\Delta \theta_{1} \rightarrow 0$ соотношение (8) дает однозначную связь между углом вывода ИВЧ в воздух и наклоном мишени $\psi$ (рис. $18, a)$, причем для любого $\psi$ выводится только часть конуса ИВЧ. Из-за уширения черенковского конуса $\Delta \theta_{1}$, „есткая“ связь между углами $\psi$ и $\varphi$ нарушается, однако если под углом $\varphi$ подразумевается угол, соответствующий максимуму выхода ИВЧ, то график на рис. $18, b$ иллюстрирует эту связь.

Излучение Вавилова-Черенкова в кварцевом стекле имеет наименьший угол $\theta$, что облегчает его вывод 


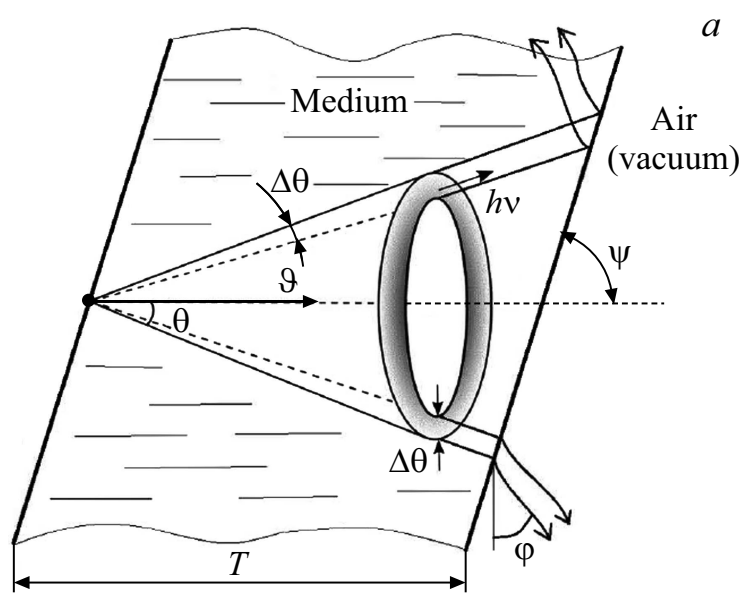

рассчитанному по формуле (5) с учетом дисперсии показателя преломления (кривая 5 на рис. 19,a). Соответствие ИВЧ регистрируемому в УФ области излучению подтверждает зависимость его спектра от угла между пластинкой и потоком электронов. При угле поворота кварцевой пластинки $\psi \approx 70^{\circ}$ относительно направления электронного пучка обеспечивалась наибольшая эффективность вывода ИВЧ, что хорошо согласуется с оценкой по формуле (8), из которой следует, что $\varphi=29^{\circ}$. При увеличении или уменьшении угла поворота пластинки интенсивность ИВЧ уменьшалась. Излучение в области длин волн 450-600 nm можно отнести к ИКЛ.

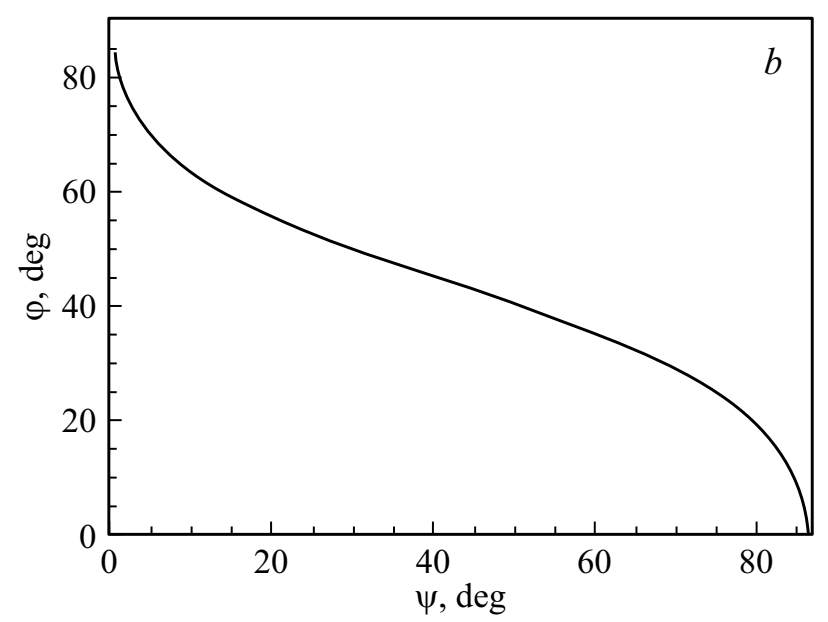

Рис. 18. Угловое распределение ИВЧ при переходе из среды в воздух (вакуум) $(a)$ и зависимость угла $\varphi$ от угла наклона пластины $\psi(b)$ [41].

из плоскопараллельной пластинки. Поэтому в [41] основное внимание было уделено исследованию ИВЧ в кварцевом стекле. Имевшиеся образцы алмаза были слишком малы, а образцы из сапфира и лейкосапфира при энергии электронов пучка $6 \mathrm{MeV}$ темнели под действием электронного пучка и рентгеновского излучения.

Спектры излучения пластинки из кварцевого стекла GE-014 при различных углах между поверхностью плоскопараллельной пластинки и направлением потока электронов приведены на рис. 19. Положение световода, передающего излучение от кварцевой пластинки к спектрометру при изменении угла $\psi$ не менялось. Этот угол между осью световода и нормалью к направлению пучка электронов в пучке составлял $\varphi=27^{\circ}$. Из рисунка видно, что распределение энергии излучения в спектре изменяется в зависимости от угла между плоскостью плоскопараллельной пластинки из кварцевого стекла и направлением потока электронов в пучке. При угле $\psi \approx 70^{\circ}$ в УФ области наблюдается наибольшая спектральная плотность энергии излучения, регистрируемая спектрометром. Этот спектр подобен спектру ИВЧ,
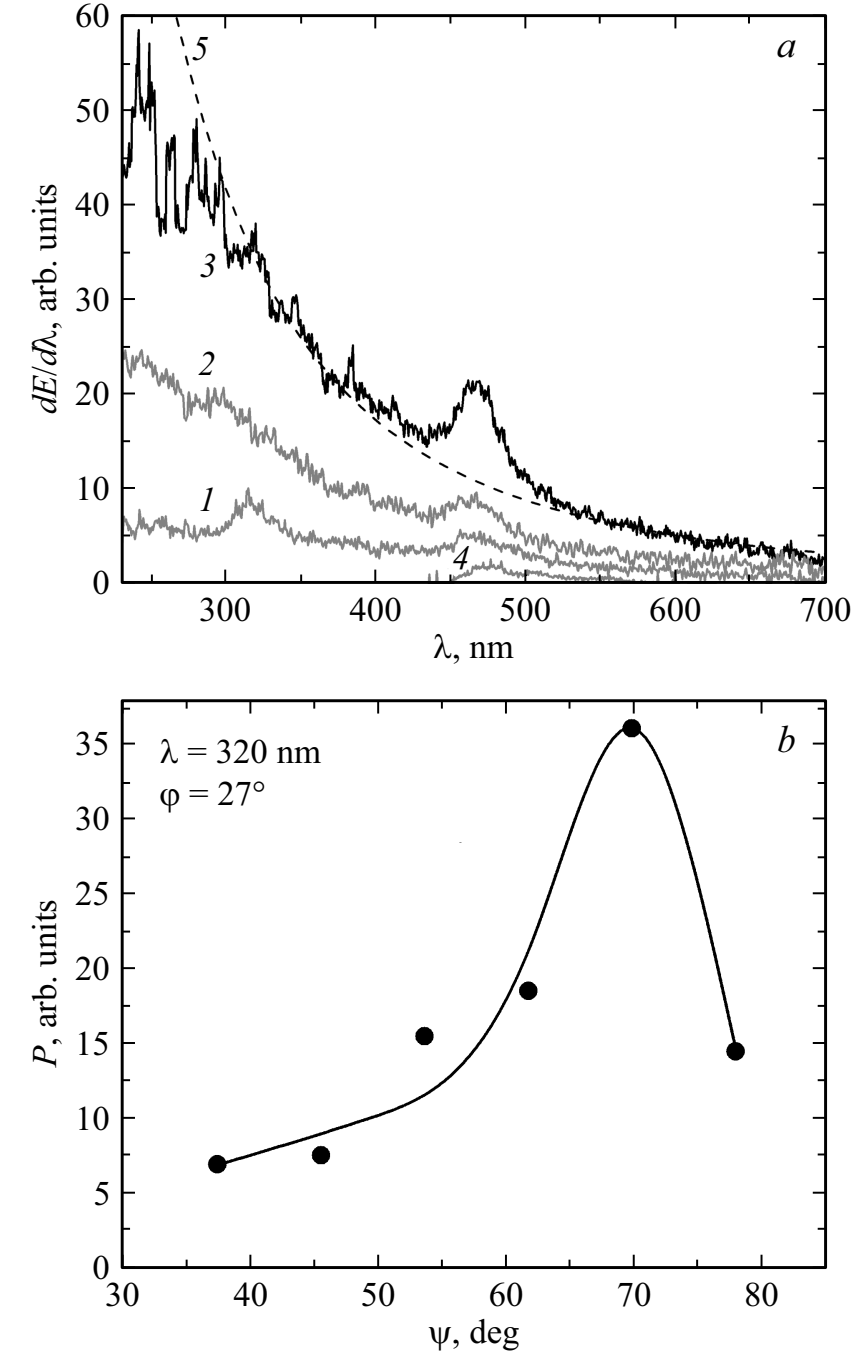

Рис. 19. (a) Спектры излучения пластинки из кварцевого стекла GE-014 при различных углах $\psi$ между поверхностью плоскопараллельной пластинки из кварцевого стекла и направлением потока электронов $\left(1-46^{\circ}, 2-54^{\circ}\right.$, $\left.3-70^{\circ}, 4-86^{\circ}\right)$ и расчетный спектр ИВЧ для энергии электронов $6 \mathrm{MeV}$ (5) [41]. Спектры 3 и 5 нормированы по интенсивности на длине волны $350 \mathrm{~nm}$. (b) Зависимость интенсивности излучения на длине волны $\lambda=320 \mathrm{~nm}$ от угла $\psi$ между плоскостью пластинки из кварцевого стекла и направлением потока электронов. 
На рис. 19, $а$ приведен расчетный спектр ИВЧ, нормированный по интенсивности на длине волны $\lambda=350 \mathrm{~nm}$ к экспериментальному спектру, полученному при угле между пластинкой из кварцевого стекла и пучком электронов $\psi=70^{\circ}$. Интенсивность излучения на обоих спектрах в области короче $450 \mathrm{~nm}$ возрастает с уменьшением длины волны. Этот факт, как и зависимость интенсивности излучения от угла между плоскостью пластинки из кварцевого стекла и направлением пучка электронов (рис. 19, $b$ ), однозначно доказывает регистрацию в данной работе спектров ИВЧ. Следует отметить, что изменение угла наклона на $25^{\circ}$ (от $\psi=70^{\circ}$ до $\psi=45^{\circ}$ ) приводит к уменьшению интенсивности в 5 раз, но не до нуля, что объясняется уширением конуса ИВЧ $\Delta \theta_{1}=26^{\circ}$.

Таким образом, в [41] впервые был зарегистрирован спектр ИВЧ в УФ и видимой областях при возбуждении пластинок из кварцевого стекла GE-014 и КУ-1 пучком электронов с энергией $6 \mathrm{MeV}$. Показано, что изменение угла между поверхностью плоскопараллельных пластинок и направлением пучка электронов существенно влияет как на интенсивность ИВЧ, так и на спектр излучения. При больших и малых углах наклона пластинки в видимой области спектра регистрируется ИКЛ, а интенсивность ИВЧ становится низкой.

\section{5. ИКЛ и ИВЧ в полиметилметакрилате}

\section{1. Общая информация и амплитудно-временные характеристики}

Полиметилметакрилат широко используется в качестве материала для радиатора в детекторах импульсного тормозного излучения и электронного пучка. Это связано с простотой изготовления радиаторов из ПММА, а также с низким уровнем люминесценции, составляющим $2-7 \%$ от ИВЧ (данные получены для $\gamma$-квантов с энергией $1 \mathrm{MeV}$ ) [96]. Полиметилметакрилат также применяется в сцинтилляционных детекторах в качестве основы, в которой растворяют флюоресцирующий агент [46]. Диапазон прозрачности ПММА зависит от наличия примесей и составляет приблизительно 350-2000 nm. Показатель преломления ПММА составляет $n_{D}=1.49$, пороговая энергия возникновения ИВЧ для электронов $E_{\text {th }}=178 \mathrm{keV}$. Кроме того, ПММА является одним из распространенных материалов при изготовлении пластиковых световодов. Такие световоды применяются в сцинтилляционных детекторах, используемых в лучевой терапии для определения поглощенной дозы [46,97]. Полиметилметакрилат и полистирол, из которых обычно изготавливают пластиковые оптические волокна, как дозиметрические материалы имеют характеристики, эквивалентные характеристикам биологических тканей или воды [98]. Однако поскольку световод, так же как и сцинтиллятор, попадает под пучок ионизирующего излучения, в нем возбуждаются ИВЧ и ИКЛ, которые вносят искажения в полезный сигнал, поступающий в приемник излучения. В англоязычной литературе эти искажения полезного сигнала ИВЧ носят название „stem effect" [47]. Однако при энергиях электронов $\sim 1 \mathrm{MeV}$ и более сравнительно низкий уровень ИКЛ делает ПММА перспективным материалом для изготовления пластиковых оптических волокон. Поэтому ИВЧ, возникающее в пластиковых оптических волокнах, находит полезное применение в пластиковых волоконно-оптических дозиметрах [44].

В ряде работ, посвященных медицинской дозиметрии $[44,45,47]$, проводились исследования свечения ПММА под действием ионизирующего излучения (в первую очередь электронов и фотонов высоких энергий), включая регистрацию спектра прошедшего через световод излучения. Следует отметить, что при облучении образцов ПММА фотонами высоких энергий в ПММА за счет комптоновского рассеяния генерируются электроны отдачи с энергией в десятки-сотни $\mathrm{keV}$, что в определенной степени соответствует ситуации взаимодействия образца с электронными пучками этого диапазона энергий. Учитывая высокую востребованность ПММА в качестве материала для радиатора в черенковских детекторах, в качестве световода, передающего излучение в сцинтилляционных дозиметрах, а также применение ПММА как пластиковой основы в органических сцинтилляторах, существует необходимость в более подробном исследовании характеристик ПММА при облучении ионизирующим излучением, в том числе и потоками электронов с энергией в сотни keV. Исследования характеристик излучения ПММА при возбуждении УЭ были начаты в работах $[48,49]$. Сообщалось о регистрации амплитудно-временных характеристик ИВЧ, возникающего под действием субнаносекундного пучка УЭ, генерируемого в воздухе атмосферного давления. Однако временное разрешение используемой аппаратуры было малым, а также не проводились спектральные исследования свечения ПММА.

Как показано выше с образцами из других материалов, для определения вкладов ИВЧ и ИКЛ в сигнал, регистрируемый фотоприемником, надо знать спектры излучения. Такой цикл исследований был проведен в работах [50-52,94]. Для получения амплитудно-временных характеристик свечения ПММА использовался ускоритель электронов СЛЭП-150М. Спектр электронного пучка представлен на рис. 6, $a$. Схема экспериментов изображена на рис. $9, b$.

Импульсы тока пучка УЭ и свечения ПММА приведены на рис. 20. Наибольшие амплитуды импульсов свечения ПММА наблюдаются при наибольшем числе электронов в токе пучка. Длительность импульса свечения на полувысоте в несколько раз превышала длительность импульса тока пучка УЭ. Отметим, что в данных экспериментах использовались и образцы ПММА из различных партий и различной толщины, но импульсы излучения ПММА имели примерно одинаковую форму и длительность на полувысоте. На основании полученных амплитудно-временных характеристик излучения 

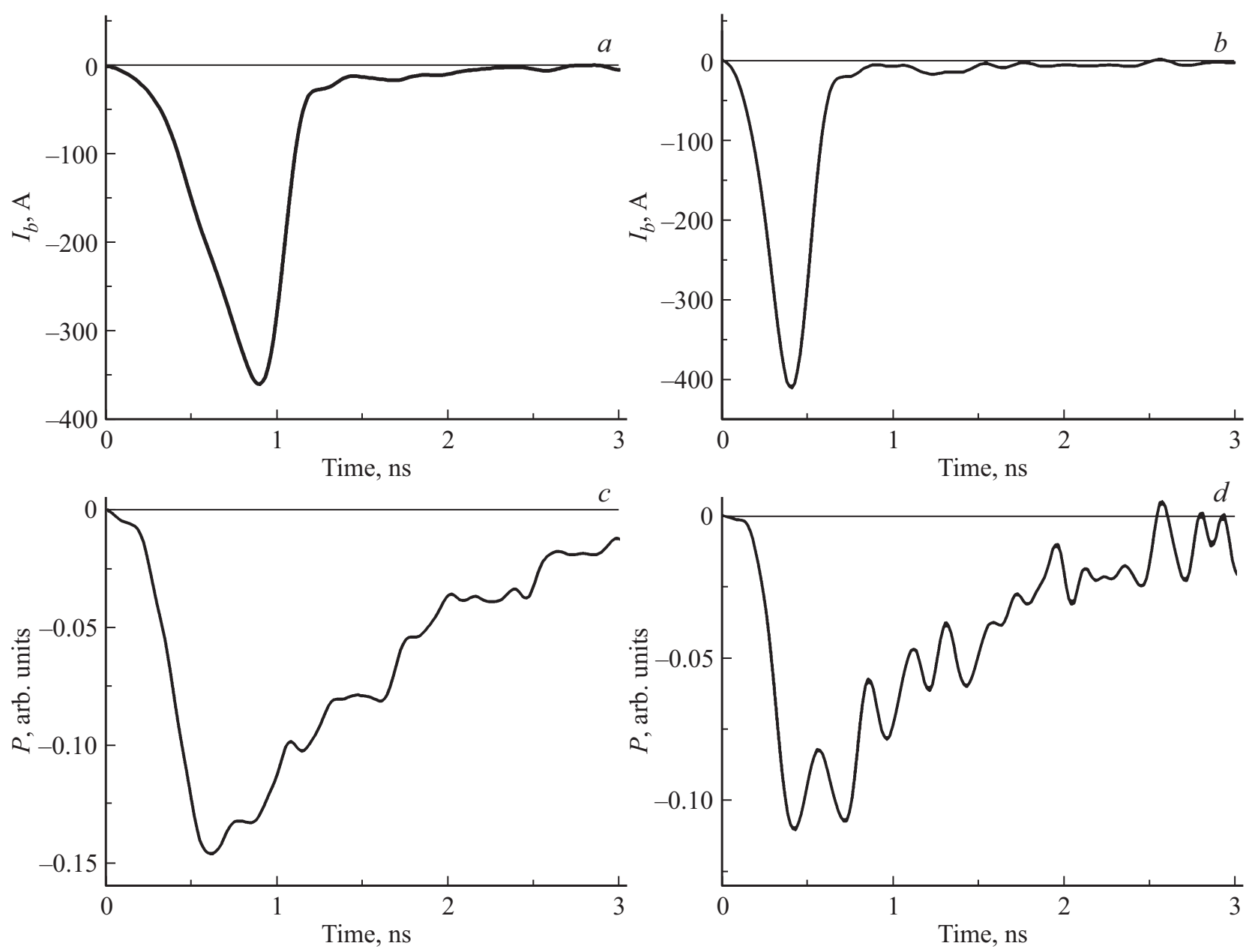

Рис. 20. Импульсы тока пучка УЭ $(a, b)$ и осциллограммы импульсов излучения образца ПММА толщиной 6 mm $(c, d)$ при давлении гелия в газовом диоде 15 Torr $(a, c)$ и 30 Torr $(b, d)$ [51]. Межэлектродный зазор в газовом диоде $d=14 \mathrm{~mm}$. Полоса пропускания осциллографа $6 \mathrm{GHz}$.

ПММА можно утверждать, что ИВЧ в экспериментах, описанных в работах $[48,49]$, также не давало существенного вклада в регистрируемое свечение ПММА.

\section{2. Спектральные характеристики свечения ПММА}

При исследовании спектральных характеристик свечения ПММА под действием электронного пучка также использовался ускоритель СЛЭП-150М с трубчатым катодом. Кроме того, для возбуждения фотолюминесцен-

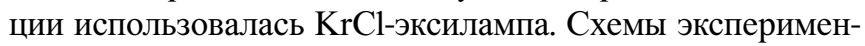
тов изображены на рис. 9, $a$. Исследования спектров свечения и пропускания ПММА с различными образцами показало, что спектры излучения и пропускания в трех образцах не имеют существенных отличий. Спектры свечения ПММА вместе со спектрами пропускания приведены на рис. 21. Сильное поглощение обоих образцов начинается в области спектра короче $350 \mathrm{~nm}$. В области с малым поглощением ПММА видна только одна полоса с максимумом спектральной плотности энергии на длине волны $\sim 490 \mathrm{~nm}$. Излучение ВавиловаЧеренкова зарегистрировать не удалось, что связано с его малой интенсивностью при использовании ускорителя СЛЭП-150М по сравнению с интенсивностью люминесценции.

При увеличении числа электронов в СЛЭП интенсивность люминесценции ПММА возрастала. Однако форма спектров излучения в трех образцах ПММА совпадала и не зависела от амплитуды и длительности импульса тока пучка. В спектрах свечения видна полоса с максимумом в области $490 \mathrm{~nm}$, положение которого не изменялось при изменении плотности тока СЛЭП. Коротковолновая граница поглощения ПММА, которая для трех образцов лежит в области $300 \mathrm{~nm}$, не влияет на форму спектра излучения.

В одном из образцов ПММА (толщиной $3 \mathrm{~mm}$ ) в спектре свечения была зарегистрирована вторая полоса с максимумом в области $400 \mathrm{~nm}$. Резкое уменьшение интенсивности излучения этой полосы в УФ области спектра совпадает с ростом поглощения этого образца в области 350-400 nm. Смещение коротковолновой 

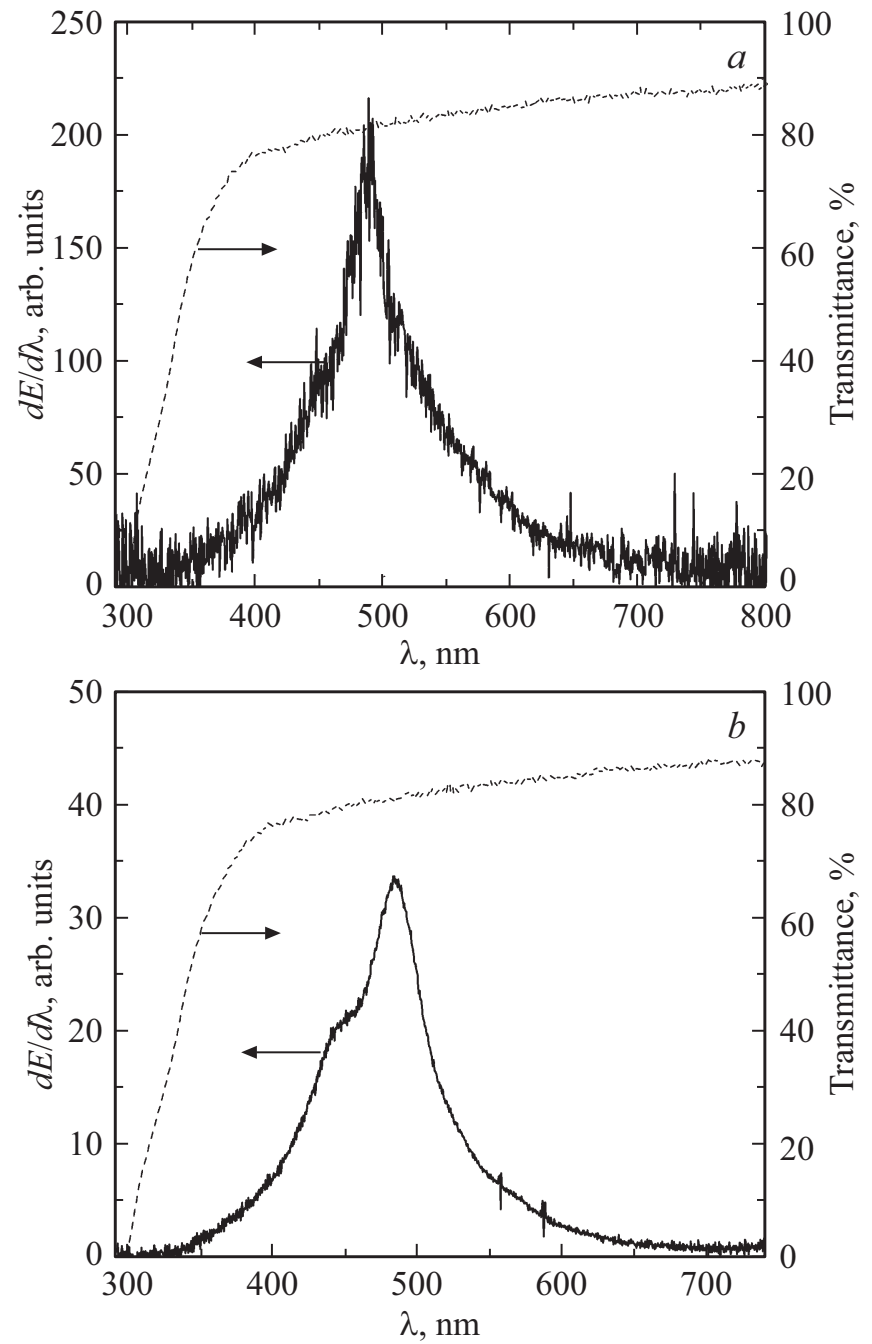

Рис. 21. Спектры излучения (сплошные кривые) и пропускания (штриховые кривые) образца ПММА толщиной $6 \mathrm{~mm}$ при возбуждении пучком электронов $(a)$ и эксилампой $(b)[51]$.

границы полосы пропускания в образце ПММА толщиной $3 \mathrm{~mm}$ в длинноволновую область (по сравнению с другими образцами) можно объяснить присутствием в образце дополнительных примесей. Однако полосу с максимумом в области $400 \mathrm{~nm}$ нельзя отнести к ИВЧ, так как подобная полоса отсутствует в других образцах ПММА с тем же показателем преломления, в которых поглощение в области 350-400 nm мало.

Данный вывод также подтверждает спектр излучения данной пластинки при возбуждении $\mathrm{KrCl}$-эксилампой с длиной волны $222 \mathrm{~nm}$. Как и при возбуждении СЛЭП, в данном образце имеются две полосы излучения. Вид этих полос при возбуждении пучком электронов и УФ излучением эксилампы примерно совпадает, а излучение эксилампы не должно приводить к появлению ИВЧ. Из рис. 20 видно, что спектры излучения образца ПММА толщиной $6 \mathrm{~mm}$ при возбуждении эксилампой и пучком электронов также практически совпадают. Подобный спектр был зарегистрирован и для образцов толщи- ной 0.9 и $10 \mathrm{~mm}$. Это дополнительно подтверждает, что природа наблюдаемого излучения в данных экспериментах связана с ИКЛ.

Проведенные исследования позволили установить очень важную особенность, которая следует из экспериментов с эксилампой. Ультрафиолетовое излучение эксилампы приводит к появлению полосы люминесценции с максимумом интенсивности на длине волны $\sim 490 \mathrm{~nm}$. В образце толщиной $3 \mathrm{~mm}$, кроме того, регистрируется вторая полоса в области $350-450 \mathrm{~nm}$. Соответственно следует ожидать, что ИВЧ в УФ области спектра будет приводить к усилению интенсивности люминесценции в ПММА в видимой области спектра. Как известно, интенсивность ИВЧ возрастает при уменьшении длины волны и увеличении энергии электронов. Таким образом, ИВЧ с длиной волны короче $300 \mathrm{~nm}$, которое возникает, а затем поглощается в ПММА, должно усиливать интенсивность люминесценции на длине волны $\sim 490 \mathrm{~nm}$. При этом соотношение интенсивностей ИВЧ и люминесценции должно зависеть от распределения электронов пучка по энергиям.

\section{3. Разрушение ПММА под действием электронного пучка}

Эксперименты по исследованию разрушения ПММА и природы свечения образцов при облучении электронным пучком [52] были проведены на двух установках: с ускорителем СЛЭП-150М, к которому подключался газовый диод, и с ускорителем ГИН-600, к которому подключался вакуумный диод. Параметры ГИН-600, так же как и параметры СЛЭП-150М, приведены в разд. 2. Плотности энергии пучка электронов $(H)$ в экспериментах варьировались от $10^{-4}$ до $0.4 \mathrm{~J} / \mathrm{cm}^{2}$, а длительности импульса тока пучка на полувысоте составляли $0.1-0.6 \mathrm{~ns}$ и $12 \mathrm{~ns}$.

При возбуждении пучком электронов пластинок ПММА (толщиной $0.9,3,6$ и $10 \mathrm{~mm}$ ) наблюдалось свечение голубого цвета, интенсивность которого возрастала с ростом амплитуды и длительности импульса СЛЭП. Свечение всех пластинок из оргстекла при атмосферном давлении гелия, азота и воздуха в газовом диоде и плотности электронов пучка на квадратный сантиметр $\sim 2 \cdot 10^{10}$ было слабым, так что его можно было регистрировать только визуально при полном затемнении комнаты с установкой.

На рис. 22 приведены фотографии свечения ПММА при максимальных плотностях энергии электронного пучка $\left(\sim 0.01 \mathrm{~J} / \mathrm{cm}^{2}\right)$ после первых импульсов возбуждения $(a)$, а также после 100 и более импульсов возбуждения $(b)$. Анализ фотографий, приведенных на рис. 22, свидетельствует о том, что в первых импульсах возбуждения и максимальных плотностях тока пучка $\left(H \sim 0.01 \mathrm{~J} / \mathrm{cm}^{2}\right)$, а также при малых плотностях тока СЛЭП $\left(H \leq 0.001 \mathrm{~J} / \mathrm{cm}^{2}\right)$ наблюдается сравнительно равномерная по облучаемой поверхности катодолюминесценция образцов. Наблюдаемые неоднородности на 

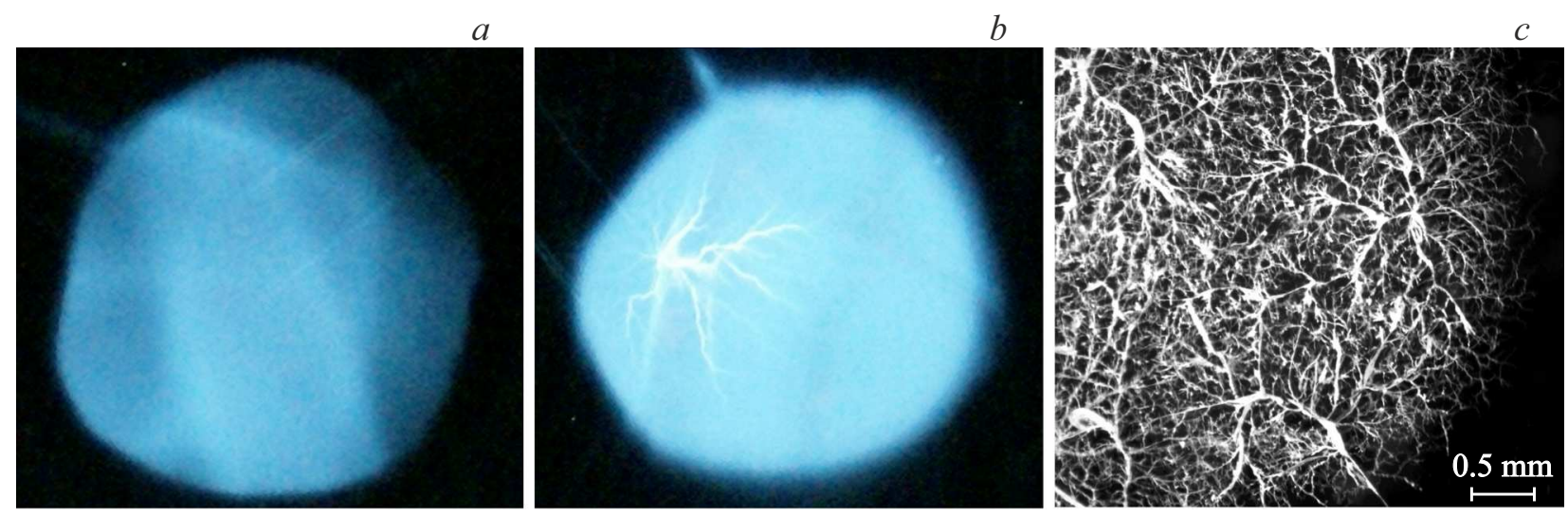

Рис. 22. Фотографии свечения ПММА за один импульс после первых импульсов возбуждения $(a)$, а также после 100 и более импульсов возбуждения $(b)$. Морфология остаточных разрушений $(c)$, образующихся в зоне торможения СЛЭП в результате развития электрического пробоя [51]. Диаметр светящейся области $(a, b)$ и зоны разрушения $(c)$, изображение которой увеличено, $\sim 6 \mathrm{~mm}$. Количество импульсов облучения $\sim 500$ при частоте $1 \mathrm{~Hz}(c)$. Ускоритель СЛЭП-150М.

рис. 22, $а$ связаны с флуктуациями плотности тока пучка в отдельных импульсах. Увеличение числа импульсов облучения при $H \approx 0.01 \mathrm{~J} / \mathrm{cm}^{2}$, привело к накоплению инжектированного в образец отрицательного объемного заряда СЛЭП и инициированию электрического пробоя ПММА в зоне торможения электронного пучка с наибольшей плотностью. Электрический пробой реализуется в виде стримерных разрядов (СР). Электрические разряды регистрируются как по свечению плотной плазмы, образующихся в каналах электрического пробоя (КЭП) (рис. 22, $b$ ), так и по морфологии остаточных разрушений (рис. 22, с). Длительность свечения плазмы, образующейся в КЭП при $H<0.01 \mathrm{~J} / \mathrm{cm}^{2}$, с помощью фотодиода PD025 зарегистрировать не удалось из-за малой интенсивности излучения СР по сравнению с интенсивностью ИКЛ. Преобладание сплошного спектра излучения СР над ИКЛ происходило при возбуждении ускорителем ГИН-600 при плотности энергии пучка $H>0.2 \mathrm{~J} / \mathrm{cm}^{2}$ [52], что соответствует порогу формирования СР и появлению остаточных КЭП в данном материале.

Таким образом, результаты экспериментальных исследований излучения ПММА при возбуждении пучком УЭ и $\mathrm{KrCl}$-эксилампой с длиной волны излучения $222 \mathrm{~nm}$ показали, что в обоих случаях основной вклад в излучение дает полоса ИКЛ с максимумом на длине волны $\sim 490 \mathrm{~nm}$. Интенсивность свечения этой полосы изменяется пропорционально числу электронов в пучке, что позволяет использовать это излучение для определения числа высокоэнергетических электронов в электронных пучках. На основании экспериментов с эксилампой предполагается, что ИВЧ с длиной волны короче $300 \mathrm{~nm}$ должно усиливать интенсивность люминесценции на полосе с длиной волны $\sim 490 \mathrm{~nm}$. При наличии примесей в образцах ПММА может регистрироваться вторая полоса люминесценции с максимумом на длине волны $\sim 400 \mathrm{~nm}$.
Многоимпульсное облучение ПММА СЛЭП при $H \geq 0.01 \mathrm{~J} / \mathrm{cm}^{2}$ приводит к электрическому пробою внутри образца вследствие накопления отрицательного объемного заряда электронного пучка и формирования в зоне торможения пучка сильного электрического поля. Электрические разряды регистрируются как по свечению плотной плазмы, образующейся в КЭП, так и по морфологии остаточных разрушений. При энергии электронов до $400 \mathrm{keV}$ на установке ГИН-600 ИВЧ в ПММА не было зарегистрировано [52]. По-видимому, интенсивность сплошного спектра излучения СР была существенно выше не только ИКЛ, но и ИВЧ.

Сложность регистрации ИВЧ в ПММА при энергиях электронов пучка в сотни $\mathrm{keV}$ обусловлена следующими причинами. Во-первых, ПММА имеет низкий порог разрушения из-за пробоя электронами пучка, накопленными в диэлектрике. Во-вторых, сильное поглощение в ПММА начинается уже с $300-350 \mathrm{~nm}$, а интенсивность ИВЧ возрастает обратно пропорционально кубу длины волны. В-третьих, ПММА имеет относительно небольшой коэффициент преломления $n_{D}=1.49$, соответственно пороговая энергия электронов составляет $E_{\mathrm{th}}=178 \mathrm{keV}$. Все электроны с энергией меньше пороговой возбуждают катодолюминесценцию, на фоне которой трудно выделить ИВЧ. Однако сокращение длительности импульса тока пучка до 350 ps и увеличение энергии электронов до $450 \mathrm{keV}$ позволило в ПММА зарегистрировать ИВЧ на фоне ИКЛ [99].

\section{6. Заключение}

Приведенные исследования свечения различных образцов, возбуждаемого пучком электронов субнаносекундной и наносекундной длительности, позволили зарегистрировать в УФ и видимом диапазонах спектры ИВЧ в алмазе (природном и синтетическом), кварцевом стекле, сапфире, лейкосапфире, $\mathrm{MgF}_{2}, \mathrm{Ga}_{2} \mathrm{O}_{3}$ и 
других прозрачных материалах. Определены условия, в которых при энергии электронов пучка до $350 \mathrm{keV}$ с помощью стандартного спектрометра удается зарегистрировать ИВЧ. Расчеты, учитывающие влияние энергии электронов и показателя преломления вещества на интенсивность ИВЧ и его спектр, а также на пространственные характеристики излучения, подтверждают полученные экспериментальные данные по влиянию энергии электронов на спектры ИВЧ. Установлено, что в ПММА из-за поглощения излучения в области короче 300-350 nm, а также из-за внутреннего пробоя образцов вследствие накопления в них электронов при больших плотностях тока пучка или(и) длительностях импульсов регистрация ИВЧ затруднена. Для регистрации ИВЧ на фоне ИКЛ в образцах из ПММА необходимо увеличивать энергию электронов, что было продемонстрировано в работе [99] при субнаносекундной длительности импульса тока пучка.

Из проведенного анализа полученных данных о спектрах излучения различных образцов следует, что для регистрации параметров пучков электронов, в том числе убегающих, можно использовать как ИКЛ, так и ИВЧ. Это подтверждает недавняя работа [100]. При исследовании генерации УЭ в установке IR-T1 Tokamak были использованы для регистрации два сцинтилляционных кристалла LYSO $\left(\mathrm{Lu}^{1.8} \mathrm{Y}^{0.2} \mathrm{SiO}^{5}: \mathrm{Ce}\right)$, которые помещались в графитовый корпус и разделялись фильтром из графита. Применение ИКЛ более целесообразно при энергиях электронов до $200-300 \mathrm{keV}$, поскольку интенсивность ИКЛ в большинстве прозрачных материалов существенно превышает интенсивность ИВЧ. Кроме того, ИКЛ излучается во всех направлениях относительно направления электронов пучка, что облегчает ее регистрацию. Из исследованных образцов можно рекомендовать для создания детекторов электронов кристаллы ZnS и $\mathrm{ZnSe}$, которые имеют большую интенсивность ИКЛ и обладают высокой лучевой прочностью. Кроме того, в этих кристаллах возможен режим сверхизлучения [89], что должно повысить эффективность вывода излучения из зоны облучения.

Регистрация параметров пучков электронов с помощью ИВЧ имеет преимущества при энергиях электронов $\sim 400 \mathrm{keV}$ и более. При этом из исследованных образцов наиболее перспективным для создания детекторов ИВЧ является синтетический алмаз типа IIA, полученный методом газофазного осаждения, а также (при достаточно высоких энергиях электронов) кварцевое стекло, обладающее высоким пропусканием в УФ области спектра, например, КУ-1. При создании детекторов ИВЧ надо принимать во внимание угловое распределение излучения и внутреннее отражение. Для алмаза, кроме того, следует учитывать появление при увеличении плотности тока пучка интенсивной экситонной полосы с максимумом на длине волны $235 \mathrm{~nm}$.

При высоких энергиях электронов надо принимать во внимание радиационное повреждение образцов. Например, как показали эксперименты при энергии элек- тронов $6 \mathrm{MeV}$, образцы из сапфира и лейкосапфира быстро темнели под воздействием мощного и высокоэнергетического рентгеновского излучения. Как известно, эффективность генерации рентгеновского излучения существенно возрастает при увеличении энергии электронов > $1 \mathrm{MeV}$ [101]. Особенностью образцов из ПММА является их быстрое разрушение разрядами, возникающими в диэлектрике при больших плотностях и длительностях тока пучка электронов.

О регистрации ИВЧ у поверхности Земли под воздействием „солнечного ветра“ сообщалось в [102]. Предполагаем, что данный обзор повысит интерес к изучению спектральных и амплитудно-временных характеристик ИВЧ, в том числе в различных газах и жидкостях.

\section{Благодарности}

Авторы выражают благодарность своим коллегам С.Б. Алексееву, Д.В. Белоплотову, А.В. Вуколову, Е.И. Липатову, М.И. Ломаеву, В.И. Олешко, А.П. Потылицыну, И.А. Прудаеву, Д.А. Сорокину и другим, с которыми проводились совместные исследования характеристик ИВЧ и ИКЛ.

\section{Финансирование работы}

Исследования в 2018-2020 гг. характеристик ИВЧ и ИКЛ, а также написание данного обзора выполнены за счет гранта Российского научного фонда (проект № 1819-00184).

\section{Конфликт интересов}

Авторы заявляют, что у них нет конфликта интересов.

\section{Список литературы}

[1] Cherenkov P. In Nobel Lectures, Physics: 1942-1962. Nobel Foundation Staff. Elsevier, 1964. 63 p. doi 10.1016/C2013-007831-0

[2] Sumiyoshi T., Adachi I., Enomoto R., Iijima T., Suda R., Yokoyama M., Yokogawa H. // JNCS. 1998. V. 225. P. 369. doi 10.1016/S0022-3093(98)00057-X

[3] Зрелов В.П. Излучение Вавилова-Черенкова и его применение в физике высоких энергий. Ч. 2. М.: Атомиздат, 1968. $302 \mathrm{c}$

[4] Болотовский Б.М. // УФН. 2009. Т. 179. № 11. С. 1161; Bolotovskii B.M. // Phys.-Usp. 2009. V. 52. P. 1099. doi 10.3367/UFNr.0179.200911c.1161

[5] Ginis V., Danckaert J., Veretennicoff I., Tassi P. // Phys. Rev. Lett. 2014. V. 113. P. 167402. doi 10.1103/PhysRevLett.113.167402

[6] Lin X., Easo S., Shen Y., Chen H., Zhang B., Joannopoulos J.D., Soljačić M., Kaminer I. // Nature Phys. 2018. V. 14. P. 816. doi 10.1038/s41567-018-0138-4.

[7] Potylitsyn A.P., Gogolev S.Y. // Phys. Part. Nucl. Lett. 2019. V. 16. P. 127. doi 10.1134/S1547477119020110 
[8] Bowers G.S., Blaine W., Shao X.M., Dingus B., Smith D.M., Schneider M., Martinez-McKinney F., McCarthy M.P., BenZvi S., Nellen L., Fraija N. // Phys. Rev. D. 2019. V. 100. P. 043021. doi 10.1103/PhysRevD.100.043021

[9] Akasofu S.I., Chapman S. Solar-terrestrial physics. Oxford: The Clarendon press, 1972. $901 \mathrm{p}$. doi 10.1002/qj.49709942230

[10] Valley S.L. Handbook of geophysics and space environments. N. Y:: McGraw-Hill, 1965. 1042 p.

[11] Tsunesada Y., Katsuya R., Mitsumori Y., Nakayam K., Kakimoto F., Tokuno H., Tajima N., Miranda P., Salinas J., Tavera W. // Nucl. Instrum. Methods Phys. Res. A. 2014. V. 763. P. 320. doi 10.1016/j.nima.2014.06.054

[12] Vries K.D., Berg A.M., Scholten O., Werner K. // Phys. Rev. Lett. 2011. V. 107. P. 061101. doi 10.1103/PhysRevLett.107.061101

[13] Landau L.D., Bell J.S., Kearsley M.J., Pitaevskii L.P., Lifshitz E.M., Sykes J.B. Electrodynamics of Continuous Media. Oxford: Pergamon Press, 1984. 475 p.

[14] Vukolov A.V., Novokshonov A.I., Potylitsyn A.P., Uglov S.R. // J. Phys. Conf. Ser. 2016. V. 732. P. 012011. doi 10.1088/17426596/732/1/012011

[15] Nanbu K.I., Saito Y., Saito H. // Particles. 2018. V. 1. P. 305. doi 10.3390/particles 1010025

[16] Plyusnin V.V., Jakubowski L., Zebrowski J., Fernandes H., Silva C., Malinowski K., Duarte P., Rabinski M., Sadowski M.J. // Rev. Sci. Instrum. 2008. V. 79. P. 10F505. doi 10.1063/1.2956960

[17] Jakubowski L., Sadowski M.J., Zebrowski J., Rabinski M., Malinowski K., Mirowski R., Lotte Ph., Gunn J., Pascal J-Y., Colledani G., Basiuk V., Goniche M., Lipa M. // Rev. Sci. Instrum. 2010. V. 81. P. 013504. doi 10.1063/1.3280221

[18] Jakubowski L., Sadowski M.J., Zebrowski J., Rabinski M., Jakubowski M.J., Malinowski K., Mirowski R., Lotte Ph., Goniche M., Gunn J., Colledani G., Pasca J.-Y., Basiuk V. // Rev. Sci. Instrum. 2013. V. 84. P. 016107. doi $10.1063 / 1.4776190$

[19] Bagnato F., Romano A., Buratti P., Doria A., Gabellieri L., Giovenale E., Grosso A., Jakubowski L., Pacella D., Piergotti V. // Plasma Phys. Control. Fusion. 2018. V. 60. N 11. P. 115010. doi 10.1088/1361-6587/aae0b3

[20] Ghanbari M.R., Ghoranneviss M., Elahi A.S., Mohammadi S., Arvin R. // J. Fusion Energy. 2016. V. 35. P. 180. doi 10.1007/s10894-015-9992-6

[21] Pourshahab B., Abdi M. R., Sadighzadeh A., Rasouli C. // Phys. Plasmas. 2016. V. 23. P. 072501. doi $10.1063 / 1.4955218$

[22] Zhou R.J., Hu L.Q., Zhang Y., Zhong G.Q., Lin S.Y., The EAST Team // Nuclear Fusion. 2017. V. 57. N 11. P. 114002. doi 10.1088/1741-4326/aa7c9d

[23] Zeng L., Chen Z.Y., Dong Y.B., Koslowski H.R., Liang Y., Zhang Y.P., Zhuang H.D., Huang D.W., Gao X. // Nuclear Fusion. 2017. V. 57. P. 046001. doi 10.1088/17414326/aa57d9

[24] Rubel M., Brezinsek S., Coenen J.W., Huber A., Kirschner A., Kreter A., Petersson P., Philipps V., Pospieszczyk A., Schweer B., Sergienko G., Tanabe T., Ueda Y., Wienhold P. // Matter Radiat. Extremes. 2017. V. 2. N 3. P. 87. doi 10.1016/j.mre.2017.03.002
[25] Dai A.J., Chen Z.Y., Huang D.W., Tong R. H., Zhang J., Wei Y.N., Ma T.K., Wang X.L., Yang H.Y., Gao H.L. // Plasma Phys. Control. Fusion. 2018. V. 60. P. 055003. doi 10.1088/1361-6587/aab16d

[26] Li J., Wan Y. // J. Fus. Energy. 2019. V. 38. P. 113. doi 10.1007/s10894-018-0165-2

[27] Vlainic M., Ficker O., Mlynar J., Macusova E. // Atoms. 2019. V. 7. N 1. doi 10.3390/atoms7010012

[28] Zebrowski J., Jakubowski L., Rabinski M., Sadowski M.J., Jakubowski M.J., Kwiatkowski R., Malinowski K., Mirowski R., Mlynar J., Ficker O. // J. Phys. Conf. Ser. 2018. V. 959. P. 012002. doi 10.1088/1742-6596/959/1/012002

[29] Sadowski M.J. // Nukleonika. 2011. V. 56. P. 85.

[30] Savrukhin P.V., Shestakov E.A. // Nucl. Fusion. 2015. V. 55. N 4. P. 043016. doi 10.1088/0029-5515/55/4/043016

[31] Zaitsev A.M. Optical properties of diamond: a data handbook. Springer Science \& Business Media, 2013. 502 p. doi 10.1007/978-3-662-04548-0

[32] Yamamoto N., Sugiyama H. // Radiat. Eff. Defects Solids. 1991. V. 117. P. 5. doi 10.1080/10420159108220585

[33] Yamamoto N., Sugiyama H., Toda A. // Proc. Roy. Soc. London. A. 1996. V. 452. P. 2279. doi 10.1098/rspa.1996.0122

[34] Sorokin D.A., Burachenko A.G., Beloplotov D.V., Tarasenko V.F., Baksht E.Kh., Lipatov E.I., Lomaev M.I. // J. Appl. Phys. 2017. V. 122. N 15. P. 154902. doi $10.1063 / 1.4996965$

[35] Бураченко А.Г., Тарасенко В.Ф., Белоплотов Д.В., Бакшт Е.X. // Известия вузов. Физика. 2017. Т. 60. № 9. C. 66; Buranchenko A.G., Tarasenko V.F., Beloplotov D.V., Baksht E.Kh. // Russ. Phys. J. 2018. V. 60. P. 1533. doi 10.1007/s11182-018-1247-3

[36] Lipatov E.I., Burumbayeva K.R., Genin D.E., Ripenko V.S., Shulepov M.A., Tarasenko V.F. // Proc. SPIE 10614, Int. Conf. on Atomic and Molecular Pulsed Lasers XIII, 106141H (16 April 2018). doi 10.1117/12.2307089

[37] Соломонов В.И., Михайлов С.Г. Импульсная катодолюминесценция и ее применение для анализа конденсированных веществ. Екатеринбург: Издательство УрО РАН, 2003. $182 \mathrm{c}$

[38] Lipatov E.I., Lisitsyn V.M., Oleshko V.I., Polisadova E.F., Tarasenko V.F., Baksht E.H. // Cathodoluminescence / Ed. by Yamamoto N. Rijeka, Croatia: IntechOpen, 2012. P. $51-70$.

[39] Dobrev J., Marković P. Calcite: Formation, Properties and Applications. Nova Science Publishers, Inc., 2012. 318 p.

[40] Tarasenko V.F., Oleshko V.I., Erofeev M.V., Lipato E.I., Beloplotov D.V., Lomaev M.I., Burachenko A.G., Baksht E.Kh. // J. Appl. Phys. 2019. V. 125. N 24. P. 244501. doi 10.1063/1.5094956

[41] Бакшт Е.Х., Вуколов А.В., Ерофеев М.В., Науменко Г.А., Потылищын А.П., Тарасенко В.Ф., Бураченко А.Г., Шевелев М.В. // Письма в ЖЭТФ. 2019. Т. 109. № 9. С. 584; Baksht E.K., Vukolov A.V., Erofeev M.V., Naumenko G.A., Potylitsyn A.P., Tarasenko V.F., Burachenko A.G., Shevelev M.V. // JETP Lett. 2019. V. 109. P. 564. doi 10.1134/S0021364019090078

[42] Tarasenko V.F., Baksht E.Kh., Beloplotov D.V., Burachenko A.G., Lomaev M.I. // Jpn. J. Appl. Phys. 2020. V. 59.N SH. P. SHHD01. doi 10.35848/1347-4065/ab7475 
[43] Frelin A.M., Fontbonne J.M., Ban G., Colin J., Labalme M., Batalla A., Isambert A., Vel A., Leroux T. // Med. Phys. 2005. V. 32. N 9. P. 3000. doi $10.1118 / 1.2008487$

[44] Jang K.W., Yagi T., Pyeon C.H., Yoo W.J., Shin S.H., Jeong C., Min B.J., Shin D., Misawa T., Lee B. // J. Biomed. Opt. 2013. V. 18. N 2. C. 027001. doi 10.1117/1.JBO.18.2.027001

[45] Lee B., Shin S.H., Yoo W.J., Jang K.W. // Opt. Rev. 2016. V. 23. N 5. P. 806. doi 10.1007/s10043-016-0240-8

[46] Kharzheev Y.N. // Phys. Part. Nuclei. 2019. V. 50. N 1. P. 42. doi 10.1134/S1063779619010027

[47] Therriault-Proulx F., Beaulieu L., Archambault L., Beddar S. // Phys. Med. Biol. 2013. V. 58. N 7. P. 2073. doi 10.1088/0031-9155/58/7/2073

[48] Бабич Л.П., Лойко Т.В., Родигин А.В. // ДАН. 2014. Т. 457. № 6. C. 646. doi 10.7868/S0869565214240104; Babich L.P., Loiko T.V., Rodigin A.V. // Dokl. Phys. 2014. V. 59. P. 351. doi 10.1134/S1028335814080102

[49] Babich L.P., Loiko T.V., Rodigin A.V. // IEEE Trans. Plasma Sci. 2014. V. 42. N 4. P. 948. doi 10.1109/TPS.2014.2308529

[50] Бакшт Е.Х., Бураченко А.Г., Белоплотов Д.В., Тарасенко В.Ф. // Изв. вузов. Физика. 2016. Т. 59. № 4. C. 15; Baksht E.K., Burachenko A.G., Beloplotov D.V., Tarasenko V.F. // Russ. Phys. J. 2016. V. 59. N 4. P. 484. doi 10.1007/s11182-016-0798-4

[51] Tarasenko V.F., Baksht E.Kh., Burachenko A.G., Beloplotov D.V., Kozyrev A.V. // IEEE Trans. Plasma Sci. 2017. V. 45. N 1. P. 76. doi 10.1109/TPS.2016.2637570

[52] Олешко В.И., Бакшт Е.Х., Бураченко А.Г., Тарасенко В.Ф. // ЖТФ. 2017. Т. 87. № 2. С. 271; Oleshko V.I., Baksht E.K., Burachenko A.G., Tarasenko V.F. // Tech. Phys. 2017. V. 62. N 2. P. 299. doi 10.1134/S1063784217020232

[53] Черенков А.П. // ДАН СССР. 1934. Т. 2. № 8. С. 451. doi 10.3367/UFNr.0093.196710n.0385

[54] Вавило С.И. // ДАН СССР. 1934. Т. 2. № 8. С. 457. doi 10.3367/UFNr.0093.196710m.0383

[55] Тамм И.Е., Франк И.М. // ДАН СССР. 1937. Т. 14. № 3. C. 107. doi 10.3367/UFNr.0093.196710o.0388

[56] Jelly J.V. Cherenkov radiation and its applications. London: Pergamon Press, 1958. 331 р. Перевод: Джелли Джс. Черенковское излучение и его применения. М.: Издательство иностранной литературы, 1960. 334 с.

[57] Зрелов В.П. Излучение Вавилова-Черенкова и его применение в физике высоких энергий. Ч. 1. М.: Атомиздат, 1968. $274 \mathrm{c}$.

[58] Беспалов В.И. Взаимодействие ионизирующих излучений с веществом. Томск: Томский политехнический университет, 2008. 368 с.

[59] Строганова Е.А., Паршина И.Н., Киекпаев М.А., Пономарева П.А. Органическая химия. Ч. 2. Методы выделения, очистки и идентификации органических соединений: практикум. Оренбург: ОГУ, 2013. 126 с.

[60] Сорокин Д.А., Бураченко А.Г., Тарасенко В.Ф., Бакum Е.Х., Ломаев М.И. // ПТЭ. 2018. № 2. С. 102; Sorokin D.A., Burachenko A.G., Tarasenko V.F., Baksht E.Kh., Lomaev M.I. // Instrum. Exp. Tech. 2018. V. 61. P. 262. doi 10.1134/S0020441218020240

[61] Костыря И.Д., Рыбка Д.В., Тарасенко В.Ф. // ПТЭ. 2012. № 1. C. 80; Kostyrya I.D., Rybka D.V., Tarasenko V.F. // Instrum. Exper. Tech. 2012. T. 55. N 1. P. 72. doi 10.1134/S0020441212010071
[62] Tarasenko V.F., Kostyrya I.D., Baksht E.Kh., Rybka D.V. // IEEE Trans. Dielectr. Electr. Insul. 2011. V. 18. N 4. P. 1250. doi 10.1109/TDEI.2011.5976123

[63] Тарасенко В.Ф., Алексеев С.Б., Бакшт Е.Х., Бураченко А.Г., Ломаев М.И. // ПТЭ. 2020. № 3. C. 78; Tarasenko V.F., Alekseev S.B., Baksht E.K., Burachenko A.G., Lomaev M.I. // Instrum. Exp. Tech. 2020. V. 63. P. 359. doi 10.1134/S0020441220040090

[64] Mesyats G.A., Korovin S.D., Rostov V.V., Shpak V.G. // Proc. IEEE. 2004. V. 92. N 7. P. 1166. doi 10.1109/JPROC.2004.829005

[65] Тарасенко В.Ф. // Физика плазмы. 2011. Т. 37. № 5. C. 444; Tarasenko V.F. // Plasma Phys. Rep. 2011. V. 37. N 5. P. 409. doi 10.1134/S1063780X11040118

[66] Baksht E.H., Burachenko A.G., Kozhevnikov V.Yu., Kozyrev A.V., Kostyrya I.D., Tarasenko V.F. // J. Phys. D. 2010. V. 43. N 30. P. 305201. doi 10.1088/00223727/43/30/305201

[67] Бураченко А.Г., Тарасенко В.Ф. // Письма в ЖТФ. 2010. T. 36. № 24. C. 85; Burachenko A.G., Tarasenko V.F. // Tech. Phys. Lett. 2010. V. 36. P. 1158. doi 10.1134/S1063785010120278

[68] Шиак В.Г., Яландин М.И. // ПТЭ. 2001. № 3. С. 5; Yalandin M.I., Shpak V.G. // Instrum. Exp. Tech. 2001. V. 44. P. 285. doi 10.1023/A:1017535304915

[69] Tarasenko V.F., Rybka D.V. // High Voltage. 2016. V. 1. N 1. P. 43. doi 10.1049/hve.2016.0007.

[70] Tarasenko V.F., Baksht E.Kh., Burachenko A.G., Lomaev M.I., Sorokin D.A. // IEEE Trans. Plasma Sci. 2010. V. 38. N 10. P. 2583. doi 10.1109/TPS.2010.2041474

[71] Науменко Г.А., Потылищын А.П., Каратаев П.В., Шипуля М.А., Блеко В.В. // Письма в ЖЭТФ. 2017. Т. 106. № 2. C. 115; Naumenko G.A., Potylitsyn A.P., Karataev P.V., Shipulya M.A., Bleko V.V. // JETP Lett. 2017. V. 106. 127. doi 10.1134/S0021364017140089

[72] Олешко В.И., Тарасенко В.Ф., Белоплотов Д.В., Вильчинская С.C. // Опт. и спектр. 2018. Т. 125. № 5. C. 595; Oleshko V.I., Tarasenko V.F., Beloplotov D.V., Vil'chinskaya S.S. // Opt. Spectrosc. 2018. V. 125. P. 627. doi 10.1134/S0030400X18110218

[73] Тарасенко В.Ф., Бакшт Е.Х., Белоплотов Д.В., Бураченко А.Г., Ерофеев М.В., Липатов Е.И., Ломаев М.И., Олешко В.И. // Известия вузов. Физика. 2019. Т. 62. № 7. C. 79; Tarasenko V.F., Baksht E.K., Beloplotov D.V., Burachenko A.G., Erofeev M.V., Lipatov E.I., Lomaev M.I., Oleshko V.I. // Russ. Phys. J. 2019. V. 62. P. 1181. doi 10.1007/s11182-019-01833-6

[74] Бураченко А.Г., Белоплотов Д.В., Прудаев И.А., Сорокин Д.А., Тарасенко В.Ф., Толбанов О.П. // ОПт. и спектр. 2017. Т. 123. № 6. С. 861; Burachenko A.G., Beloplotov D.V., Prudaev I.A., Sorokin D.A., Tarasenko V.F., Tolbanov O.P. // Opt. Spectrosc. 2017. V. 123. P. 867. doi 10.1134/S0030400X17110042

[75] Kuramata A., Koshi K., Watanabe S., Yamaoka Y., Masui T., Yamakoshi S. // Jpn. J. Appl. Phys. 2016. V. 55. N 12. P. 1202A2. doi 10.7567/JJAP.55.1202A2

[76] Бакшт E.Х., Ерофеев М.В., Тарасенко В.Ф., Соломонов М.И., Шитов В.А. // Известия вузов. Физика. 2020. T. 63. № 7. C. 41; Baksht E.K., Erofeev M.V., Tarasenko V.F., Solomonov M.I., Shitov V.A. // Russ. Phys. J. 2020. V. 63. P. 1150. doi 10.1007/s11182-020-02165-6 
[77] Osipov V.V., Kotov Y.A., Ivanov M.G., Samatov O.M., Lisenkov V.V., Platonov V.V., Murzakaev A.M., Medvedev A.I., Azarkevich E.I. // Laser Phys. 2006. V. 16. N 1. C. 116. doi 10.1134/S1054660X06010105

[78] Refractive index database. [Электронный ресурс]. Режим доступа: https://refractiveindex.info

[79] Электростекло. [Электронный ресурс]. Режим доступа: http://www.elektrosteklo

[80] Опто-технологическая лаборатория. [Электронный ресурс] Режим доступа: https://optotl.ru/materials/crystals_ glass_reference_information

[81] Lomaev M.I., Sosnin E.A., Tarasenko V.F. // Progress in quantum electronics. 2012. V. 36. N 1. P. 51. doi 10.1016/j.pquantelec.2012.03.003

[82] Lipatov E.I., Genin D.E., Grigor'ev D.V., Tarasenko V.F., Burachenko A.G., Baksht E.Kh., Beloplotov D.V. // AIP Conf. Proc. 2019. V. 2069. N 1. P. 040007. doi 10.1063/1.5089850

[83] Tarasenko V.F., Lomaev M.I., Baksht E.Kh., Beloplotov D.V., Burachenko A.G., Sorokin D.A., Lipatov E.I. // Matter Radiat. Extremes. 2019. V. 4. N 3. P. 037401. doi $10.1063 / 1.5096563$

[84] Бакшт Е.Х., Бураченко А.Г., Тарасенко В.Ф. // Письма в ЖТФ. 2010. Т. 36. № 21. С. 102; Baksht E.K., Burachenko A.G., Tarasenko V.F. // Tech. Phys. Lett. 2010. 36. P. 1020. doi 10.1134/S1063785010110143

[85] Plyusnin V.V., Jakubowski L., Zebrowski J., Duarte P., Malinowski K., Fernandes H., Silva C., Rabinski M., Sadowski M.J. // Rev. Sci. Instrum. 2010. V. 81. N 10. P. 10D304. doi 10.1063/1.3478658

[86] Липатов Е.И., Лисицын В.М., Олешко В.И., Тарасенко В.Ф. // Известия вузов. Физика. 2007. Т. 50. № 1. С. 53; Lipatov E.I., Lisitsyn V.M., Oleshko V.I., Tarasenko V.F. // Russ. Phys. J. 2007. V. 50. P. 52. doi 10.1007/s11182-0070005-8

[87] Takeuchi D., Watanabe H., Yamanaka S., Okushi H., Sawada H., Ichinose H., Sekiguchi T., Kajimura K. // Phys. Rev. B. 2001. V. 63. N 24. P. 245328. doi 10.1103/PhysRevB.63.245328

[88] Васильев Е.А., Иванов-Омский В.И., Помазанский Б.С. Богуш И.Н. // Письма в ЖТФ. 2004. Т. 30. № 19. C. 7; Vasil'ev E.A., Ivanov-Omskii V.I., Pomazanskii B.S., Bogush I.N. // Tech. Phys. Lett. 2004. V. 30. P. 802. doi $10.1134 / 1.1813714$

[89] Насибов А.С. // Генерация убегающих электронов и рентгеновского излучения в разрядах повышенного давления / Под ред. Тарасенко В.Ф. Томск: STT, 2015. С. 297-316.

[90] Takiyama K., Abd-Elrahman M. I., Fujita T., Oda T. // Solid State Commun. 1996. V. 99. N 11. P. 793. doi 10.1016/00381098(96)00309-2

[91] Lipatov E.I., Genin D.E., Grigor'ev D.V., Tarasenko V.F. // Luminescence - An Outlook on the Phenomena and their Application / Ed. by Thirumalai J. Rijeka, Croatia: IntechOpen, 2016. P. 191-224.

[92] Ерофеев М.В., Бакшт Е.Х., Олешко В.И., Тарасенко В.Ф. // Известия вузов. Физика. 2020. № 5. С. 111; Erofeev M.V., Baksht E.K., Oleshko V.I., Tarasenko V.F. // Russ. Phys. J. 2020. V. 63. P. 831. doi 10.1007/s11182-02002105-4
[93] Лисицына Л.А., Корепанов В.И., Гречкина Т.В. // Опт. и спектр. 2003. Т. 95. № 5. С. 797; Lisitsyna L., Korepanov V.I., Grechkina T.V. // Opt. Spectrosc. 2003. V. 95. N 5. P. 746. doi 10.1134/1.1628723

[94] Тарасенко В.Ф., Бакшт Е.Х., Бураченко А.Г., Белоплотов Д.В., Козырев А.В. // ДАН. 2016. Т. 471. № 2. C. 150. doi 10.7868/S0869565216320104; Tarasenko V.F., Baksht E.K., Burachenko A.G., Beloplotov D.V., Kozyrev A.V. // Dokl. Phys. 2016. V. 61. P. 539. doi $10.1134 / \mathrm{S} 1028335816110082$

[95] Бакшт Е.Х., Артемов К.П., Бураченко А.Г., Тарасенко В.Ф. // Опт. и спектр. 2019. Т. 127. В. 4. C. 642; Baksht E.K., Artemov K.P., Burachenko A.G., Tarasenko V.F. // Opt. Spectrosc. 2019. V. 127. P. 694. doi 10.1134/S0030400X19100047

[96] Альбиков З.А., Веретенников А.И., Козлов О.В. Детекторы импульсного ионизирующего излучения. М: Атомиздат, 1978. $176 \mathrm{c}$.

[97] Lee B., Kwon G., Shin S.H., Kim J., Yoo W.J., Ji Y.H., Jang K.W. // Sensors. 2015. V. 15. N 11. P. 29003. doi $10.3390 / \mathrm{s} 151129003$

[98] Jang K.W., Yoo W.J., Seo J.K., Heo J.Y., Moon J., Park J.-Y., Hwang E.J., Shin D., Park S.-Y., Cho H.-S., B. Lee // Nucl. Instrum. Methods Phys. Res. A. 2011. V. 652. N 1. P. 841. doi 10.1016/j.nima.2010.08.120.

[99] Тарасенко В.Ф., Бакшт Е.X., Ерофеев М.В. // Письма в ЖТФ. 2021. Т. 47. № 6. C. 7; Tarasenko V.F., Baksht E.K., Erofeev M.V. // Tech. Phys. Lett. 2021. V. 47. N 6. doi 10.21883/PJTF.2021.06.50749.18601

[100] Afsari T., Ghoranneviss M., Meshkani S., Ghanbari M. R. // J. Theor. Appl. Phys. 2020. V. 14. P. 101. doi 10.1007/s40094019-00366-0

[101] Dwyer J.R., Saleh Z., Rassoul H.K., Concha D., Rahman M., Cooray V., Jerauld J., Uman M.A., Rakov V.A. // J. Geophysical Research: Atmospheres. 2008. V. 113. N D23. P. D23207. doi 10.1029/2008JD010315

[102] Липатов Е.И., Тарасенко В.Ф., Ерофеев М.В., Рипенко В.С., Шулепов М.A. // Оптика атмосферы и океана. 2019. T. 32. № 10. C. 841; Lipatov E.I., Tarasenko V.F., Erofeev M.V., Ripenko V.S. Shulepov M.A. // Atmos. Ocean. Opt. 2020. V. 33. P. 195. doi 10.1134/S1024856020020049 